\title{
CONTRIBUIÇÃO DO CAPITAL HUMANO PARA O CRESCIMENTO DA AGROPECUÁRIA BRASILEIRA - PERÍODO DE 1970 A 1996
}

\author{
CLAILTON ATAÍDES DE FREITAS \\ Economista
}

Orientador: Prof. Dr. CARLOS JOSÉ CAETANO BACHA

Tese apresentada à Escola Superior de Agricultura "Luiz de Queiroz", Universidade de São Paulo, para obtenção do título de Doutor em Ciências, Área de Concentração: Economia Aplicada.

PIRACICABA

Estado de São Paulo - Brasil

Julho -2001 
Dados Internacionais de Catalogaçāo na Publicaçāo (CIP)

DIVISÃO DE BIBLIOTECA E DOCUMENTAÇÃO - Campus "Luiz de Queiroz"/USP

\author{
Freitas, Clailton Ataides de \\ Contribuição do capital humano para o crescimento da agropecuária brasileira - \\ período de 1970 a 1996 / Clailton Ataídes de Freitas. - - Piracicaba, 2001.
}

$150 \mathrm{p}$.

Tese (doutorado) - Escola Superior de Agricultura Luiz de Queiroz, 2001. Bibliografia.

1. Agropecuária 2. Capital humano 3. Crescimento econômico 4. Educação agrícola 5. Economia brasileira 6. Inovação tecnológica 7. Trabalhador nural I. Título

CDD 338.9

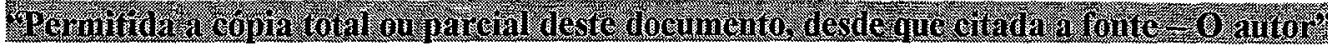


Aos meus queridos e inestimáveis pais,

Eucrezina (in memorian) e João

OFEREÇO

À minha amada esposa,

Wania

DEDICO 


\section{AGRADECIMENTOS}

À Universidade Federal de Santa Maria (UFSM), em especial ao Departamento de Ciências Econômicas, pelo apoio para a realização de um sonho.

Em especial ao meu orientador, Prof. Carlos José Caetano Bacha, por sua dedicação e competência em conduzir-me por um caminho que me permitiu atingir os meus verdadeiros objetivos.

Ao Professor Rodolfo Hoffmann que sempre se prontificou a esclarecer com muita competência as dúvidas que foram surgindo ao longo do caminho trilhado. Ah.. Como o mundo seria mais eficiente, competente, dinâmico e solidário se fosse repleto de pessoas como ele.

Aos Professores Paulo Cidade, Alexandre Mendonça de Barros e Joaquim Bento de Souza Ferreira Filho pelas valiosas críticas e contribuições sugeridas em versões anteriores deste trabalho.

Aos demais Professores do DEAS da ESALQ/USP pelos ensinamentos valiosos que me serão úteis ao longo de toda a minha vida acadêmica.

Aos funcionários do DEAS da ESALQ/USP, em especial à Luciane, Ligiana, Maelli e Helena pelo apoio e amizade.

A todos os colegas do Curso, em especial ao Espedito, Jaenes e Jefferson pela solidariedade, pelo saudável convívio e amizade. Conviver com vocês ajudou-me a enfrentar, por um bom tempo, a distância e a solidão. Ao se aproximar o fim de uma jornada, já estou sentindo falta das nossas longas conversas e brincadeiras. Sem elas e 
sem vocês, vencer os obstáculos teria se tornado uma tarefa bem mais árdua do que realmente foi.

À minha mãe que, apesar de não ter tido estudo formal, compreendeu como poucos que a educação é o bem maior do ser humano e soube passar isto para mim com muita competência. "Mãe, desde a sua partida, sinto que o imenso vazio deixado em minha vida pode agora, com a conclusão deste estudo, ser um pouco preenchido, porque eu sei que esse era também um sonho seu." 


\section{SUMÁRIO}

Página

LISTA DE TABELAS ….........................................................................................

LISTA DE QUADROS ……………....................................................................

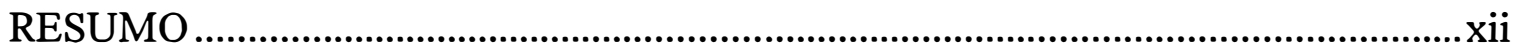

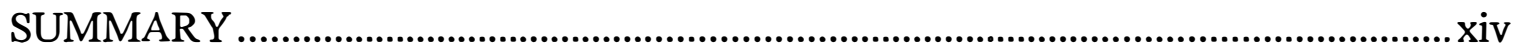

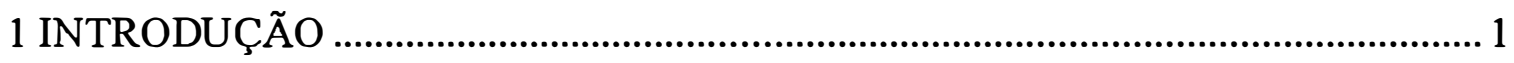

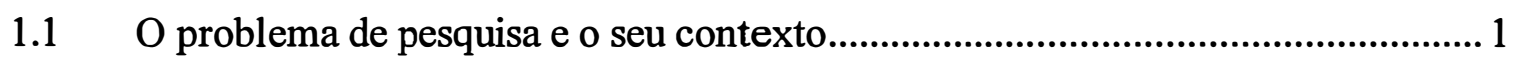

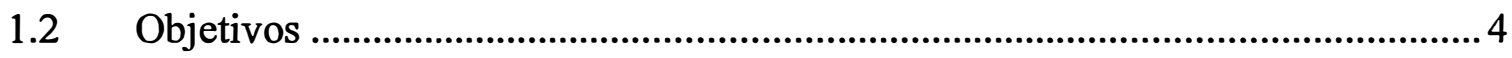

1.3 Importância do trabalho...................................................................................

1.4 As abordagens do capital humano na economia brasileira..................................... 6

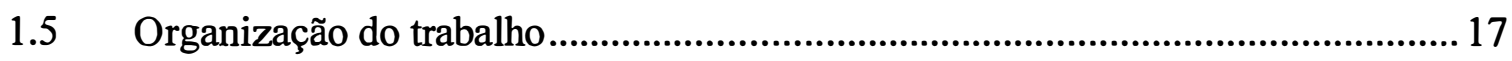

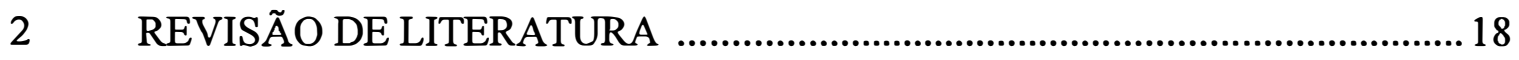

2.1 Análise do desempenho econômico do setor agropecuário

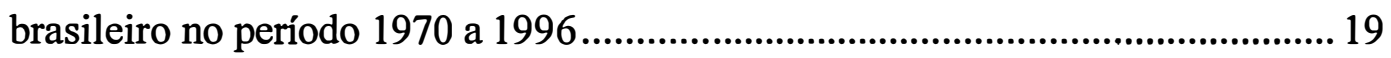

2.2 Diferenças no processo de crescimento do setor agropecuário brasileiro entre os estados...................................................................................... 31 
2.3 A origem e evolução do modelo de crescimento neoclássico

2.4 Os determinantes do crescimento econômico e os fundamentos

do modelo neoclássico

2.5 Algumas considerações a respeito do modelo de crescimento endógeno 53

2.5.1 A função de produção com progresso tecnológico endógeno ..................................54

2.5.2 Os fundamentos dos modelos de crescimento endógeno 57

2.5.3 A interpretação da taxa de crescimento do produto segundo o enfoque do modelo de crescimento endógeno.

2.6 Restrições em aplicar os modelos de crescimento endógeno em análises empíricas do setor agropecuário

2.7 O modelo neoclássico alternativo 64

2.7.1 Os fundamentos teóricos e quantitativo do modelo neoclássico alternativo 65

2.7.2 O modelo neoclássico alternativo proposto por Benhabib \& Spiegel

2.8 Modelos teóricos considerados para teste ……………................................... 75

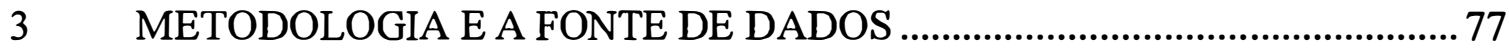

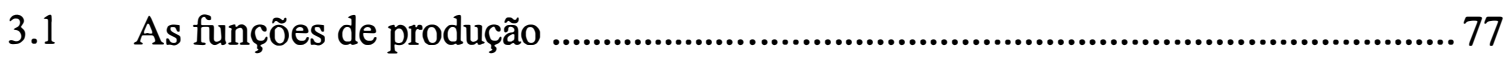

3.2 O modelo neoclássico tradicional aumentado ....................................................... 81

3.2.1 O modelo econométrico para a estimação do efeito threshold............................... 88

3.3 O modelo econométrico para considerar o capital humano numa perspectiva de crescimento neoclássico alternativo 91

3.4 A base de dados e as suas fontes 
4 RESULTADOS E DISCUSÃO

4.1 Comentários gerais acerca do modelo de regressão e as violações dos seus pressupostos

4.2 Análise dos resultados das regressões................................................................ 103

4.2.1 Os resultados da estimação do modelo neoclássico tradicional ......................... 104

4.2.2 Os resultados da estimação do efeito threshold da educação média na agropecuária brasileira

4.2.3 Os resultados da estimação do modelo de crescimento neoclássico alternativo

5 CONCLUSÕES 


\section{LISTA DE TABELAS}

Página

1 Taxas anuais de crescimento da produção agropecuária brasileira.........................20

2 Crédito rural contratado segundo a sua finalidade de 1970 a 1996 (em milhões de Reais de agosto de 1994)

3 Participação percentual das regiões brasileiras no produto agropecuário e no crédito rural - anos selecionados

4 Participações das regiões no PIB a custo de fatores - anos selecionados

5 Produção agrícola brasileira, vários anos 30

6 Estatísticas de crescimento da agropecuária dos estados brasileiros. Valores em Reais deflacionados - base agosto de 1994

7 Evolução da relação entre capital e trabalho na agropecuária brasileira 36

8 Anos médios de estudo dos trabalhadores com 10 anos ou mais de idade 38

9 Distribuição regional do valor da produção per capita $(\hat{Y})$ do setor agropecuário, Brasil - anos selecionados 
10 Teste de heteroscedasticia usando o Teste de White 102

11 Resultados da estimativa da equação (53) ajustada pelo método ECVH de White 104

12 Resultado do ajustamento da equação (57) usando o método ECVH de White 108

13 Coeficientes da equação (61) usando o método ECVH de White 110

3.1 Dados básicos da Pesquisa 138

3.2 Dados utilizados no processo de estimação da equação (53) 141

3.3 Dados utilizados no processo de estimação da equação (57) 143

3.4 Dados utilizados no processo de estimação da equação (61) 146

4.1 Resultados das estimativas, por períodos, da equação (53) ajustada pelo método ECVH de White

4.2 Resultados das estimativas, por períodos, da equação (57) ajustada pelo método ECVH de White 149

4.3 Resultados das estimativas, por períodos, da equação (61) ajustada pelo método ECVH de White 150 


\section{LISTA DE QUADROS}

Página

1 Resumo dos trabalhos relacionados ao capital humano publicados no Brasil

2 Comparação entre os modelos de crescimento neoclássico tradicional e alternativo. .75

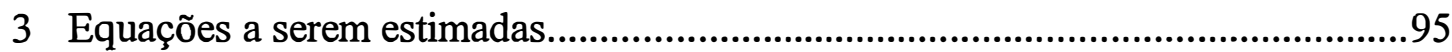




\title{
CONTRIBUIÇÃO DO CAPITAL HUMANO PARA O CRESCIMENTO DA AGROPECUÁRIA BRASILEIRA - PERÍODO DE 1970 A 1996
}

\author{
Autor: CLAILTON ATAÍDES DE FREITAS \\ Orientador: Prof. Dr. CARLOS JOSÉ CAETANO BACHA
}

\section{RESUMO}

O presente estudo avalia a contribuição do capital humano para o crescimento do setor agropecuário brasileiro no período de 1970 a 1996. Para tanto, aplicam-se duas versões do modelo neoclássico: o padrão e o alternativo. Os dados utilizados neste trabalho foram coletados nos Censos Agropecuários de 1970, 1975, 1980, 1985 e 1995/96, e nos Censos Demográficos de 1970, 1980 e 1991. A modernização do setor agropecuário brasileiro, ocorrida ao longo do período analisado pelo presente trabalho, provocou profundas transformações na estrutura produtiva desse setor. Apesar desse processo de modernização ter atingido o país como um todo, os estados das Regiões Centro-Oeste, Sul e Sudeste se diferenciam em relação aos demais estados. $\mathrm{O}$ crescimento do setor agropecuário brasileiro ocorreu de maneira desigual entre os estados. O primeiro modelo teórico utilizado para analisar o papel do capital humano no crescimento do setor agropecuário é conhecido como neoclássico tradicional. Este modelo considera o insumo capital humano como tendo comportamento semelhante aos demais insumos (capital e trabalho). O segundo modelo recebe a denominação de 
modelo de crescimento neoclássico alternativo, porque trata o capital humano como um insumo especial, capaz de gerar difusão tecnológica entre os estados. Com o propósito de atingir o objetivo acima proposto, os dados foram organizados em pooling e utilizouse o método de estimação dos mínimos quadrados ordinários com o estimador consistente da variância levando em consideração a heteroscedasticia de White (ECVH de White) para estimar as equações de regressão propostas. A primeira destas equações estimadas foi uma função do tipo Cobb-Douglas sob a perspectiva neoclássica tradicional. A segunda equação estimada foi também uma Cobb-Douglas tradicional remodelada para capturar o efeito threshold do capital humano sobre o crescimento do setor agropecuário brasileiro. A terceira regressão foi uma Cobb-Douglas com fundamentos do modelo neoclássico alternativo. Os resultados indicaram que o efeito do capital humano sobre a taxa de crescimento da produção agropecuária foi positivo e altamente significativo em todas as equações estimadas. Ao desagregar os dados relativos ao capital humano, com o propósito de avaliar a existência ou não de efeito threshold na escolaridade média dos trabalhadores rurais, constatou-se que não há evidências capazes de apoiar a existência de um efeito threshold mínimo da educação média na agropecuária brasileira. A variável incorporada na regressão do modelo neoclássico alternativo com o propósito de captar a difusão tecnológica entre os estados foi pouco significativa e a magnitude do parâmetro a ele relacionada foi próximo de zero. Isto indica que o modelo especificado não confirma a existência de um processo de difusão de tecnologia entre os estados no setor agropecuário. As estimativas desta pesquisa evidenciam que o capital humano realmente vem tendo, ao longo dos anos, papel ativo no processo de desenvolvimento do setor agropecuário brasileiro, mas não confirmam a existência de difusão tecnológica entre os estados. 


\title{
THE CONTRIBUTION OF HUMAN CAPITAL FOR THE BRAZILIAN AGRICULTURAL GROWTH - FROM 1970 TO 1996
}

\author{
Author: CLAILTON ATAÍDES DE FREITAS \\ Adviser: CARLOS JOSÉ CAETANO BACHA
}

SUMMARY

This thesis evaluates the contribution of human capital for the Brazilian agricultural growth during the time period from 1970 to 1996 . Two different versions of neoclassic models are used: the raditional model and the alternative one. The data set utilized comprised information collected from the Agricultural and Demographic Census available for the 1970s, 1980s and 1990s. From 1970 to 1996, the Brazilian agricultural modernization as followed by large transformations in its productive structure. All country's regions took place in the agricultural modernization process, however, the states located in the Center-Western, Southeast and Southern of Brazil reached larger modernization than the other states. The growth of Brazil's agriculture was uneven among the states. The first model used to analyze the role of human capital in the Brazilian agricultural growth is named Traditional Neoclassic Model. In that model, human capital is treated as a common input, such as capital and labor are. In the second model, named Alternative Neoclassic Model, human capital is treated as a special input. It is capable to produce technological diffusion among the Brazil's states. 
The data set was organized in pooling, and the OLS White's method was used to estimate regression equations. The first equation estimated was a Cobb-Douglas built according to the Traditional Neoclassic Model. The second one was also a CobbDouglas, but the Traditional Neoclassic Model was remodeled in order to show the threshold effect of human capital into the growth of Brazilian agriculture. The third equation was a Cobb-Douglas with arguments from the Alternative Neoclassic Model. All equations showed that the human capital had a positive and statistically significant effect on the agricultural production. However, two different facts, in relation to what is expected from the theory or previous literature, were found: a) the second equation do not prove the existence of threshold effect into the Brazil's agriculture; b) the coefficient related to catch-up variable was poorly statistically significant and near to zero. The latter implies that there is not a technological diffusion process among the Brazil's states. This dissertation shows the significant role of capital human in the growth of Brazilian agriculture. However, there is no statistic proof that technological diffusion has happened in agriculture among Brazilian states. 


\section{INTRODUÇÃO}

\subsection{O problema de pesquisa e o seu contexto}

O propósito deste trabalho é avaliar a contribuição do capital humano na formação do produto agropecuário brasileiro no período de 1970 a 1996. O capital humano tem sido considerado um fator muito importante na explicação do processo de crescimento econômico dos países. No entanto, pouco se conhece sobre sua importância na agropecuária brasileira.

Fonseca (1992) coloca uma questão bastante intrigante: como o Canadá, com uma população 5,5 vezes menor que a brasileira, consegue produzir um PNB 37,4\% maior que o brasileiro? E mais, o que explicaria a ascensão econômica no pós-guerra do Japão, da Alemanha, da Coréia do Sul, Singapura, etc.?

As causas do sucesso desses países, evidentemente, não se devem à existência de recursos naturais e nem à exploração de mão-de-obra barata. Alguns fatores fundamentais são a capacidade de iniciativa, a competência profissional, a disciplina de sua população. A tendência do mundo moderno é tornar, cada vez mais, o ser humano o elemento diferencial para o sucesso econômico (Fonseca, 1992).

Pelo menos uma lição pode ser tirada do mundo moderno: o que separa o sucesso e o fracasso dos países relaciona-se, em grande medida, à devida atenção dada à educação e à tecnologia da informação, enfim, ao capital humano, e não se o país A ou B 
tem mais riquezas minerais, solos férteis, clima propício para a agricultura, ausência de fenômenos naturais como vulcões, furacões, terremotos, entre outros.

O capital humano é um tipo diferente de capital, porque envolve a qualificação, o treinamento do indivíduo, os gastos com saúde e outros. Apesar de ser investimento de capital no indivíduo, não é possível separar uma pessoa de seu conhecimento (Becker, 1993). A morte significa que grande parte do capital investido pela sociedade no indivíduo se perde. Contudo, as suas idéias sobrevivem à sua morte. Como, por exemplo, o desenvolvimento de uma fórmula matemática ou um procedimento agronômico que conseguiu controlar uma determinada praga.

O desenvolvimento econômico dos países está intrinsecamente ligado aos seus recursos humanos. Assim, espera-se que quanto menos preparadas forem as pessoas que os governam e quanto menos conhecimento e informações tiverem os seus empresários e trabalhadores; mais difícil para os países será conseguir o rompimento com o atraso tecnológico, e mais tempo será necessário para a diminuição do hiato econômico que o separa das nações mais desenvolvidas. A desigualdade econômica poderá até aumentar se ocorrerem conflitos políticos, ideológicos e religiosos, convulsões sociais ou se a corrup̧̧ão se generalizar na burocracia estatal.

Não se constrói, logicamente, o processo de acumulação de riqueza de um país apenas com capital humano, muito embora se admita a sua importância nos modelos atuais de crescimento. Entretanto, é necessário que, aliado à força de trabalho qualificada, haja também estoque de capital físico e poupança interna para alavancar e sustentar o processo de desenvolvimento econômico. Como afirma Chamley (1992, p.335), "A acumulação de capital humano e físico são as duas engrenagens do crescimento econômico".

Nesse sentido, é possível imaginar que os produtores rurais com maior nível de educação tenham também maiores habilidades empresariais e consigam, com mais 
facilidade, adequar os seus planos de produção às mudanças conjunturais, tanto nos preços pagos pelos insumos, quanto nos preços recebidos por seus produtos. Espera-se que quanto maior seja o nível educacional do produtor mais recèptivo ele estaria à adoção de novas tecnologias ${ }^{1}$. Neste sentido, vislumbra-se uma relação positiva entre o nível de estoque de capital humano nos estados e o seu grau de desenvolvimento.

A grande maioria dos economistas aceita o papel ativo do capital humano no processo de desenvolvimento econômico. O desafio enfrentado nas últimas décadas refere-se a como mensurar ou quantificar seu papel na alavancagem do desenvolvimento. A saída encontrada por Mankiw et al. (1992) foi adicionar a proxy do capital humano numa função de produção aumentada. Essa abordagem é conhecida como tradicional, pois foi e continua sendo usada por vários economistas.

A outra abordagem relaciona-se aos modelos de crescimento endógeno. $\mathrm{O}$ capital humano, através do progresso tecnológico, gera externalidades positivas. Esses modelos de crescimento apresentam rendimentos crescentes à escala, em razão do capital humano ser um insumo com características especiais na função de produção. Vários autores vêm se destacando na elaboração e aplicação desses modelos, como por exemplo, Romer (1986, 1990 e 1994), Grossman \& Helpman (1991), Aghion \& Howitt (1992) e Lucas (1988).

Um enfoque alternativo na avaliação do papel do capital humano foi proposto Benhabib \& Spiegel (1994). Estes autores apresentaram um modelo de crescimento, denominado no presente trabalho de modelo de crescimento neoclássico alternativo, cujo propósito era avaliar o efeito do capital humano sobre a produtividade total dos fatores a partir de duas variáveis: i) a variável capital humano materializada na capacidade dos países em promover inovações tecnológicas endógenas; e ii) a

\footnotetext{
${ }^{1}$ Entende-se o termo tecnologia como sendo a forma como a totalidade de insumos envolvidos no processo de produção é transformada em produtos.
} 
potencialidade do capital humano para captar a difusão de tecnologia entre os países, através do termo catch-up.

A falta de uma política educacional de maior qualidade no Brasil, talvez, tenha contribuído para dificultar o rompimento com os resquícios do subdesenvolvimento. Isto porque a forma como se deu o processo de acumulação de capital no Brasil gerou, por um lado, a exclusão social - e isto fica evidente pelo crescimento das favelas e da marginalidade nas principais cidades brasileiras - e, por outro, resultou em profundos desequilíbrios regionais. Esse processo de acumulação de capital é fruto, em parte, da política econômica adotada no Brasil, especialmente a partir da década de 50, que dava prioridade ao crescimento do setor urbano-industrial - visto como sinônimo de progresso e desenvolvimento econômico dos países. Os dispêndios com a educação no Brasil, os quais levariam ao incremento do estoque de capital humano, ao que tudo indica, eram vistos pelos governantes brasileiros não como um investimento de longo prazo, mas sim como uma despesa de curto prazo. Isso pode ser constatado através do grande número de analfabetos existente no Brasil ${ }^{2}$.

Apesar de ampla literatura internacional acerca da importância do capital humano no processo de crescimento econômico, ainda muito pouco foi avaliado sobre seu papel no crescimento dos setores e dos estados na economia brasileira, em especial, para o crescimento do setor agropecuário no Brasil no período mais recente.

\subsection{Objetivos}

O objetivo geral deste trabalho é avaliar, de 1970 a 1996, a contribuição do capital humano para o crescimento do setor agropecuário brasileiro, tanto sob a ótica neoclássica tradicional quanto sob a perspectiva do modelo neoclássico alternativo. Os resultados obtidos nos dois modelos serão comparados com o propósito de se ter uma

\footnotetext{
${ }^{2}$ Para obter mais informações, ver Anuário Estatístico de América Latina y el Caribe.
} 
melhor avaliação do papel do capital humano no desempenho econômico da agropecuária brasileira.

Para tanto, os objetivos específicos do rabalho são:

a) analisar o desenvolvimento da agropecuária brasileira no período compreendido por esse estudo (1970 a 1996), ressaltando as diferenças existentes entre os estados e como essas diferenças se relacionam com o nível educacional dos trabalhadores;

b) discutir as formulações teóricas do modelo neoclássico tradicional e do modelo neoclássico alternativo, verificando como eles incorporam o capital humano;

c) formular as equações econométricas para estimar os modelos acima mencionados; e

d) estimar os modelos neoclássicos tradicional e alternativo para a agropecuária brasileira, comparando seus resultados quanto à contribuição do capital humano para o crescimento do produto agropecuário.

\subsection{Importância do trabalho}

Por entender que o capital humano realmente se converteu em um insumo fundamental em todos os setores da economia, o presente trabalho procura estudar um pouco mais esse papel no desenvolvimento da agropecuária brasileira. Dessa maneira, os resultados desta pesquisa poderão se juntar a outros trabalhos que também procuram compreender a importância da qualificação do homem para a alavancagem do desenvolvimento da economia brasileira como um todo. 


\subsection{As abordagens do capital humano na economia brasileira}

No Brasil, alguns trabalhos já exploraram o papel do capital humano no crescimento econômico. Destacam-se, entre eles, os trabalhos de Patrick \& Kehrberg (1975), Engler (1979), Ilha \& Lima (1989), Hoffmann et al. (1990), Silva (1996) e Lau et al. (1993), que utilizaram a função de produção neoclássica tradicional do tipo CobbDouglas em sua versão aumentada.

O trabalho de Patrick \& Kehrberg (1975), com dados primários coletados no início da década de 70, faz estimativas dos custos e dos retornos da educação formal e da extensão rural em algumas áreas da Região Leste do país. Pelo menos dois resultados interessantes foram obtidos pelos autores: i) observa-se um impacto positivo da educação sobre a renda do agricultor; ii) os retornos da educação são maiores nas áreas de agricultura mais modernizada.

O propósito de Engler (1979) era avaliar a eficiência econômica na agricultura do Estado de São Paulo e analisar as diferenças regionais de produção e produtividade. Para atingir esse objetivo, o autor estimou uma função de produção para o setor agropecuário daquele estado, utilizando dados primários coletados em 1972, e incluiu, além dos insumos tradicionais, os insumos não-convencionais como, por exemplo, a educação formal, assistência técnica e experiência do produtor rural. Os resultados encontrados indicaram que os coeficientes de elasticidade parcial de produção foram altamente significativos para os insumos modernos e para o capital humano. Entretanto, conforme destaca o autor, a educação contribui mais em regiões de agricultura mais modemizada, enquanto assistência técnica oferece contribuição maior em regiões com agricultura pouco modernizada.

Ilha \& Lima (1989) procuraram analisar o efeito da educação na produção e produtividade em regiões com agricultura modernizada e tradicional do Estado de Minas Gerais. Esses autores estimaram uma típica função de produção Cobb-Douglas, 
utilizando-se de dados primários referentes ao ano agrícola 1985/86. Como em Engler (1979), Ilha e Lima especificaram a função de produção com insumos convencionais (terra, trabalho e capital) e não convencionais (educação e assistência técnica).

A avaliação do papel da educação foi realizada por Ilha \& Lima (1989) através do efeito trabalhador e efeito alocativo da educação. $\mathrm{O}$ efeito trabalhador foi calculado através da fórmula: $V P M A a_{e}=\widehat{\beta}\left(\frac{Y}{E}\right)$, em que $V P M A a_{e}$ é o valor do produto marginal da educação, $\hat{\beta}$ é o coeficiente estimado da educação na função produto físico, $Y$ e $E$ são as médias geométricas do produto físico e educação, respectivamente. $O$ efeito alocativo foi definido como sendo a adição do efeito insumo-alocação e do efeito insumo-seleção. Para calcular o efeito alocativo, os autores seguiram três passos: 1) calculou-se o valor do produto marginal da educação nas funções valor adicionado e vendas brutas através da fórmula $V P M A a_{e}=\bar{\beta}\left(\frac{Y}{E}\right)$, onde $\hat{\beta}$ é o coeficiente estimado da variável educação nas funções valor adicionado e vendas brutas; 2) o efeito insumoalocação resultou da diferença entre o valor do produto marginal da educação na função vendas brutas e o valor do produto marginal da educação na função produto físico; 3) o efeito insumo-seleção resulta da diferença entre o valor do produto marginal na função valor adicionado e valor do produto marginal da educação na função vendas brutas.

Os resultados obtidos pelos autores, acima mencionados, apontaram que o efeito alocativo da educação foi mais importante do que o efeito trabalhador. Isto indica que a educação aumenta a produção agrícola, principalmente, pela melhoria da habilidade no processo decisório do agricultor (efeito alocativo) e apenas de forma secundária por alterações na eficiência técnica.

No estudo desenvolvido por Hoffmann et al. (1990) foram estimadas as metafunções de produção da agropecuária brasileira para as 332 microrregiões homogêneas (MRH) que compõem as Regiões Nordeste, Sudeste, Sul e Centro-Oeste do 
Brasil no período de 1975 a 1980. O objetivo dos autores não era verificar, especificamente, o papel do capital humano, mas sim a contribuição dos principais fatores de produção para a formação do valor bruto da produção agropecuária. Para tanto, eles utilizaram, basicamente, a função de produção Cobb-Douglas e não recorreram à técnica do pooling. As estimativas foram realizadas com dados crosssection de 1975 e 1980.

Assim como no caso de Engler (1979) e Ilha e Lima (1989), Hoffmann et al. (1990) incorporaram na função de produção os insumos não-convencionais (escolaridade, e grau de urbanização), ao lado dos insumos convencionais (capital, trabalho e terra). Hoffmann et al. (1990), no cálculo da variável escolaridade, de interesse particular do presente estudo, consideraram tanto a população urbana como a rural, uma vez que os dados para a população rural, por MRH, não foram publicados separadamente, segundo argumentam os autores.

Várias simulações com a inclusão e exclusão de variáveis nas metafunções de produção foram feitas por Hoffmann et al. (1990). Os resultados apresentados pelos autores evidenciam que o parâmetro associado ao nível de escolaridade foi significativo em todas as regressões estimadas, apesar do problema relacionado à construção dessa variável, como já argumentado.

O trabalho de Silva (1996) teve como principal objetivo verificar a contribuição dos fatores de produção na agropecuária brasileira, no período de 1975 a 1985. A forma como o autor especificou as variáveis dependentes e independentes segue, basicamente, a metodologia adotada por Hoffmann et al. (1990). No entanto, o wabalho de Silva(1996) difere daquele realizado por Hoffmann et al. (1990) em pelo menos dois pontos: i) abrange um período mais recente (1975 a 1985) e, ii) os dados utilizados por Silva (1996) se referem a $300 \mathrm{MRH}$ (32 a menos do que no trabalho de Hoffmann et al. 1990) que compõem as Regiões Nordeste, Sudeste (exclusive São Paulo), São Paulo, e Região Sul. 
A variável escolaridade foi significativa em todas as regressões estimadas para o cross-section de 1980, não o sendo nas regressões dos cross-section de 1975 e 1985. Resultados distintos para o cross-section de 1975, relacionado ao nível de significância da escolaridade, foi obtido por Hoffmann et al. (1990), como já apresentado. Entretanto, argumenta Silva “...sempre que essa variável foi excluída das regressões, a qualidade estatística da maioria das estimativas dos coeficientes das demais variáveis foi reduzida" (1996, p.138). Para o autor, isto mostra que essa variável, direta e/ou indiretamente, é importante para a determinação do valor da produção agropecuária. Provavelmente, a forma como a variável escolaridade foi construída - incluindo a escolaridade da população urbana - pode ajudar a explicar os motivos da nãosignificância da escolaridade nas estimativas cross-section de 1975 e 1985. Entretanto, o autor não discutiu com maior profundidade os resultados distintos relacionados à escolaridade entre o seu estudo e o do Hoffmann et al. (1990).

Como uma parte do presente estudo segue a metodologia de Lau. et al. (1993), acredita-se que seja conveniente apresentar, mesmo que seja de forma resumida, o modelo básico trabalhado por esses autores e alguns de seus resultados. Eles se propuseram a estimar uma metafunção de produção Cobb-Douglas, com os dados em pooling, para a economia brasileira para o período de 1970 a 1980. Esta função, que trás o capital humano como um de seus argumentos, pode ser escrita como segue:

$$
\ln Y_{i t}=-\ln A_{i o}(t)+\ln Y_{o}+a_{k} \ln K_{i t}^{*}+a_{l} \ln L_{i t}^{*}+a_{e} E D_{i t}^{*}
$$

onde $Y_{i t}, K^{*}{ }_{i t}, L^{*}$ it são as quantidades de equivalentes-eficiente ${ }^{3}$, respectivamente, do produto, capital e trabalho do iésimo estado no tempo t; $E D^{*}{ }_{i t}$ é uma medida do capital humano; e, $A_{i o}(t)$ permite capturar a eficiência técnica da produção através do progresso tecnológico que, nessa função, é tratado como exógeno.

\footnotetext{
${ }^{3}$ Equivalentes-eficiente é entendido como sendo uma medida que permite comparar a eficiência técnica dos insumos e do produto nos diferentes estados brasileiros.
} 
Ao proceder à primeira diferença e realizar algumas transformações matemáticas da equação (1), Lau et al. (1993) estimaram uma nova equação e chegaram à conclusão que o efeito estimado da educação média era 0,21 , sendo estatisticamente significante ao nível de $10 \%$. Isto significa que um ano adicional de educação média con ribui com $21 \%$ para a taxa de crescimento do produto per capita. Outras manipulações matemáticas foram realizadas no modelo proposto com o intuito de isolar o efeito da educação média. O que os autores observaram foi que o capital humano permaneceu estatisticamente significante, independentemente da variável isolada.

Lau et al. (1993) encontraram indícios de que o nível de educação da força de rabalho no Brasil alcançou um nível de threshold crítico ${ }^{4}$, já que em um outro trabalho, também de Lau et al. (1990), verificou-se que o efeito da educação média sobre o produto foi de 0,05 . Para proceder-se ao cálculo do efeito threshold é necessário desagregar os anos médios de educação em classes, como por exemplo, 1 a 2, 2 a 3, 3 a 4 anos médios de estudo, como o que será apresentado no Capítulo 4, subitem 4.2.1. Assim, é possível verificar qual a classe de anos de estudo estaria afetando mais significativamente o comportamento do produto per capita. A existência do efeito threshold seria captada através da significância estatística de algum parâmetro relacionado a uma classe intermediária, ao passo que os parâmetros das demais classes deveriam ser pouco significativos ou não-significativos estatisticamente. Neste sentido, pode-se definir o efeito threshold como sendo o efeito da educação média sobre o crescimento do produto per capita sendo explicado por uma classe específica de anos de educação. No estudo desenvolvido por Lau et al. (1993), o nível de educação da mão-deobra no Brasil alcançou um nível de threshold crítico entre 3 e 4 anos. E, finalmente, Lau et al. (1993) tentaram verificar a existência de complementaridade entre capital humano e capital físico, tal que a eficiência de um seja aumentada pela presença do outro. Para modelar a complementaridade entre os fatores, eles utilizaram uma forma

\footnotetext{
${ }^{4}$ A definição de efeito threshold está no capítulo 4, subitem 4.2.1.
} 
funcional mais flexível conhecida como função de produção translog ${ }^{5}$. As evidências empíricas não permitiram apoiar a hipótese da complementaridade entre os fatores de produção.

A literatura sobre o papel do capital humano cresceu substancialmente nas duas últimas décadas com a publicação de vários trabalhos, como o de Mankiw, Romer \& Weil (1992), tratando o capital humano como um insumo adicional na função de produção aumentada. $\mathrm{Na}$ linha de crescimento endógeno, têm-se os trabalhos de Romer (1986, 1990 e 1994), Grossman \& Helpman (1991), Aghion \& Howitt (1992) e Lucas (1988). Usando um modelo neoclássico alternativo, Benhabib \& Spiegel (1994) analisaram o efeito do capital humano sobre o produto per capita.

Gonçalves et al. (1998) procuraram ajustar, para o Brasil, o modelo proposto por Benhabib \& Spiegel (1994). Além disso, o trabalho também procurou testar, seguindo Barro \& Sala-i-Martin (1995), as hipóteses da convergência ${ }^{6}$. Os resultados do estudo de Gonçalves et al. (1998) apontaram que o insumo capital humano apresentou elasticidade maior do que 1. Os demais coeficientes relacionados ao capital e ao trabalho foram significativos e diferentes de zero. Quanto à hipótese da convergência, foi verificada, pelos autores, que a velocidade de convergência estimada foi de $1,2 \%$ ao ano.

$\mathrm{Na}$ linha de considerar modelos de crescimento endógeno, tem-se o trabalho desenvolvido por Ellery Junior (1999). O autor recorre ao modelo de Lucas (1988) e introduz nesse modelo a hipótese do learning-by-doing induzido pela acumulação de capital humano. Os resultados alcançados pelo autor mostram que, na presença de learning-by-doing, o nível ótimo de escolaridade tende a decrescer. $\mathrm{O}$ autor conclui que o modelo de Lucas (1988) superestima a importância do tempo dedicado à escola. Em

\footnotetext{
${ }^{5}$ A especificação desta forma funcional está em Lau L. et al. (1993, p.63).

${ }^{6}$ Ver Capítulo 3, subitem 3.2.1, a respeito das diferentes hipóteses da convergência.
} 
síntese, com esse trabalho, mostrou-se como a hipótese, acima mencionada, pode afetar a taxa de crescimento da economia e o tempo ótimo a ser dedicado à educação formal.

Bueno (1998) procura avaliar de forma discursiva, isto é, sem utilizar evidências empíricas, se a teoria do crescimento endógeno poderia explicar o subdesenvolvimento econômico brasileiro. $\mathrm{O}$ autor argumenta o seguinte:

“... pode-se dizer que a economia capitalista só está apta a empregar uma parcela limitada de sua população em cargos realmente criativos. A grande maioria terá de permanecer vinculada às linhas de montagem de produção em larga escala, em tarefas para as quais um maior nivel educacional poderia até prejudicar a eficiência do trabalho" (Bueno, 1998,p.15).

Com esta afirmação, Bueno (1998) argumenta que boa parte do estoque de capital humano não foi aproveitada ou é subaproveitado nas economias capitalistas. Sendo assim, é inútil o esforço da sociedade em incrementar o estoque de capital humano.

Em uma outra passagem a respeito da economia brasileira, Bueno afirma que "...a dinâmica observada da economia brasileira nas últimas décadas teve muito pouco (se é que teve algo) a ver com os investimentos em capital humano" (1998, p.16). $\mathrm{Na}$ sua visão, a teoria do crescimento endógeno não deveria considerar o investimento em capital humano isoladamente, mas sim incluir outros tipos de variáveis, tais como os realizados em pesquisa e desenvolvimento e em infra-estrutura, por exemplo. $\mathrm{O}$ autor chega a concluir que a teoria do crescimento endógeno, da forma como tem sido concebida, não serve para explicar o subdesenvolvimento.

A tese defendida por Bueno "...é a de que, contrariamente ao prescrito pela teoria do crescimento endógeno, uma trajetória de crescimento sustentado só poderá ser 
alcançada, no Brasil, através de um dramático esforço de inversão física, dirigido sobretudo para a remodelação do aparato produtivo" (Bueno, 1998, p.18).

A argumentação de Bueno (1998) não parece correta. Primeiro, porque o autor não chega a apresentar dados empíricos consistentes capazes de ancorar seus argumentos. Segundo, acredita-se que a visão céptica de Bueno (1998) não condiz com a realidade brasileira, especialmente porque os trabalhos de Gonçalves et al. (1998) mostram que o capital humano tem desempenhado um papel ativo no desenvolvimento da economia brasileira.

De modo diferente à argumentação de Bueno (1998), acredita-se que o capital humano tem contribuído para o desenvolvimento dos países e, consequentemente, dos estados dentro dos países. Contudo, admite-se que Bueno (1998) tem razão em criticar os modelos de crescimento que não incorporam outras variáveis, como, por exemplo, os gastos em pesquisa e desenvolvimento (P\&D)?

Da exposição acima, observa-se a seguinte lacuna: a análise do papel do capital humano no crescimento da agropecuária brasileira, como um todo, e para o período mais recente, ainda não foi realizada, quer seja utilizando o modelo neoclássico tradicional, ou os modelos neoclássicos alternativos de crescimento. Portanto, pretendese dar uma contribuição metodológica (adaptando os modelos mencionados para o estudo em termos de um setor em nível de estado e não com a agregação que eles sugerem atualmente) e empírica (ao ampliar o entendimento do papel do capital humano no desenvolvimento do setor agropecuário no Brasil).

\footnotetext{
${ }^{7}$ Infelizmente, devido às limitações de dados disponíveis no Brasil relacionados ao montante gasto em pesquisas em nível de Estados no setor agropecuário, o presente estudo optou por especificar as equações que explicam o crescimento do produto agropecuário utilizando apenas os anos médios de educação.
} 
O Quadro 1 resume os principais trabalhos que foram desenvolvidos no Brasil e que abordaram o capital humano. 


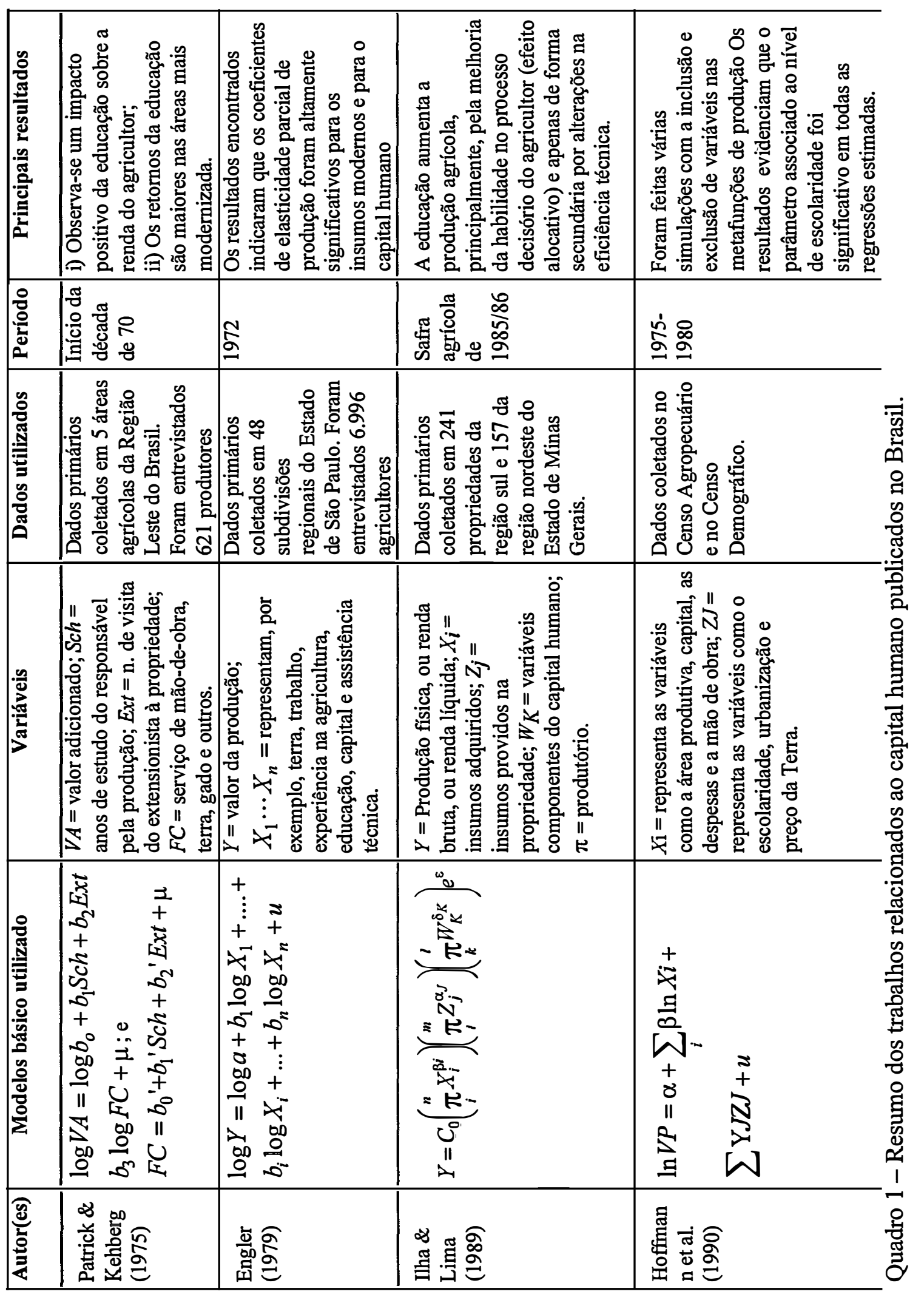




\begin{tabular}{|c|c|c|c|c|c|}
\hline 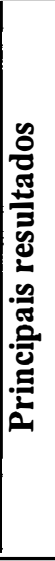 & 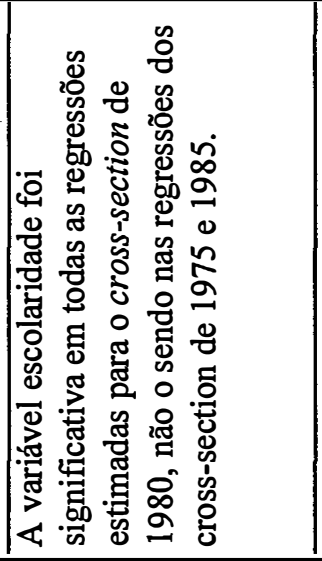 & 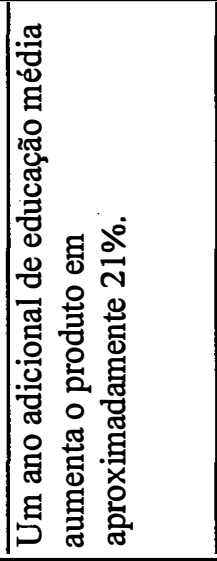 & 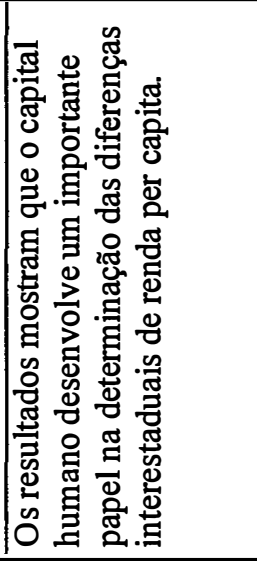 & 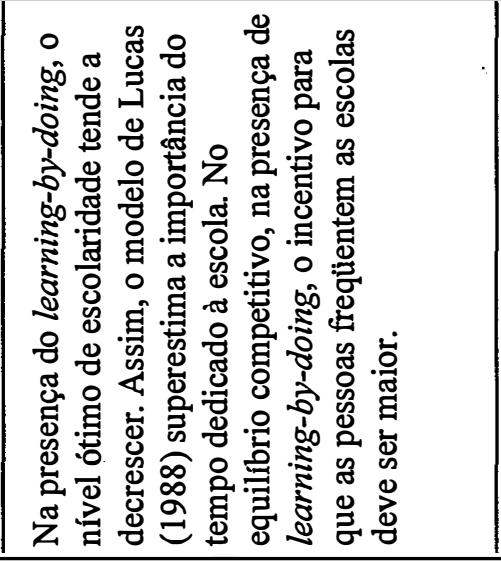 & 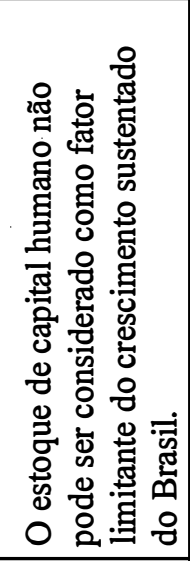 \\
\hline 옴 & 官 & 옹 & ํํำ & 욜 売 & 율 욜 \\
\hline 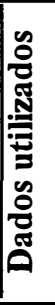 & 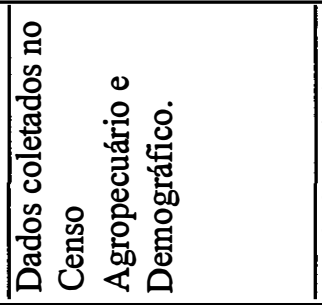 & 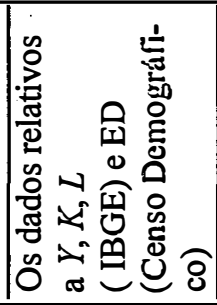 & 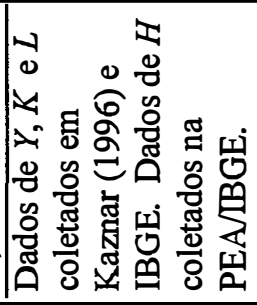 & 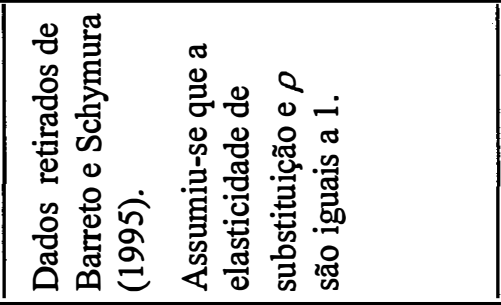 & 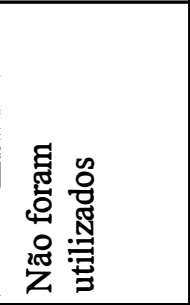 \\
\hline 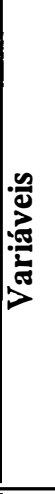 & 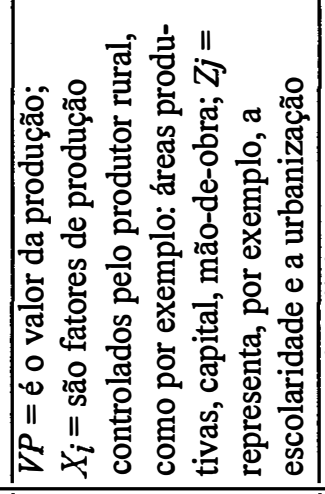 & 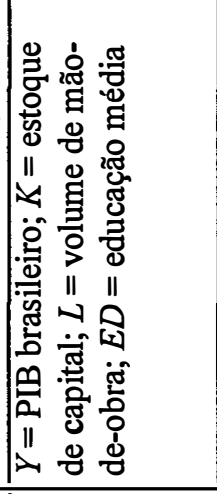 & 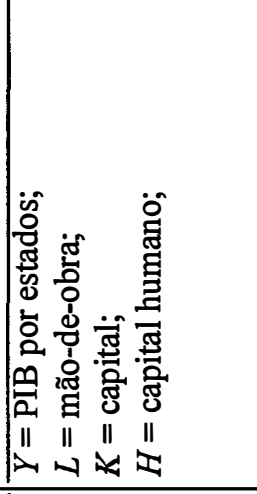 & 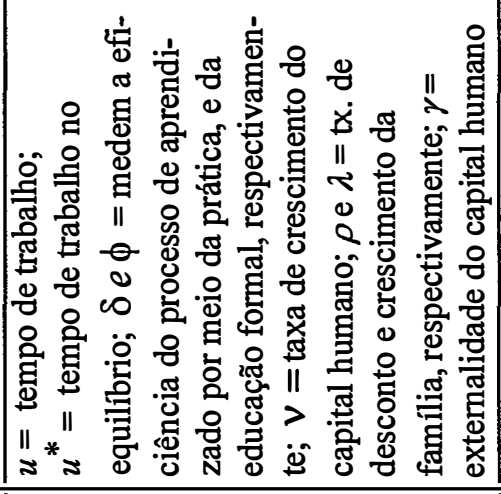 & 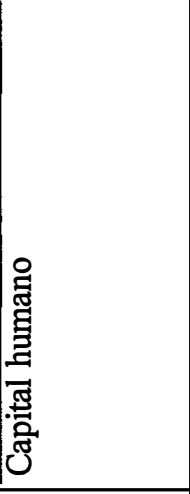 \\
\hline 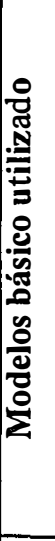 & 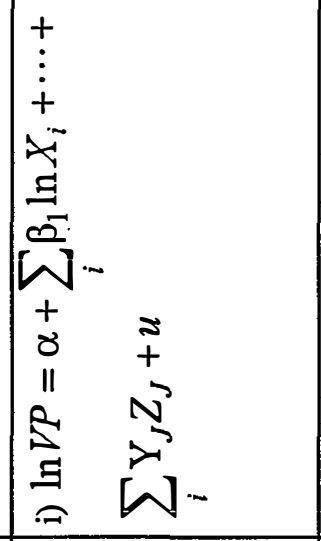 & 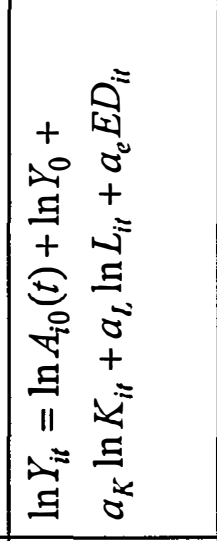 & 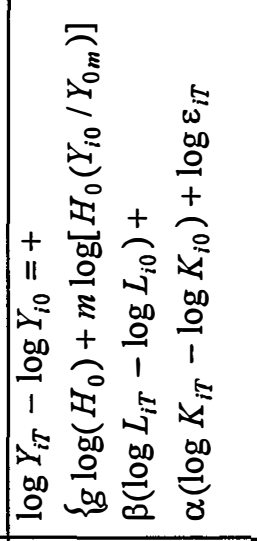 & 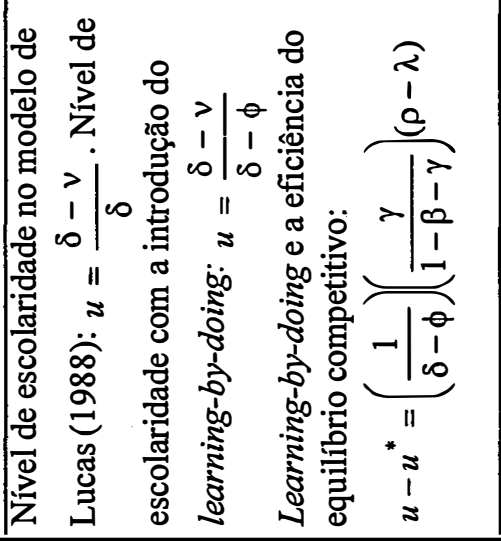 & 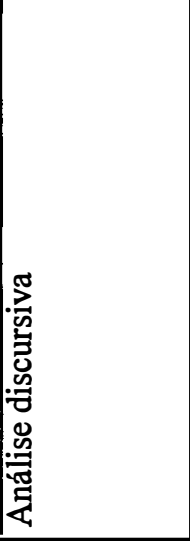 \\
\hline 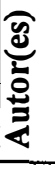 & 串 & 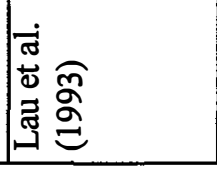 & 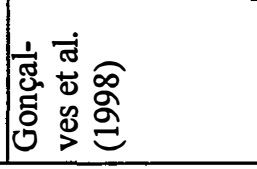 & 空.气 & 올 \\
\hline
\end{tabular}




\subsection{Organização do trabalho}

Para abordar de forma sistemática os objetivos previamente definidos, dividiu-se este trabalho em seis capítulos, incluindo esta introdução. A revisão de literatura é tratada no Capítulo 2. Neste capítulo analisa-se a evolução da agropecuária brasileira no período de 1970 a 1996, evidenciando como essa foi afetada pelas políticas agrícolas adotadas nesse período. Além desse ponto são destacadas também as diferenças de desenvolvimento e crescimento existentes entre os estados em relação ao setor agropecuário, e como elas podem estar relacionadas ao nível educacional dos trabalhadores. Neste mesmo capítulo discute-se também os determinantes do crescimento econômico e os fundamentos dos modelos de crescimento neoclássicos (padrão e alternativo). O Capítulo 3 expõe os procedimentos econométricos e os dados a serem usados para estimar as equações definidas segundo os modelos neoclássicos padrão e alternativo. As estimativas dessas regressões serão utilizadas para explicar o crescimento da agropecuária brasileira de 1970 a 1996 . Os resultados dessas estimativas são discutidos no Capítulo 4. Por fim, no Capítulo 5 são apresentadas as conclusões do presente trabalho. 


\section{REVISÃO DE LITERATURA}

Este capítulo está dividido em oito itens. No item 2.1, é realizada a análise do desempenho econômico do setor agropecuário brasileiro no período de 1970 a 1996. No item 2.2, evidenciam-se as diferenças existentes de desenvolvimento e crescimento do setor agropecuário nos diferentes estados brasileiros, a partir de alguns indicadores de crescimento normalmente discutidos na literatura econômica. Em seguida, analisamse os anos médios de educação nos respectivos estados, procurando salientar as possíveis implicações da escolaridade sobre o desenvolvimento do setor agropecuário. Este item se encerra com uma abordagem comparativa acerca do valor da produção per capita entre os estados. No item 2.3 são analisadas a origem e a evolução dos modelos de crescimento neoclássico. No item 2.4 são apresentados os fatores que se consideram decisivos para alavancar o crescimento econômico dos países e o modelo neoclássico tradicional, como concebido por Solow. Além do mais, analisa-se a visão de outros pesquisadores sobre o que de fato influencia o crescimento do chamado resíduo de Solow. No item 2.5 levantam-se alguns argumentos a respeito do modelo de crescimento endógeno; bem como a função de produção com progresso tecnológico endógeno (subitem 2.5.1); os fundamentos teóricos dos modelos de crescimento endógeno (subitem 2.5.2); e uma abordagem acerca da interpretação da taxa de crescimento do produto, de acordo com o enfoque de crescimento endógeno (subitem 2.5.3). No item 2.6 apresenta-se uma breve discussão sobre as restrições em usar os modelos de crescimento endógeno em análises específicas do setor agropecuário. No item 2.7 realiza-se uma discussão mais detalhada do modelo neoclássico alternativo. Neste item apresentam-se os fundamentos teóricos e quantitativos desse modelo (subitem 2.7.1); e o 
modelo neoclássico alternativo proposto por Benhabib \& Spiegel (subitem 2.7.2). E, finalmente, no item 2.8 , sintetizam-se os modelos a serem considerados na presente tese.

\subsection{Análise do desempenho econômico do setor agropecuário brasileiro no período de 1970 a 1996}

O período de referência deste trabalho (1970 a 1996) e a década imediatamente anterior foram caracterizados por profundas transformações na maneira de produzir do agricultor brasileiro. Essas transformações estão associadas às inovações ocorridas no setor agropecuário. De acordo com De Janvry $(1973)^{8}$, citado por Bacha (1992), as inovações podem ser mecânicas, biológicas, químicas e agronômicas. As inovações mecânicas aumentam a produtividade do trabalho, pois com a introdução das máquinas, o produtor consegue cultivar mais terra com o mesmo tempo de trabalho. As inovações biológicas correspondem ao desenvolvimento de novas variedades de plantas e novas espécies de animais, o que usualmente leva ao aumento da produtividade da terra. As inovações químicas dizem respeito à utilização de fertilizantes, inseticidas e pesticidas. Normalmente, classifica-se esse tipo de inovação como sendo tecnologia poupadora de terra. Finalmente, têm-se as inovações agronômicas que consistem em novas práticas culturais, como rotação de culturas e análise do solo entre outras.

Essas inovações contribuíram para que a taxa geométrica de crescimento do produto agropecuário brasileiro, na década de 70 , ficasse em torno de $3,9 \%$ ao ano. Entretanto, não deixa de ser um desempenho modesto se comparado aos $8,1 \%$ ao ano de crescimento do PIB brasileiro (Silva, 1991, p.270).

$\mathrm{Na}$ década de 70, as chamadas culturas de exportação - como é o caso da soja, da laranja e da cana-de-açúcar, por exemplo - receberam um impulso muito maior, em razão das políticas agrícolas que as beneficiavam mais diretamente; em detrimento

${ }^{8}$ DE JANVRY, A. A socioeconomic model of induced innovations for Argentine agricultural development. Quarterly Journal of Economics, v.3, p.410-435, ago., 1973. 
das culturas voltadas ao mercado interno, como o arroz, mandioca e milho, por exemplo. A Tabela 1 mostra as taxas de crescimento anuais da produção, na década de 70, para algumas culturas selecionadas destinadas ao mercado interno e ao mercado externo. Fica evidente que as culturas destinadas ao mercado interno, realmente, tiveram crescimento da produção bem inferior ao apresentado pelas culturas destinadas ao mercado externo.

Tabela 1. Taxas anuais de crescimento da produção agropecuária brasileira.

\begin{tabular}{lc}
\hline \multicolumn{1}{c}{ Produto } & 1970 a 1979 \\
\hline Culturas destinadas ao mercado interno & \\
Arroz & 1,46 \\
Feijão & $-1,90$ \\
Mandioca & $-2,09$ \\
Milho & 1,75 \\
Batata & 3,73 \\
Culturas destinadas ao mercado externo & \\
Soja & 22,47 \\
Laranja & 12,57 \\
Cana-de-açúcar & 6,30 \\
Fumo & 6,16 \\
Cacau & 3,73 \\
Café & $-1,54$ \\
Produtos pecuários & $1975-1980$ \\
Bovinos (peso das carcaças) & 1,76 \\
Suínos (peso das carcaças) & 6,25 \\
Aves (peso das carcaças) & 18,00 \\
Leite (quantidade produzida) & 6,67 \\
\hline
\end{tabular}

Fonte: Kageyama \& Silva $(1983$, p.542).

Conforme argumentaram Barros \& Graham (1978), a distinção entre o grupo das culturas exportáveis e o das domésticas estava no mecanismo de formação de preços. A dinâmica de preços das culturas domésticas era determinada pelo equilíbrio de mercado e pela capacidade do Governo em intervir, mediante os seus estoques reguladores. Já o desempenho dos preços das culturas de exportação era determinado pelo comportamento do mercado internacional. O baixo dinamismo das atividades 
agrícolas voltadas ao mercado interno era provocado pela própria expansão das culturas de exportação. As facilidades de financiamento do custeio e de investimento para as culturas de exportação incentivavam o agricultor a substituir a produção de alimentos por culturas exportáveis, o que provocava a realocação dos fatores de produção, especialmente do insumo terra.

É evidente que a preocupação do governo, ao priorizar algumas culturas em detrimento de outras, era gerar divisas que seriam utilizadas para cobrir parte do déficit em transações correntes, agravado em decorrência da crise do petróleo na década de 70 . Por trás de todo o processo de modernização agropecuária ocorrido no país, ao longo dos anos 60 e 70, estão as políticas agrícolas, tais como: o crédito rural subsidiado e a política de garantia de preços mínimos, principalmente. Sabe-se que o principal instrumento de política agrícola, ao longo dessas duas décadas e início dos anos 80 , foi o crédito rural subsidiado, ou seja, as taxas de juros reais relacionadas aos empréstimos se mantiveram sistematicamente negativas (Goldin \& Resende, 1993). A tabela 2 traz os valores concedidos como crédito rural de 1970 a 1996. 
Tabela 2. Crédito rural contratado segundo a sua finalidade de 1970 a 1996 (em milhões de Reais de agosto de 1994)

\begin{tabular}{rcccr}
\hline Ano & Custeio & Investimento & Comercialização & Total \\
\hline 1970 & 4.138 & 2.518 & 2.621 & 9.277 \\
1971 & 4.669 & 3.165 & 2.895 & 10.729 \\
1972 & 5.524 & 4.389 & 3.356 & 13.269 \\
1973 & 8.012 & 6.208 & 4.543 & 18.762 \\
1974 & 10.447 & 7.023 & 5.732 & 23.203 \\
1975 & 14.826 & 10.521 & 8.429 & 33.827 \\
1976 & 14.634 & 11.242 & 8.802 & 34.678 \\
1977 & 14.632 & 7.507 & 8.805 & 30.944 \\
1978 & 15.002 & 7.856 & 8.599 & 31.457 \\
1979 & 19.719 & 9.794 & 9.692 & 39.205 \\
1980 & 21.214 & 7.033 & 9.245 & 37.492 \\
1981 & 19.072 & 5.026 & 8.422 & 32.520 \\
1982 & 20.256 & 4.130 & 7.104 & 31.490 \\
1983 & 14.795 & 3.972 & 5.026 & 23.793 \\
1984 & 10.234 & 1.787 & 2.498 & 14.520 \\
1985 & 14.722 & 2.683 & 3.299 & 20.704 \\
1986 & 17.272 & 9.894 & 3.709 & 30.875 \\
1987 & 17.076 & 4.162 & 3.102 & 24.339 \\
1988 & 11.682 & 2.751 & 2.741 & 17.174 \\
1989 & 12.245 & 1.648 & 1.491 & 15.684 \\
1990 & 6.707 & 982 & 1.270 & 8.959 \\
1991 & 7.600 & 786 & 859 & 9.245 \\
1992 & 6.458 & 1.225 & 2.567 & 10.250 \\
1993 & 4.893 & 1.809 & 2.099 & 8.802 \\
1994 & 6.667 & 2.328 & 3.721 & 12.716 \\
1995 & 3.418 & 1.196 & 902 & 5.517 \\
1996 & 3.368 & 1.156 & 297 & 4.821 \\
\hline
\end{tabular}

Fonte: (Bacha \& Rocha, 1998, p.37 e 38).

O volume de crédito concedido ao longo da década de 70 foi crescente. Em 1970 foram concedidos 9,3 bilhões de Reais (a preços de agosto de 1994). Em 1975 foram concedidos 33,8 bilhões de Reais; em 1979, 39,2 bilhões de Reais. Simultaneamente, as taxas de juros reais cobradas nesses empréstimos caíram, 
implicando aumento de subsídio. De acordo com Araújo \& Almeida (1996) ${ }^{9}$, citados por Bacha \& Rocha (1998), “...durante a década de 70 e início da década de 80, havia predominância de crédito subsidiado, ou seja, com taxas de juros reais negativas, atingindo em muitos casos valores próximos a $40 \%$ ao ano."

Os empréstimos do sistema nacional de crédito rural materializaram-se em compras de máquinas e insumos modernos. $\mathrm{O}$ consumo de defensivos agrícolas no Brasil, conseqüentemente, cresceu à taxa de 7,2\% ao ano no período de 1970 a 1980 . O consumo de fertilizantes multiplicou-se por quatro no mesmo período, crescendo a uma taxa de $15,5 \%$ ao ano. Quanto à mecanização, observa-se que o número de tratores utilizados nos estabelecimentos agropecuários multiplicou-se por três nesse período (Kageyama \& Silva, 1983).

É importante ressaltar que a distribuição de crédito, por regiões do Brasil, foi altamente concentrada durante toda a década de 70 e não necessariamente proporcional ao produto agropecuário gerado nas regiões. Apenas para referendar esta afirmação, apresenta-se uma pequena amostra (Tabela 3) da distribuição de crédito por regiões. Três delas foram particularmente beneficiadas pela política de crédito rural: a Sul e Sudeste, principalmente, e em menor escala a Centro-Oeste. Pode-se observar que a Região Sudeste recebeu aproximadamente $37 \%$ do crédito rural e produziu apenas $30 \%$ do produto agropecuário, em média, no período de 1974 a 1976. Já a Região Sul foi beneficiada com $38 \%$ do crédito e gerou, em média, $40 \%$ do produto agropecuário. A Região Centro-Oeste, por sua vez, recebeu em média $10,8 \%$ do crédito e contribuiu com apenas $7,2 \%$ para a formação do produto agropecuário brasileiro. A Região Norte pouco se beneficiou da política de crédito rural, tendo recebido por volta de $1,5 \%$ em média do crédito rural e contribuindo com $2,2 \%$ do produto agrícola brasileiro. A Região Nordeste recebeu cerca de $12,6 \%$ do crédito e gerou cerca de $20,6 \%$ do produto agrícola brasileiro.

\footnotetext{
${ }^{9}$ ARAÚJO, P.F.C.; ALMEIDA, A. Financiamento da Agricultura no Brasil: da crise do crédito barato à perpectiva de um novo modelo. In TEIXEIRA, E. C.; VIEIRA, W.C. (coords.). Reforma da política agrícola e abertura econômica. Viçosa, 1996.
} 
Tabela 3. Participação percentual das regiões brasileiras no produto agropecuário e no crédito rural - anos selecionados.

\begin{tabular}{|c|c|c|c|c|c|c|}
\hline \multirow[t]{2}{*}{ Região } & \multicolumn{3}{|c|}{ Produto Agropecuário } & \multicolumn{3}{|c|}{ Crédito rural } \\
\hline & 1974 & 1975 & 1976 & 1974 & 1975 & 1976 \\
\hline Sudeste & 32,5 & 28,2 & 29,2 & 37,8 & 37,5 & 35,7 \\
\hline Centro-Oeste & 6,5 & 7,0 & 8,2 & 10,7 & 10,2 & 11,5 \\
\hline Norte & 1,8 & 2,3 & 2,6 & 1,2 & 1,5 & 1,7 \\
\hline Nordeste & 19,7 & 22,5 & 19,5 & 11,7 & 12,5 & 13,5 \\
\hline Sul & 39,5 & 40,0 & 40,3 & 38,6 & 38,3 & 37,6 \\
\hline
\end{tabular}

Quando se fala em modernização da agropecuária brasileira, o senso comum leva a pensar que o processo de produção no país como um todo passou a utilizar insumos modernos. Entretanto, o que realmente aconteceu, na década de 70, foi a concentração da modernização, em razão dos incentivos da política agrícola, nas Regiões Sul e Sudeste, ao passo que as Regiões Norte e Nordeste, relativamente, pouco aproveitaram os benefícios do crédito rural. Mas mesmo assim, essas duas regiões contribuíram significativamente para a formação do produto agropecuário brasileiro.

Pela Tabela 4 observa-se que em 1970 as Regiões Norte e Nordeste contribuíram com cerca de $25 \%$ do produto agrícola brasileiro. Em parte, devido à falta de uma política agrícola mais adaptada à realidade dessas duas regiões, esta participação, em 1975, diminuiu para 23,5\%. A perda da posição relativa do Norte e Nordeste pode ter sido conseqüência da discriminação na distribuição do crédito rural por regiões. Entretanto, conforme Pinto (1979), o aumento na liberação do crédito rural não representou incremento da produção agropecuária na mesma magnitude. Essa afirmação pode ser constatada pelos dados da Tabela 4 . Ali pode-se observar que a participação das Regiões Norte e Nordeste no PIB agropecuário brasileiro subiu para 25,14\% em 1980 e, a partir de então, a participação das duas Regiões na composição do produto agrícola vêm aumentando gradativamente - atingindo 31,02\% em 1994. Cabe ressaltar que esse aumento se deve, em maior proporção, à excelente performance do setor agropecuário na Região Norte. 
Tabela 4. Participações das regiões no PIB a custo de fatores - anos selecionados.

\begin{tabular}{|c|c|c|c|}
\hline Regiões & Total geral & Agropecuário & Indústria \\
\hline \multicolumn{4}{|l|}{ Ano: $1970^{(a)}$} \\
\hline Norte & 2,16 & 4,06 & 1,07 \\
\hline Nordeste & 11,71 & 20,87 & 7,01 \\
\hline Sudeste & 65,55 & 34,23 & 79,09 \\
\hline Sul & 16,71 & 33,42 & 11,95 \\
\hline Centro-Oeste & 3,87 & 7,41 & 0,89 \\
\hline \multicolumn{4}{|l|}{ Ano: $1975^{(a)}$} \\
\hline Norte & 2,05 & 3,70 & 1,32 \\
\hline Nordeste & 11,07 & 19,81 & 7,46 \\
\hline Sudeste & 64,86 & 32,08 & 75,27 \\
\hline Sul & 17,90 & 36,14 & 14,82 \\
\hline Centro-Oeste & 4,11 & 8,27 & 1,13 \\
\hline \multicolumn{4}{|l|}{ Ano: $1980^{(a)}$} \\
\hline Norte & 3,34 & 5,65 & 3,22 \\
\hline Nordeste & 11,96 & 19,49 & 9,33 \\
\hline Sudeste & 62,34 & 34,68 & 69,04 \\
\hline Sul & 16,97 & 29,51 & 16,23 \\
\hline Centro-Oeste & 5,39 & 10,67 & 2,19 \\
\hline \multicolumn{4}{|l|}{ Ano: $1985^{(\mathrm{a})}$} \\
\hline Norte & 4,08 & 6,47 & 4,05 \\
\hline Nordeste & 13,64 & 20,61 & 12,04 \\
\hline Sudeste & 59,15 & 38,31 & 65,80 \\
\hline Sul & 17,15 & 27,10 & 15,70 \\
\hline Centro-Oeste & 5,98 & 7,50 & 2,40 \\
\hline \multicolumn{4}{|l|}{ Ano: $1990^{(b)}$} \\
\hline Norte & 5,02 & 8,46 & 27,7 \\
\hline Nordeste & 14,02 & 20,66 & 9,38 \\
\hline Sudeste & 58,50 & 41,51 & 48,1 \\
\hline Sul & 15,85 & 22,13 & 11,6 \\
\hline Centro-Oeste & 6,61 & 7,24 & 2,87 \\
\hline \multicolumn{4}{|l|}{ Ano: $1994^{(\mathrm{b})}$} \\
\hline Norte & 4,82 & 8,15 & 4,48 \\
\hline Nordeste & 13,97 & 22,87 & 11,49 \\
\hline Sudeste & 56,57 & 38,39 & 60,50 \\
\hline Sul & 17,55 & 23,00 & 18,85 \\
\hline Centro-Oeste & 7,08 & 7,60 & 4,68 \\
\hline
\end{tabular}

Fonte: (a) Anuário Estatístico do Brasil - 1992; (b) Silva et al. (1996, p.32-58). 
Basicamente, o resultado do processo de modernização da agropecuária na década de 70 , estimulado pela política de crédito rural, foi altamente seletivo, pois privilegiou alguns estados em detrimento de outros, privilegiando as culturas voltadas para exportação. $\mathrm{O}$ balanço final dessa política agrícola apresentou pontos positivos e negativos. Positivos porque o governo realmente conseguiu atingir sua meta de gerar mais divisas para o país (ver, por exemplo, Barros 1979). Negativos, porque, como destaca Barros (1979), a produção de alimentos estava relegada a segundo plano no período compreendendo 1970 a 1977. Como o preço real dos alimentos aumentou em $52 \%$ e dada a importância dos alimentos na formação dos índices de inflação, a performance da agropecuária deixou de ser um problema de crescimento para se tornar um problema de estabilidade de preços.

Ao longo dos anos 80, a política de crédito rural sofreu mudanças significativas, se comparada à década de 70 . O crédito rural tornou-se mais restritivo e a política de garantia de preços mínimos se converteu em um dos principais instrurnentos de política agrícola, através do sistema de aquisição do Governo Federal (AGF) e empréstimos do Governo Federal (EGF). Essa política foi particularmente importante na expansão das regiões de fronteiras agrícolas, como as do Centro-Oeste e Norte (Gasques \& Villa Verde, 1990).

Olhando o comportamento econômico do setor agropecuário, ao longo da década de 80 , é possível perceber que esse setor vinha enfrentando um cenário econômico desfavorável em razão de, basicamente, quatro fatores. Primeiro, a grande disponibilidade de crédito rural subsidiado que persistiu até 1982 deixou de existir. Entre 1983 e 1984, o volume de empréstimo rural liberado caiu drasticamente - apenas para confirmar essa afirmação, em 1984 o volume de crédito rural destinado a custeio caiu em cerca de $50 \%$ se comparado aos três primeiros anos da década de 80 , conforme se pode ver pela Tabela 2; enquanto o do investimento se reduziu a $25 \%$ do que era em 1980. Segundo fator: o sistema nacional de crédito rural foi reformado com a instituição plena da correção monetária para os empréstimos rurais. Terceiro, houve em certos anos 
quebra de safra na Região Centro-Oeste e seca no Nordeste. E quarto, para completar o quadro desfavorável, a economia brasileira estava em recessão (Rezende, 1989).

Frente a essa conjunção de problemas, nessa década, era plausível esperar uma crise de liquidez no setor agropecuário, com reflexos importantes sobre a produção e na renda dos agricultores. Entretanto, como destaca Rezende (1989), não aconteceu nenhuma crise; pelo contrário, a produção agrícola expandiu-se consideravelmente.

Na década de 80, a produção agropecuária continuou a aumentar, apesar da redução da disponibilidade do crédito rural. No período compreendido entre $1978 \mathrm{e}$ 1987, a taxa geométrica anual de crescimento da produção de lavoura atingiu aproximadamente 6,7\% (Bacha \& Rocha, 1998). Em compensação, nesse mesmo período, o desempenho agregado da pecuária - considerando cinco produtos (gado bovino, frango, ovo, suíno e leite) - foi relativamente fraco, resultando numa taxa anual de crescimento de 2,6\% ao ano (Silva, G. 1991), apesar de algumas atividades, como é o caso das aves, ter apresentado taxa de crescimento médio de 18\% no período 1975-1980, conforme se observa na Tabela 1 .

Segundo Ferreira Filho (1994), na década de 80 o crescimento intensivo do setor agropecuário esteve associado ao aumento da produtividade física. Além disto, esse crescimento estava associado, de um lado, à uma queda no consumo aparente de fertilizantes e defensivos agrícolas e, de outro lado, à queda dos preços industriais em termos agregados. A redução do consumo aparente de fertilizantes e defensivos agrícolas associou-se, por sua vez, à redução na disponibilidade de crédito rural.

De um modo geral, a crise econômica que assolou o Brasil na década de 80, conhecida pelos economistas como a década economicamente perdida, não atingiu a agropecuária. Como destacaram Rezende (1989) e Mello (1990), o crescimento médio geométrico anual da agropecuária de 1980 a 1988 foi de 3,1\% e de 1,2\% para a indústria. Ao desagregar os dados por produto, Mello (1990) verificou que os produtos agrícolas 
domésticos, ou voltados para o mercado interno, apresentaram taxa de crescimento, durante a década, de $2,05 \%$ ao ano. Para os produtos agrícolas voltados à exportação, essa taxa reduziu-se de $8 \%$, nos anos 70 , para $4,5 \%$ ao ano na década de 80 . Para os produtos animais, essa taxa foi de $3,43 \%$, sinalizando que a divisão entre produtos agrícolas exportáveis e de consumo interno estava perdendo importância. Dois foram os motivos destacados: i) uma parte significativa dos produtos exportáveis estava sendo cada vez mais consumida no mercado interno; e ii) a perda de dinamismo do mercado internacional. Segundo Manoel \& Barros (1987, p.107),

"Contrariamente aos anos 70, que foram caracterizados pelo aumento do intercâmbio agrícola, o crescimento da produção, elevação do consumo; os anos 80 estão mostrando outra direção, vale dizer, auto-suficiência por parte dos países importadores, queda na demanda exterior devido a problemas de endividamento e escassez de divisas."

Na década de 90, observa-se uma nítida redução dos gastos públicos com a agropecuária. O Estado estava deixando de utilizar os mecanismos tradicionais de financiamento da produção agropecuária, como o crédito rural e a política de garantia de preços mínimos. Diante disso, Bacha \& Rocha (1998, p.40), citando Almeida (1995) ${ }^{10}$ e Gasques \& Villa Verde (1996) ${ }^{11}$, argumentaram que:

\footnotetext{
${ }^{10}$ ALMEIDA, A. Mercados infonnais como fonte altemativa de liquidez para os agricultores. Piracicaba, 1994. Dissertação de mestrado - Universidade de São Paulo, Escola Superior de Agricultura "Luiz de Queiroz".

"GASQUES, J. G.; VILLA VERDE, C. M. Novas fontes de recursos, propostas e experiências de financiamento rural. Revista de Economia e Sociologia Rural, v.34, n.3-4, p.39-80, jul./dez., 1996
} 
“... as novas alternativas para o financiamento da agricultura são os recursos da caderneta de poupança, os recursos externos e os recursos livres do sistema financeiro $e$ os novos mecanismos desenhados pela iniciativa privada, como Certificado de Mercadorias com Entrega Garantida - CMG, Cédula de Produto Rural $C P R$ e Contrato de Compra e Venda de Soja Verde. Tais recursos implicam a cobrança de taxa de juros real positiva."

Apesar de não se ter uma política agrícola tão ativa como no passado, a produção agrícola vem mantendo tendência de alta desde meados da década de 90 . Entre 1987 e 1993 a taxa de crescimento da produção de lavouras foi praticamente nula, com a produção se estagnando em torno de 370 milhões de toneladas. Nos dois anos posteriores (1994 a 1996) essa taxa de crescimento situou-se em 7,7\% (ver Tabela 5). Este crescimento da produção é explicado, em parte, pelo aumento da produtividade da terra, pois a área colhida vem caindo, passando de 53.880 mil hectares em 1989, para 47.631 mil hectares, em 1996. Entre 1989 e 1993, a produtividade da terra passou de $6.914 \mathrm{~kg} / \mathrm{ha}$ para $7.894 \mathrm{~kg} / \mathrm{ha}$, respectivamente. Em 1996 essa produtividade alcançou $9.455 \mathrm{~kg} / \mathrm{ha}$ (Bacha \& Rocha, 1998, p.50-52). 
Tabela 5. Produção agrícola brasileira, vários anos.

\begin{tabular}{lc}
\hline Ano & Produção agrícola (em milhões de toneladas) \\
\hline 1978 & 207,01 \\
1979 & 221,44 \\
1980 & 241,46 \\
1981 & 251,30 \\
1982 & 280,34 \\
1983 & 303,76 \\
1984 & 316,90 \\
1985 & 352,45 \\
1986 & 339,38 \\
1987 & 380,05 \\
1988 & 368,47 \\
1989 & 372,50 \\
1990 & 367,74 \\
1991 & 367,58 \\
1992 & 387,32 \\
1993 & 360,72 \\
1994 & 416,76 \\
1995 & 434,34 \\
1996 & 450,35 \\
\hline
\end{tabular}

Fonte: Bacha \& Rocha, 1998, p.56.

A importância do crescimento da produtividade na expansão da produção agropecuária também é ressaltada pelos autores que calcularam a produtividade total dos fatores (PTF). Barros (1999) apresenta um conceito simples de PTF, mas bem elucidativo. PTF “...consiste na parcela do crescimento do produto não explicada pela variação na quantidade dos insumos" (Barros, 1999, p.72). Nesse sentido, a PTF estaria associada ao progresso tecnológico, aos ganhos em escala e às mudanças institucionais.

No entanto, existem diferentes formas de computar a PTF, o que leva a diferentes cálculos de seu valor. Por exemplo, para o período de 1970 a 1985, Dias \& Bacha (1998) estimaram que a PTF na agropecuária do Brasil cresceu à taxa de 4,3\% ao ano. As estimativas do crescimento da PTF para o mesmo período feitas por Amade (1992) e Ávila \& Evenson (1995) foram de 2,25\% e 2,45\%, respectivamente. 
Gasques \& Conceição (1997) estimaram que a PTF na agropecuária brasileira cresceu a 3,88\% ao ano no período de 1976 a 1994, sendo que de 1988 a 1994 a expansão da PTF foi de 3,11\% ao ano. Para todo o período de 1970 a 1995, Barros (1999) estima que a PTF na agropecuária do Brasil cresceu entre 1 e 1,6\% ao ano (dependendo de como o estoque de capital foi mensurado).

Apesar de substanciais diferenças entre os diversos estudos, foi possível perceber que todos eles evidenciaram o crescimento da PTF, corroborando a tese de que a agropecuária tem se expandido devido, também, aos ganhos de produtividade.

\subsection{Diferenças no processo de crescimento do setor agropecuário brasileiro entre os estados}

Uma radiografia estanque do mundo mostraria que, em termos comparativos, existe em um extremo os países ricos, com as suas economias bem estruturadas, e no outro extremo os países pobres com dificuldades de manter taxas de crescimento econômico acima do crescimento demográfico. Entre os dois extremos está a maioria dos países com suas economias em transição. São os chamados países em desenvolvimento, que se caracterizaram por apresentar elevadas taxas de crescimento econômico, acima de $5 \%$ ao ano nas últimas décadas ${ }^{12}$. No entanto, esses países ainda convivem com problemas relacionados ao déficit público, endividamento externo, inflação e concentração de renda entre outros.

Os desequilíbrios regionais, que caracterizam o processo de acumulação no sistema capitalista, resultam em parte do movimento do capital. Este se aloca em algumas regiões tentando aproveitar-se de algumas variáveis que são fundamentais para a geração de economias de escala, tais como: disponibilidade de mão-de-obra qualificada e no volume requisitado, proximidade dos centros consumidores, facilidade de transporte das matérias-primas e dos produtos acabados, e infra-estrutura eficiente e adequada às exigências dos investimentos.

${ }^{12}$ Ver Jones (1999, p.4). 
Trazendo a discussão da desigualdade econômica para o Brasil, percebe-se que, de um lado, têm-se alguns estados que poderão ser considerados ricos, levando em conta a realidade do país, e no outro extremo estão os estados pobres. $\mathrm{Na}$ zona intermediária se encontram os estados com economias em transição. Vários trabalhos já analisaram essa desigualdade ${ }^{13}$. Por esta razão, esse estudo procurou apresentar alguns indicadores econômicos, já consagrados na literatura de crescimento econômico, com a finalidade de utilizá-los como referência para estudar as diferenças no comportamento econômico recente da agropecuária nos estados brasileiros.

No presente trabalho, optou-se pela utilização do valor da produção per capita e por equivalente-homem ${ }^{14}$ (força de trabalho) como indicador de crescimento, ao invés de se usar, como é comum nas análises econômicas, o PIB per capita, ou outros indicadores sociais, como mortalidade infantil, expectativa de vida e analfabetismo, por exemplo. A razão para adotar este procedimento se deveu ao fato do valor da produção ser a variável que se deseja explicar no presente trabalho. Ou dizendo de outra forma, nos modelos teóricos e econométricos a serem expostos nos Capítulos 3 e 4, respectivamente, o valor da produção é a variável dependente.

A Tabela 6 apresenta três variáveis que são úteis para comparar o crescimento e o desenvolvimento econômico entre os estados brasileiros. As segunda e terceira colunas mostram a relação entre o valor da produção e o equivalente-homem. Trata-se de uma medida agregada de produtividade do trabalho. Pode-se constatar que a produtividade do trabalho na agropecuária em alguns estados vem crescendo a elevadas taxas. Por exemplo, no Distrito Federal, Mato Grosso, Goiás, Santa Catarina, São Paulo e Maranhão, o crescimento da produtividade do trabalho entre 1970 e 1996 foi acima de $6 \%$ ao ano. No entanto, essa variável teve relativamente pequeno crescimento na maioria dos estados da Região Norte. A situação pareceu estar crítica para Roraima e Rondônia

\footnotetext{
${ }^{13}$ Ver, por exemplo, Lavinas et al. (1993) e Barros et al. (1997).

${ }^{14} \mathrm{~A}$ fórmula de cálculo do número de equivalente-homem está apresentada no Capítulo 4, no tópico 4.4.
} 
que apresentaram taxa de crescimento da produtividade do trabalho próxima de zero e negativa, respectivamente, entre 1970 e 1996.

Tabela 6. Estatísticas de crescimento da agropecuária dos estados brasileiros. Valores em Reais deflacionados - base agosto de 1994.

\begin{tabular}{|c|c|c|c|c|c|c|c|c|c|}
\hline \multirow[t]{2}{*}{$\overline{\mathrm{UF}}$} & \multicolumn{3}{|c|}{$\begin{array}{l}\text { VP. Por EH e taxa de } \\
\text { cresc. Anual }{ }^{\mathrm{I}} \mathrm{em} \%\end{array}$} & \multicolumn{3}{|c|}{$\begin{array}{l}\text { VP. Per capita e taxa de } \\
\text { cresc. Anual }{ }^{1} \text { em } \%\end{array}$} & \multicolumn{3}{|c|}{ EH/população rural } \\
\hline & 1970 & 1996 & Var. $^{1}$ & 1970 & 1996 & Var. $^{\prime}$ & 1970 & 1996 & Var. $^{1}$ \\
\hline RO & 802,82 & 891,65 & 0,39 & 246,13 & 449,15 & 2,25 & 0,31 & 0,50 & 1,86 \\
\hline $\mathrm{AC}$ & 651,03 & 965,59 & 1,47 & 202,81 & 399,32 & 2,54 & 0,31 & 0,41 & 1,05 \\
\hline $\mathrm{AM}$ & 626,44 & 885,69 & 1,29 & 239,62 & 368,78 & 1,61 & 0,38 & 0,42 & 0,31 \\
\hline $\mathrm{RR}$ & 1745,82 & 1522,92 & $-0,50$ & 473,22 & 549,74 & 0,56 & 0,27 & 0,36 & 1,07 \\
\hline PA & 460,71 & 1114,91 & 3,33 & 166,72 & 293 & 2,11 & 0,36 & 0,26 & $-1,18$ \\
\hline AP & 1055,20 & 3449,89 & 4,49 & 159,33 & & 6,66 & 0,15 & 0,26 & 2,08 \\
\hline MA & 71,76 & 447,86 & 7,02 & 28,87 & & 7,27 & 0,40 & 0,43 & 0,23 \\
\hline PI & 176,75 & 476,96 & 3,75 & 64,09 & & 4,75 & 0,36 & 0,47 & 0,97 \\
\hline $\mathrm{CE}$ & 179,70 & 706,07 & 5,20 & 58,60 & & 6,52 & 0.33 & 0,46 & 1,25 \\
\hline $\mathrm{RN}$ & 271,15 & 934,81 & 4,69 & 86,97 & & 5,49 & 0,32 & 0,39 & 0,76 \\
\hline PB & 304,76 & 1038,17 & 4,64 & 104,68 & & 5,02 & 0,34 & 0,38 & 0,36 \\
\hline PE & 402,11 & 1234,38 & 4,24 & 154,33 & & 4,57 & 0,38 & 0,42 & 0,32 \\
\hline AL & 537,02 & 1464,75 & 3,79 & 190,49 & & 3,96 & 0,35 & 0,37 & 0,17 \\
\hline SE & 390,00 & 907,48 & 3,18 & 171,97 & & 3,92 & 0,44 & 0,53 & 0,72 \\
\hline BA & 519,18 & 994,99 & 2,44 & 189,89 & & 3,01 & 0,37 & 0,42 & 0,55 \\
\hline MG & 1193,45 & 3506,69 & 4,07 & 367,02 & 168 & 5,81 & 0,31 & 0,48 & 1,67 \\
\hline ES & 1797,43 & 3990,19 & 3,00 & 506,64 & 190 & 5,02 & 0,28 & 0,48 & 1,97 \\
\hline $\mathrm{RJ}$ & 1221,16 & 3777,40 & 4,27 & 258,60 & & 5,09 & 0,21 & 0,26 & 0,78 \\
\hline SP & 1752,67 & 9369,27 & 6,41 & 621,15 & 336 & 6,45 & 0,35 & 0,36 & 0,04 \\
\hline PR & 1429,84 & 4662,61 & 4,48 & 506,18 & 251 & 6,12 & 0,35 & 0,54 & 1,58 \\
\hline SC & 81,56 & 4951,78 & 6,60 & 307,77 & 2153 & 7,47 & 0,35 & 0,43 & 0,82 \\
\hline RS & 1426,69 & 4806,27 & 4,60 & 542,54 & 2615,69 & 6,00 & 0,38 & 0,54 & 1,34 \\
\hline MT & 988,78 & 8625,70 & 8,35 & 320,90 & 4558,05 & 10,33 & 0,32 & 0,53 & 1,82 \\
\hline GO & 750,94 & 4828,94 & 7,14 & 204,05 & 2879,74 & 10,30 & 0,27 & 0,60 & 2,95 \\
\hline DF & 928,66 & 9548,34 & 9,01 & 255,49 & 971,07 & 5,07 & 0,28 & 0,10 & $-3,62$ \\
\hline
\end{tabular}

Fonte: ${ }^{\triangle}$ Anuário Estatístico do Brasil - 1998; 'Dados da pesquisa retirados do Apêndice 3, Tabela 3.1. 'Variação dada pela fórmula $V a=V o(1+i)^{n}$.

Observando somente a taxa de crescimento da produtividade do trabalho, um leitor poderia ser levado, erroneamente, a classificar a agropecuária de alguns estados, 
como o Maranhão e Ceará, por exemplo, como sendo mais dinâmica que a de estados da Região Sudeste. Entretanto, um trabalhador em São Paulo, Mato Grosso e Distrito Federal, em 1996, gerou um valor da produção 10 vezes superior à média dos estados nordestinos e do Norte do Brasil, com exceção do Amapá.

As quinta e sexta colunas da Tabela 6 evidenciam o valor da produção agropecuária per capita em 1970 e 1996, respectivamente. Trata-se de outro indicador de desenvolvimento econômico, ou uma medida de bem-estar da população no meio rural. A maioria dos estados apresentou taxa de crescimento para esta variável acima de $5 \%$ ao ano, no período 1970-1996, com destaque para Goiás, Mato Grosso, Santa Catarina e Maranhão, cujas taxas de crescimento superaram 7\% ao ano. Contudo, o valor da produção per capita no Maranhão é 17 vezes menor do que o verificado em São Paulo. Em média, os valores da produção per capita dos estados das Regiões Norte e Nordeste foram oito vezes menores do que o obtido por São Paulo.

De acordo com os valores da produção per capita, verificou-se que o maior bem-estar da população no meio rural encontra-se nas Regiões Sudeste (com exceção do Rio de Janeiro), Sul e Centro-Oeste (excluindo o Distrito Federal). Nessas Regiões, o valor da produção per capita superou os $\mathrm{R} \$ 1.600,00$, em 1996. As Regiões Norte e Nordeste apresentaram o valor da produção per capita inferior a $\mathrm{R} \$ 600,00$, neste mesmo ano, excetuando Amapá que, diferentemente dos outros estados da Região Norte, teve valor da produção per capita acima de $\mathrm{R} \$$ 900,00 em 1996.

As oitava e nona colunas da Tabela 6 apresentam as proporções das pessoas que trabalham sobre as que vivem no meio rural. Quanto mais próximo de um for esse valor, menor a proporção de crianças e idosos sobre a quantidade total de equivalentehomem e também menor o desemprego da mão-de-obra no campo. Somente em cinco estados a proporção de EH sobre a população rural superou os 50\% em 1996. Na maioria dos estados, a taxa de ocupação da mão-de-obra ficou entre 25\% e 50\% em 1996.

De modo geral, houve aumento da taxa de ocupação da mão-de-obra nos estados entre 1970 a 1996. Uma exceção foi o Estado de São Paulo, que manteve sua 
taxa de ocupação da mão-de-obra, no período de 1970 a 1996, praticamente estagnada. Como se trata da agropecuária mais desenvolvida do Brasil, esse número poderia estar sinalizando que a taxa de ocupação, respeitando as condições institucionais do país, deva estar próxima aos $40 \%$. Isso parece ser coerente com os resultados obtidos em grande parte dos estados.

As elevadas taxas de ocupação da mão-de-obra verificadas na Região Sul podem ser explicadas, em boa medida, pela característica fundiária da Região. Isso ocorre especialmente no Rio Grande do Sul e Santa Catarina, onde predominam as pequenas propriedades com o uso intensivo de mão-de-obra familiar em algumas atividades, como no caso da cultura do fumo e da produção integrada de frango e suína ${ }^{15}$.

A Tabela 7 apresenta a relação capital/trabalho na agropecuária brasileira. Em uma típica função de produção (excluindo o estágio III), quanto maior for a quantidade de capital por trabalhador a ser utilizada, maior será o produto por trabalhador a ser obtido. Observa-se na quarta coluna da Tabela 7 que em 1995/96 os estados do Sudeste, Sul e Centro-Oeste eram os que tinham maior relação $K / L^{16}$. Isto explica o fato de eles também serem os que tinham maior valor da produção per capita no mesmo ano (como elucidado na Tabela 6).

\footnotetext{
${ }^{15}$ As elevadas taxas verificadas em Goiás e Mato Grosso precisariam ser melhor investigadas, assim como a baixíssima taxa encontrada para o Distrito Federal. Fica, portanto, como objeto para futuras pesquisas. ${ }^{16}$ A proxy utilizada para o capital foi a potência dos tratores, medida em número de cavalos (c.v.) em cada estado. $\mathrm{O} L$ refere-se ao número de $\mathrm{EH}$, calculado conforme apresentado no item 4.4.
} 
Tabela 7. Evolução da relação entre capital e trabalho na agropecuária brasileira.

\begin{tabular}{crrrrrr}
\hline UF & \multicolumn{3}{c}{ Proporção de $K / L$} & \multicolumn{3}{c}{ Variação anual (\%) $^{\mathrm{I}}$} \\
\hline $1970^{\mathrm{I}}$ & $1980^{\mathrm{I}}$ & $1995 / 96^{\mathrm{I}}$ & $1970 \mathrm{a} 1980^{\mathrm{I}}$ & $1980 \mathrm{a} 1996^{\mathrm{I}}$ & $1970^{\mathrm{a}} 1996^{\mathrm{I}}$ \\
\hline RO & 0,13 & 0,26 & 0,71 & 2,76 & 3,72 & 6,58 \\
AC & 0,02 & 0,19 & 0,35 & 9,54 & 2,24 & 12,00 \\
AM & 0,01 & 0,09 & 0,10 & 9,76 & 0,20 & 9,99 \\
RR & 0,02 & 0,68 & 0,86 & 13,68 & 0,90 & 14,70 \\
PA & 0,09 & 0,35 & 0,51 & 5,23 & 1,43 & 6,74 \\
AP & 0,17 & 0,37 & 0,72 & 2,91 & 2,47 & 5,45 \\
MA & 0,01 & 0,13 & 0,22 & 10,79 & 2,05 & 13,05 \\
PI & 0,03 & 0,16 & 0,27 & 7,07 & 1,88 & 9,08 \\
CE & 0,03 & 0,26 & 0,26 & 7,78 & 0,00 & 7,66 \\
RN & 0,09 & 0,52 & 0,69 & 6,69 & 1,04 & 7,81 \\
PB & 0,08 & 0,36 & 0,44 & 5,73 & 0,75 & 6,53 \\
PE & 0,08 & 0,32 & 0,37 & 5,28 & 0,57 & 5,88 \\
AL & 0,16 & 0,57 & 0,60 & 4,90 & 0,15 & 5,05 \\
SE & 0,11 & 0,49 & 0,56 & 5,72 & 0,50 & 6,25 \\
BA & 0,05 & 0,38 & 0,68 & 7,64 & 2,19 & 9,99 \\
MG & 0,27 & 1,56 & 3,21 & 6,66 & 2,70 & 9,54 \\
ES & 0,19 & 1,02 & 1,81 & 6,35 & 2,14 & 8,63 \\
RJ & 0,78 & 1,70 & 2,77 & 2,95 & 1,83 & 4,84 \\
SP & 2,44 & 7,16 & 13,25 & 4,06 & 2,31 & 6,46 \\
PR & 0,52 & 3,74 & 8,49 & 7,56 & 3,08 & 10,88 \\
SC & 0,32 & 2,28 & 5,71 & 7,58 & 3,45 & 11,29 \\
RS & 1,69 & 5,66 & 9,30 & 4,58 & 1,85 & 6,52 \\
MT & 0,75 & 5,95 & 11,76 & 7,96 & 2,55 & 10,71 \\
GO & 0,63 & 3,02 & 6,41 & 6,00 & 2,83 & 9,00 \\
DF & 0,88 & 5,13 & 9,11 & 6,77 & 2,15 & 9,07 \\
\hline
\end{tabular}

Fonte: ${ }^{\star}$ Anuário Estatístico do Brasil - 1998; ${ }^{1}$ Dados da pesquisa retirados do Apêndice 3, Tabela 3.1.

Examinando a evolução da relação $K / L$, fica patente o processo de intensificação do uso de capital na agropecuária brasileira. Em 1970, somente São Paulo e o Rio Grande do Sul possuíam relação $K / L$ maior do que 1 . Observa-se que a relação $K / L$ era em média, em 1970, muito baixa para os estados da Região Norte e Nordeste. Nos anos de 1980 e 1995/96, todos os estados das Regiões Sudeste, Sul e Centro-Oeste já apresentavam a proporção $K / L$ superior a 1 . Evidenciando, assim, que o processo de 
tecnificação, medido pela mecanização do setor agropecuário, tendeu a se concentrar nessas regiões em detrimento das demais.

Entre 1970 e 1980, a expansão da tratorização na agropecuária brasileira foi muito elevada. Na grande maioria dos estados do Brasil verificou-se que a taxa geométrica de crescimento da relação $K / L$ foi superior a $5 \%$ ao ano. No período de 1980 a 1996, verificou-se que o ritmo de mecanização do setor agropecuário diminuiu. As taxas de variação percentuais da proporção $K / L$ diminuíram bastante, conforme se pode perceber através da sexta coluna da Tabela 7, e comparando com as taxas da quinta coluna. Resultado semelhante foi obtido por Barros (1999).

Considerando todo o período de 1970 a 1996, é possível constatar que a relação $K / L$ vem crescendo em todos os estados brasileiros a uma taxa superior a $5 \%$ ao ano, exceto no Rio de Janeiro (ver a última coluna da Tabela 7). Em vários outros estados, essa taxa foi superior a $10 \%$ ao ano, como nos casos do Paraná, Santa Catarina e Maranhão, por exemplo. Estes indicadores estão revelando um processo de intensa tecnificação da agropecuária brasileira que culminou na substituição do trabalho por máquinas.

Apesar de ter sido crescente o volume de mão-de-obra empregado no período de 1970 a 1985, a oferta de emprego não era compatível com o crescimento populacional no meio rural. Parte dessa população rural, especialmente as pessoas mais jovens, sem ocupação no meio rural, migrou para as médias e grandes cidades em busca de novas oportunidades de trabalho e melhores salários. Sem qualificação profissional, com reduzido grau de instrução e sem capital, esses migrantes acabaram indo parar nas favelas das cidades. Na maioria das vezes, essa população excluída passou a sobreviver de trabalhos temporários, que não exigem qualificação.

Devido à importância do nível de educação para esse estudo, serão analisadas de forma mais detalhada as respostas a três questões: 1) Como evoluiu o nível 
médio de educação dos trabalhadores ligados ao setor agropecuário? 2) Comparado com a educação média brasileira, será que realmente existem grandes diferenças do nível educacional entre o trabalhador brasileiro rural e o urbano? 3) Quais seriam os estados que apresentaram os maiores níveis de educação média? Serão esses estados os que, realmente, possuem a agropecuária mais dinâmica? Para tentar responder a essas perguntas elaborou-se a Tabela 8.

Tabela 8. Anos médios de estudo dos trabalhadores com 10 anos ou mais de idade.

\begin{tabular}{|c|c|c|c|c|c|c|}
\hline \multirow[t]{2}{*}{ UF } & \multicolumn{3}{|c|}{ Setor agropecuário } & \multicolumn{3}{|c|}{ Brasil } \\
\hline & $1970^{\mathrm{I}}$ & $1980^{1}$ & $1991^{\mathrm{I}}$ & $1970^{\mathrm{P}}$ & $1980^{P}$ & $1991^{<}$ \\
\hline $\mathrm{RO}$ & 0,77 & 1,64 & 2,86 & 2,32 & 3,06 & 5,10 \\
\hline $\mathrm{AC}$ & 0,46 & 0,61 & 1,39 & 1,35 & 2,18 & 4,67 \\
\hline AM & 0,79 & 1,07 & 1,69 & 2,32 & 3,71 & 5,58 \\
\hline $\mathrm{RR}$ & 1,05 & 1,53 & 2,83 & 2,94 & 3,98 & 5,64 \\
\hline PA & 1,02 & 1,43 & 2,01 & 2,44 & 3,51 & 4,80 \\
\hline AP & 1,21 & 1,47 & 2,23 & 3,02 & 4,38 & 6,22 \\
\hline MA & 0,45 & 0,72 & 1,28 & 1,08 & 1,93 & 3,62 \\
\hline PI & 0,33 & 0,59 & 1,26 & 1,10 & 2,08 & 3,80 \\
\hline $\mathrm{CE}$ & 0,35 & 0,59 & 1,19 & 1,45 & 2,55 & 4,27 \\
\hline $\mathrm{RN}$ & 0,51 & 0,78 & 1,52 & 1,64 & 2,93 & 5,04 \\
\hline PB & 0,43 & 0,67 & 1,19 & 1,36 & 2,50 & 4,29 \\
\hline $\mathrm{PE}$ & 0,44 & 0,68 & 1,46 & 2,03 & 3,20 & 5,12 \\
\hline $\mathrm{AL}$ & 0,32 & 0,51 & 1,15 & 1,23 & 2,22 & 4,05 \\
\hline SE & 0,38 & 0,66 & 1,46 & 1,41 & 2,75 & 4,69 \\
\hline BA & 0,45 & 0,65 & 1,33 & 1,56 & 2,57 & 4,27 \\
\hline MG & 1,20 & 1,88 & 3,01 & 2,77 & 4,24 & 5,93 \\
\hline ES & 1,28 & 2,16 & 3,47 & 2,79 & 4,46 & 6,27 \\
\hline $\mathrm{RJ}$ & 1,35 & 1,93 & 3,40 & 5,11 & 6,16 & 7,94 \\
\hline SP & 1,87 & 2,68 & 4,01 & 4,23 & 5,48 & 7,24 \\
\hline PR & 1,39 & 2,36 & 3,75 & 2,57 & 4,22 & 6,20 \\
\hline SC & 2,31 & 3,20 & 4,64 & 3,38 & 4,94 & 6,78 \\
\hline $\mathrm{RS}$ & 2,53 & 3,19 & 4,46 & 4,06 & 5,22 & 6,80 \\
\hline MT & 1,16 & 1,95 & 3,25 & 2,25 & 3,72 & 5,69 \\
\hline GO & 1,01 & 1,70 & 2,95 & 2,17 & 3,77 & 5,71 \\
\hline $\mathrm{DF}$ & 1,79 & 3,12 & 4,19 & 5,32 & 6,81 & 8,47 \\
\hline Média & 0,99 & 1,51 & 2,48 & 3,03 & 4,37 & 5,53 \\
\hline
\end{tabular}


Considerando a totalidade dos setores da economia brasileira, conforme a Tabela 8 , pode-se perceber que a média dos anos de estudo do trabalhador brasileiro era de aproximadamente três anos em 1970 e 5,53 anos em 1991. Este nível de educação média apresentou crescimento da ordem de $82 \%$ entre esses dois anos.

Ainda analisando os dados da Tabela 8, verifica-se que o setor agropecuário brasileiro apresentou, em 1970, em torno de um ano de educação média de seus trabalhadores. Esse número representa apenas $33 \%$ do verificado no Brasil, para o mesmo ano. Em 1980 com o setor rural apresentando uma média de 1,51 ano de estudo, contra 4,37 para o conjunto de trabalhadores do Brasil, constata-se que, apesar dos avanços nos níveis de educação no meio rural, o número médio de anos de educação formal no setor rural continuou representando em torno de $34 \%$ da média brasileira. Essa diferença se reduz bastante em 1991, quando a educação média do trabalhador no setor agropecuário atinge $45 \%$ da estatística da educação média do conjunto de trabalhadores do Brasil.

O aumento da escolaridade média do trabalhador rural não foi suficiente para alterar fortemente o quadro de uso de mão-de-obra qualificada na agropecuária. Istake \& Bacha (1999), considerando o Estado do Paraná, encontraram que os níveis de escolaridade têm aumentado entre os trabalhadores rurais, entretanto, a qualificação do trabalhador rural ainda é muito baixa. De acordo com os dados dos mencionados autores, em 1991, mais de 82\% dos trabalhadores rurais do Paraná tinham cursado somente o ensino elementar. Esses resultados são coerentes com os obtidos para toda a agropecuária brasileira.

O aumento da educação média teve importantes reflexos sobre a evolução do PIB per capita brasileiro, conforme já enfatizado por Lau et al. (1993). Os resultados obtidos por Gonçalves et al. (1998) apontaram que o capital humano, em relação ao PIB per capita brasileiro, apresenta elasticidade maior do que um, demonstrando que as políticas de investimentos em educação no Brasil são eficazes. 
O problema é que os retornos à educação e ao treinamento são diferentes quando se comparam os setores urbano e rural. Kassouf (1996) demonstrou que os retornos à educação foram maiores no setor urbano do que no setor rural, e que os retornos à educação foram superiores ao retorno ao treinamento. Dessa maneira, conclui Kassouf (1996), as pessoas residentes no setor urbano têm maiores incentivos em investir em educação e treinamento do que as pessoas residentes no setor rural. Para a população residente no meio rural, com grau de instrução mais elevado, o caminho esperado seria a migração para as cidades, especialmente para as médias e grandes, na busca por melhores salários.

O nível médio de educação dos trabalhadores na agropecuária de todos os estados nordestinos é relativamente baixo em relação ao conjunto da nação. Em 1970, o nível de educação média nos estados nordestinos representava apenas, $41 \%$ da média nacional, nesse mesmo setor. Os estados das Regiões Sudeste e Sul foram os que apresentaram as maiores médias de anos de estudo, em torno de $60 \%$ acima da média nacional. Apesar de ser crítica a situação da educação no meio rural, foi possível constatar que, em 1980, o patamar de educação média aumentou em todos os estados em torno de $50 \%$. Essa tendência de crescimento pode ser percebida também na década seguinte, com aumento em cerca de $64 \%$. Os estados nordestinos aumentaram o nível médio de educação de seus trabalhadores agropecuários em 1991 para cerca de 53\% do nível médio de educação dos trabalhadores da agropecuária brasileira no seu conjunto. Em 1970, o nível médio de educação no setor rural dos estados da Região Centro-Oeste estava $33 \%$ acima da média nacional nesse mesmo setor, subindo esse diferencial para $40 \%$ em 1991.

Em termos relativos; observa-se, em 1980 e 1991, que os estados da Região Norte não conseguiram acompanhar, em termos do crescimento da escolaridade o desempenho médio dos demais estados. Em 1970, aquela Região possuía três estados com a educação média superior à média nacional. Nos anos de 1980 e 1991, apenas dois estados se posicionaram quanto a essa variável acima da média, com destaques para 
Roraima e Rondônia, onde se perceberam importantes melhoras nos níveis de educação dos seus trabalhadores rurais. Entretanto, constatou-se maior equilíbrio quanto a essa variável entre os estados.

Os estados das Regiões Sul, Sudeste e Centro-Oeste apresentaram, nos três anos censitários especificados na Tabela 8 , níveis de educação média dos trabalhadores rurais superiores à média nacional no mesmo setor. Alguns estados - como Rio Grande do Sul, Santa Catarina, São Paulo e Distrito Federal - chegaram a superar a média nacional em até $80 \%$, em 1991. Ao que tudo indica, e como têm mostrado as pesquisas relacionadas à teoria do capital humano, parte do desenvolvimento econômico desses estados é explicada pelo estoque de capital humano ali existente.

Comparando os valores das Tabelas 6 e 8 , pode-se perceber que a riqueza e a pobreza dos estados estão, em grande medida, relacionadas às habilidades $\mathrm{e}$ conhecimento médio dos seus trabalhadores ${ }^{17}$. Quanto mais conhecimento possuir um trabalhador, maior será o seu nível de abstração e mais dinâmico ele se torna no aprendizado e no desenvolvimento das tarefas. Com maior estoque de conhecimento, mais fácil seria também para os pequenos e médios agropecuaristas tomarem suas decisões de investimentos e de realocação de recursos frente às mudanças conjunturais. No Capítulo 5 serão avaliados, econometricamente, os efeitos da educação média dos trabalhadores rurais sobre o valor da produção agropecuária.

Para encerrar esta seção, procurou-se dar uma visão geral acerca do comportamento, a longo prazo, da distribuição regional do valor da produção na agropecuária entre os estados brasileiros. A Tabela 9 classificou os estados de acordo

\footnotetext{
${ }^{17}$ Essas Tabelas (6 e 8) mostram que o VPIEH nos estados mais ricos do Brasil como São Paulo, Rio Grande do Sul e Minas Gerais superou em 1996 R\$ 3.500,00. Ao passo que o valor médio do VP/EH dos estados nordestinos não alcança $R \$ 1.000,00$. A escolaridade média do trabalhador rural em São Paulo, Rio Grande do Sul e Minas Gerais em 1991 é de 3,8 anos; enquanto a escolaridade média dos trabalhadores rurais nos estados nordestinos, neste mesmo ano, não chega a 1,5 ano de estudo.
} 
com o valor da produção per capita. Assim, por exemplo, no primeiro limite aparecem os estados com até $15 \%$ do valor da produção per capita de São Paulo, o estado líder; no segundo limite estão os estados que possuem o valor da produção per capita entre $15 \% \mathrm{e}$ $30 \%$ do valor da produção per capita paulista. Os demais intervalos são $(30,50],(50,80]$ e $(80,100]$. É importante ressaltar que uma limitação dessa abordagem é que as mudanças dos estados para intervalos inferiores ou superiores podem ser influenciadas pelo fato da produção poder estar muito concentrada em poucos produtos. Assim, se ocorrer variação do volume de produção ou dos preços destes produtos específicos, isso pode significar uma maior aproximação ou distanciamento do estado líder.

A distribuição regional do valor da produção per capita no setor agropecuário brasileiro veio piorando sensivelmente. Considerando o limite inferior do valor da produção per capita, em 1970, aproximadamente cinco estados, ou 20,83\% dos estados, tinham até $15 \%$ do valor da produção per capita paulista. Essa percentagem sobe para 37,50\% em 1980 e atinge a incrível marca de 45,83\% em 1995/96. No limite superior, pode-se constatar que nenhum estado possuía, em 1970 , mais de $80 \%$ do valor da produção per capita de São Paulo. Entretanto, em 1995/96, dois estados se incluíram neste intervalo.

Tabela 9. Distribuição regional do valor da produção per capita $(\hat{Y})$ do setor agropecuário, Brasil - anos selecionados.

\begin{tabular}{ccccccc}
\hline Intervalo & \multicolumn{5}{c}{ Número de estados e percentuais em cada categoria } \\
\cline { 2 - 7 } & \multicolumn{2}{c}{1970} & \multicolumn{2}{c}{1980} & \multicolumn{2}{c}{$1995 / 96$} \\
\cline { 2 - 7 } & $\begin{array}{c}\mathrm{n}^{\mathbf{0}} \text {. de } \\
\text { estados }\end{array}$ & $\begin{array}{c}\text { Participação } \\
\text { (\%) }\end{array}$ & $\begin{array}{c}\mathbf{n}^{\mathbf{0}} \text {. de } \\
\text { estados }\end{array}$ & $\begin{array}{c}\text { Participação } \\
\text { (\%) }\end{array}$ & $\begin{array}{c}\mathrm{n}^{\mathbf{0}} \text {. de } \\
\text { estados }\end{array}$ & $\begin{array}{c}\text { Participação } \\
\text { (\%) }\end{array}$ \\
\hline$\hat{Y} \leq 15$ & 5 & 20,83 & 9 & 37,50 & 11 & 45,83 \\
$15<\hat{Y} \leq 30$ & 8 & 33,33 & 8 & 33,33 & 6 & 25,00 \\
$30<\hat{Y} \leq 50$ & 7 & 29,17 & 5 & 20,83 & 0 & 0,00 \\
$50<\hat{Y} \leq 80$ & 4 & 16,67 & 2 & 8,33 & 5 & 20,83 \\
$\hat{Y}>80$ & 0 & 0,00 & 0 & 0,00 & 2 & 8,33 \\
\hline
\end{tabular}

Fonte: Dados da pesquisa retirados do Apêndice 3, Tabela 3.1. 
Essas estatísticas mostram dois movimentos interessantes. Em primeiro lugar, o hiato separando São Paulo, o estado com a agropecuária mais desenvolvida, dos estados que representam até $50 \%$ do valor da produção per capita de São Paulo, aumentou substancialmente, influenciando negativamente a distribuição regional da renda entre os estados. Para esse grupo de estados (até 50\% do valor de produção per capita de São Paulo), pode-se verificar um movimento descendente, ou seja, estados passando de intervalos superiores para intervalos inferiores, ao longo do período analisado. Em segundo lugar, para os estados com distribuição do valor da produção acima de 50\% do verificado para São Paulo, parece ter ocorrido movimento oposto. Em 1970, apenas, $16,67 \%$ dos estados tinham mais de $50 \%$ do valor da produção per capita de São Paulo. Apesar de haver reduzido esse número para 8,33\%, em 1980, observa-se que em 1995/96, o valor da produção per capita para esse grupo de estados tendeu a convergir, já que, aproximadamente, $29 \%$ passaram a ter valor da produção per capita acima de 50\% do observado para São Paulo.

Talvez esse resultado ajude a explicar a extensão temporal de 57 anos, encontrada por Gonçalves et al. (1998), para que ocorra a redução pela metade da diferença da renda per capita no Brasil. Considerando apenas o valor da produção per capita do setor agropecuário, pode-se constatar que existe pouco indício de estar ocorrendo convergência do valor da produção agropecuária entre os estados brasileiros.

\subsection{A origem e evolução do modelo de crescimento neoclássico}

Após a Segunda Guerra Mundial, de acordo com Stern (1991), as abordagens relacionadas ao crescimento econômico procuravam compreender, fundamentalmente, os fatores determinantes da taxa de crescimento do produto dos países. A partir de meados da década de cinqüenta, os estudos relacionados ao tema crescimento econômico receberam um grande impulso, com a publicação de vários artigos, cujo propósito era utilizar a modelagem matemática para estudar os fatores determinantes do crescimento 
econômico. Entre esses estudos, destacam-se: Solow (1956), Kaldor (1957), Kaldor \& Mirrlees (1962) e Hahn \& Matthws (1964).

Apesar da importância desses trabalhos, um deles particularmente se destacou na literatura sobre crescimento econômico e inaugurou, formalmente a partir de 1956, a abordagem neoclássica sobre esse tema. Trata-se do artigo de Robert Solow intitulado "Uma contribuição à teoria do crescimento econômico ${ }^{18 "}$. Entretanto, foi a partir do artigo de Solow de 1957 - "O avanço tecnológico e a função de produção agregada"19, onde se estimou o resíduo de Solow - que a teoria neoclássica sobre o crescimento econômico ramificou-se em vários outros campos de estudo. Jiménez (1998) apresenta essas ramificações de forma muito clara e consistente. Procurando não repetir tudo o que já foi feito por esse autor - com relação à evolução das teorias de crescimento - buscou-se sistematizar as suas idéias.

Os modelos neoclássicos se ramificaram, por um lado, em estudos empíricos sobre a produtividade total dos fatores (Kendrick, 1961) $)^{20} \mathrm{e}$, por outro lado, sobre a fonte de crescimento econômico (Denison, 1962) ${ }^{21}$. Em meados da década de 60, os modelos

de crescimento se tornaram mais complexos em razão dos aprofundamentos teóricos e quantitativos do modelo de Ramsey $(1928)^{22}$. Nessa linha, dois autores se destacaram:

\footnotetext{
${ }^{18}$ Título original: A contribution to the theory of economic growth.

${ }^{19}$ Título original: Technical change and the agregate production function.

${ }^{20}$ KENDRICK, J. W. Productivity trends in the United States. Princeton: Princeton University Press, 1961.

${ }^{21}$ DENISON, E. F. El crecimiento económico de los Estados Unidos. EI Trimestre Econômico, v.31, p.337-354, 1962.

${ }^{22}$ RAMSEY, F. P. A mathematical theory of savings. The Economic Journal, v.38, n.152, p.543-559, 1928.
} 
Koopmans $(1965)^{23}$ e Cass $(1965)^{24}$. Eles desenvolveram tais modelos com base em controle ótimo ${ }^{25}$ (Jiménez, 1998).

Numa outra vertente, Arrow $(1962)^{26}$ mostrou as implicações do processo de aprendizagem para o aumento da produtividade, ou seja, ao trabalhar as pessoas vão acumulando capital humano e quanto maior for a experiência da pessoa na execução do seu trabalho maior será o seu nível de capital humano. Nos trabalhos de Arrow (1962) ${ }^{27}$ e Nelson $(1959)^{28}$ foram desenvolvidas análises vinculadas aos processos de inovação tecnológica e introduzidas a questão da incerteza - a atividade de investigação não promete resultados precisos em todas as situações - e da externalidade - o resultado da produção do conhecimento não pode ser completamente apropriado por seus produtores (Jiménez, 1998).

\subsection{Os determinantes do crescimento econômico e os fundamentos do modelo neoclássico}

Como o trabalho de Solow (1956) constitui-se a base de sustentação teórica para as novas abordagens das teorias do desenvolvimento e do crescimento econômico, acredita-se que seja conveniente apresentar, resumidamente, o modelo proposto pelo autor. Isso irá permitir que sejam ressaltadas as características essenciais do modelo neoclássico alternativo proposto por Benhabib \& Spiegel (1994).

${ }^{23}$ KOOPMANS, T. C. On the concept of optimal economic Growth. In: The Economic Approach to Development Planning. Amsterdam. 1965.

${ }^{24}$ CASS, D. Optimum growth in an aggregative model of capital accumulation. Review of Economic Studies, v.32, n.3, p.233-240, 1965.

${ }^{25}$ Para maiores aprofundamentos acerca do conceito de controle ótimo, ver Fischer \& Blanchard (1993, p.39 a 43).

${ }^{26}$ ARROW, K. J. The economic implications of learning by doing. Review of Economic Studies, v.29, p.155-173, 1962.

${ }^{27}$ ARROW, K. J. El bienestar económico y la asignación de recursos para la invención. El Trimestre Econômico, v.31, p.151-167, 1962.

${ }^{28}$ NELSON, R. La economia sencilha de la investigación científica básica. El Trimestre Econômico. v.31, p.136-150, 1959. 
O modelo de Solow compõe-se de duas equações básicas ${ }^{29}$ : a função de produção e uma equação de acumulação de capital, e apresenta as seguintes características: i) trata-se de uma função de produção neoclássica composta de dois insumos, capital (K) e trabalho (L); ii) a função apresenta retornos constantes à escala; iii) o progresso tecnológico é neutro, no sentido de Hicks, de modo que, ao ocorrer progresso técnico, a utilização dos fatores de produção varia na mesma proporção, tal que a taxa marginal de substituição entre os fatores permanece inalterada.; iv) a taxa de poupança e o crescimento populacional são considerados como variáveis exógenas; v) a economia é descrita apenas pelo lado da produção de bens, não se mostra o lado da demanda; vi) os países produzem e consomem um único bem (produto homogêneo); e vii) não há comércio internacional. Considerando estas pressuposições, o modelo apresenta uma situação de equilíbrio estacionário estável a médio e a longo prazo.

A forma clássica da função de produção usada por Solow pode ser formalizada como segue:

$$
Y=A \cdot F(K, L)=A K^{\alpha} L^{1-\alpha}, 0<\alpha<1
$$

onde $Y$ é o produto, $K$ é o capital, $L$ é o trabalho e $A$ é o progresso tecnológico determinado exogenamente. $\mathrm{O}$ incremento da tecnologia ocorre quando, por exemplo, o trabalho se torna mais produtivo ${ }^{30}$.

O modelo de Solow tenta explicar as diferenças econômicas entre os países através das diferenças nas taxas de crescimento da população (estoque de mão-de-obra), nas diferenças de ritmo de reposição e ampliação do estoque de capital e nas diferenças de uso da tecnologia. Utilizando as palavras de Jones (1999), ao interpretar o modelo de

\footnotetext{
${ }^{29}$ A segunda equação do modelo de Solow não será tratada neste estudo, pois o estoque de capital é tomado como sendo exógeno ao modelo. Ela descreve a acumulação de capital, como segue: $\dot{K}=i I+d K$, sendo $\dot{K}$ a variação no estoque de capital, iI o investimento bruto e $d K$ a depreciação. Para mais informações sobre esta equação, ver Jones (1999, p.19 a 21).

${ }^{30}$ A tecnologia diz respeito à forma como o conjunto de insumos é transformado em produtos.
} 
Solow, pode-se dizer que um país é rico porque investe mais e tem menores taxas de crescimento populacional, o que permite acumular mais capital por trabalhador e, com isso, aumentar a produtividade do trabalho.

É importante nesta parte do trabalho dar uma definição do que se entende por mudança tecnológica. Para tanto, recorre-se ao trabalho de Chambers (1988). Para o autor, a mudança tecnológica representa a mudança na função de produção ao longo do tempo. Quando o progresso tecnológico não requer novos insumos e a função de produção mantém a sua estrutura básica, diz-se que se trata de uma função que é separável nos seus argumentos, ou seja, a mudança técnica não foi incorporada em um insumo particular e nem em um grupo de insumos. Quando aumenta a utilização de insumo, o progresso tecnológico é dito progressivo. Diminui-se a utilização de parte dos insumos requeridos no processo de produção, o progresso tecnológico é regressivo ${ }^{31}$.

Existem, segundo Jiménez (1998), três propriedades associadas à função de produção da equação (2), são elas: i) os produtos marginais do capital e trabalho são positivos, mas decrescentes, isto é, $\frac{\partial Y}{\partial K}>0 ; \frac{\partial^{2} Y}{\partial K^{2}}<0$ e $\frac{\partial Y}{\partial L}>0 ; \frac{\partial^{2} Y}{\partial L^{2}}<0$; ii) todos os insumos são essenciais à produção, ou seja, se a função apresentar pelo menos um de seus argumentos igual a zero, não se produz nenhum bem, desse modo, $F(K, 0)=F(0, L)=0$; e iii) a função de produção exibe rendimentos constantes à escala, quer seja: $F(\lambda K, \lambda L)=\lambda F(K, L)$.

Segundo Barros (1999), a equação (2), após algumas manipulações matemáticas, passa a ser:

$$
q=a+S_{k} \dot{K}
$$

${ }^{31}$ Para mais informações, ver Chambers (1988, p. 205-213). 
sendo $q$ a taxa de crescimento do produto por trabalhador, $a$ é a taxa de crescimento do progresso técnico, $S_{k}$ é a participação do capital no produto total e $\dot{K}$ é a taxa de crescimento do capital por trabalhador. A equação (3) especifica que o crescimento do produto pode ser explicado pela acumulação de capital e pelo progresso técnico. A variável $a$ é obtida por diferença, isto é:

$$
a=q-S_{k} \dot{K}
$$

onde, $a$ passa a representar a taxa de crescimento da produtividade total dos fatores, sendo conhecida como o resíduo de Solow.

O problema com a estimação do modelo de Solow é que o resíduo passou a explicar a maior parte do crescimento econômico. Considerando os dados sistematizados por Barros (1999), para a economia norte-americana de 1909 a 1949, o resíduo explicou $88 \%$ da taxa de crescimento do produto e o capital, 12\%. Para os países da América Latina de 1950 a 1980, a proporção da taxa de crescimento explicada pelo resíduo variava muito entre os países. O resíduo explicou $21 \%$ do crescimento do produto na Argentina, 57\% no Brasil, $-6 \%$ no Chile, $42 \%$ na Colômbia, 48\% no México, $41 \%$ no Peru e $50 \%$ na Venezuela. Assim, converteu-se em um grande desafio para os economistas, após a publicação do trabalho de Solow, diagnosticar quais seriam as variáveis que poderiam estar afetando esse resíduo de Solow.

De acordo com Harberger (1998), o crescimento econômico seria afetado por quatro elementos, que o autor considerou como sendo os pilares do crescimento: i) o incremento da oferta de trabalho; ii) o incremento de estoque de capital humano; iii) o incremento no estoque de capital físico; e iv) a taxa de retorno do investimento.

O autor acima citado comenta que o perfil da força de trabalho, em vários países, tem mudado sensivelmente, especialmente pelo incremento da participação da 
mão-de-obra feminina. $\mathrm{O}$ aumento do estoque de mão-de-obra empregada pode conduzir a variações positivas e significativas na renda real per capita.

Harberger (1998) argumenta que a acumulação de capital humano educação, treinamento, "learning-by-doing" - é um dos elementos fundamentais, se não for considerado no modelo, para determinar o crescimento do resíduo de Solow.

A contribuição do capital humano foi examinada por um grande número de pesquisadores. Na grande maioria dos trabalhos examinados, o capital humano tem sido apresentado como um elemento fundamental na alavancagem do desenvolvimento. $\mathrm{O}$ problema enfrentado pelos pesquisadores pode ser resumido numa questão: como mensurar a acumulação desse capital humano ou do aprendizado humano ao longo do tempo? Duas formas tradicionais, segundo Barro \& Sala-I-Martin (1995), consagraramse na literatura especializada nesse tema. A primeira abordagem utiliza o tempo de estudo da população como uma proxy do estoque de capital humano. Assim, quanto maior a escolaridade do indivíduo maior será o estoque de capital humano de um determinado país ${ }^{32}$. A segunda forma de mensurar a importância do capital humano parte do princípio de que as pessoas ao trabalharem adquirem experiência, o que resulta em crescimento da produtividade do trabalho. Essa forma de aprendizado foi consagrada como learning-by-doing ${ }^{33}$, e foi proposta por Arrow (1962).

O terceiro elemento determinante do crescimento econômico, segundo Harberger (1998), o incremento no estoque de capital físico (medido pela taxa de investimento), sempre esteve no centro das preocupações dos economistas interessados em crescimento econômico. Isto porque, como argumenta Jones (1999), países que possuem altas proporções poupança/investimento tendem a ser mais ricos e, por essa razão, acumulam mais capital por trabalhador, o que, conseqüentemente, gera mais

\footnotetext{
${ }^{32} \mathrm{O}$ presente estudo utiliza o nível de educação média em cada estado como proxy do capital humano.

${ }^{33}$ A tradução mais apropriada para learning-by-doing seria aprendizado prático, no entanto optou-se por deixar o termo em inglês por já estar consagrado no Brasil. Esta forma de mensurar o capital humano não será abordada nesse estudo.
} 
produto por trabalhador. $\mathrm{O}$ incremento no estoque de capital é visto como um elemento fundamental para alavancar o desenvolvimento de qualquer país.

E, finalmente, a taxa interna de retorno dos investimentos que, de acordo com Harberger, não tem recebido a devida atenção nas análises de crescimento. A taxa de retorno desempenha um papel fundamental na tomada de decisão dos agentes econômicos. Quanto maior a perspectiva de retorno dos investimentos iniciais, maior é o estímulo dos empresários na realização daquele investimento. Esta variável, ao não ser considerada nas análises, converte-se em um elemento importante na explicação do crescimento do resíduo de Solow.

Portanto, para Harberger, a explicação do crescimento do resíduo de Solow se deve pela não incorporação do capital humano e da taxa de retorno dos investimentos no modelo de crescimento.

Já Stern (1991) destaca seis determinantes do crescimento econômico. Além do incremento dos estoques de capital físico e humano, ele chama a atenção também para a disponibilidade e qualidade da infra-estrutura; a alocação direta de recursos para setores produtivos; a administração e a forma de organização da produção; e a pesquisa, desenvolvimento e inovação. Como Stern interpreta a importância dos dois primeiros elementos na mesma linha de abordagem de Harberger, analisa-se, a seguir, os quatro outros determinantes.

Segundo Stern, as deficiências na infra-estrutura juntamente com as fraquezas da capacidade administrativa das organizações econômicas são, provavelmente, as causas das perdas da produtividade dos fatores em países em desenvolvimento, contribuindo para que estes países não operem sobre a curva de possibilidades de produção. Outras fontes de ineficiências relacionam-se à uma burocracia obstrutiva e direitos de propriedade não muito bem definidos, etc. Estes problemas podem até criar obstáculos ao desenvolvimento e o crescimento econômico. 
Em relação à alocação direta de recursos para os setores produtivos, pode-se dizer que as diferenças nos arranjos institucionais dos países em desenvolvimento podem conduzir a distorções, impedindo que a alocação dos recursos seja feita de maneira eficiente, o que conseqüentemente acaba por se constituir num empecilho ao crescimento. Para Jones (1999), o projeto de investimento, por exemplo, de uma multinacional em um determinado país, depende da avaliação que se faz sobre: i) o papel das instituições e das leis, se essas favorecem a produção e tentam coibir os desvios, roubos, as exigências de propinas por parte dos burocratas, etc.; ii) o grau de abertura da economia ao mercado internacional; e iii) a estabilidade das instituições econômicas.

Para demonstrar como o excesso de burocracia e a corrupção podem emperrar o desenvolvimento, Jones (1999) cita um trabalho, realizado por De Souto $(1989)^{34}$ no Peru, relacionado à implantação de uma fábrica nos arredores de Lima. O objetivo do autor seria avaliar os regulamentos, trâmites burocráticos e outras restrições ao pequeno empresário. Foram requeridas 11 exigências oficiais e foram necessários 279 dias-homem, incluindo o pagamento de duas propinas imprescindíveis à continuação do projeto, embora, fossem exigidas 10 propinas.

Em países onde as políticas públicas apoiam a produção, há um número reduzido de funcionários corruptos, os desvios e a corrupção não existem (ou são mínimos) e a sociedade consegue obter o máximo de produto a partir dos seus recursos. Contudo, em países onde a burocracia é obstrutiva, há funcionários corruptos e a corrupção está generalizada por toda a máquina administrativa, boa parte dos recursos acaba sendo destinada para a implantação de esquemas de proteção e para pagamento de propina. Ao comparar a realidade dos dois tipos de países acima citados, no primeiro caso a produtividade total dos fatores é mais elevada e, conseqüentemente, espera-se que o país seja mais desenvolvido (Jones, 1999).

${ }^{34}$ DE SOUTO, H. The other path: the invisible revolution in the third world. London: Tauris. 1989. $172 p$. 
O raciocínio apresentado no parágrafo anterior levou Jones (1999) a elaborar uma função de produção incorporando a influência da infra-estrutura juntamente com o capital humano ao lado do capital e trabalho. Esta função pode ser escrita como:

$$
Y=F(I, K, L, H)
$$

onde $Y$ é o produto interno, $K$ e $L$ recebem as mesmas denominações especificadas na equação (2), $H$ é o capital humano, e $I$ é a influência da infra-estrutura sobre a produtividade dos insumos. Segundo o autor, economias com os mesmos níveis de $K, L$ e $H$ podem apresentar montantes de produtos diferentes, devido às deficiências na infraestrutura dos países ${ }^{35}$.

O outro determinante mencionado por Stern, relacionado à pesquisa, desenvolvimento e inovação, tem recebido cada vez mais a atenção dos economistas. Dentre estes cabe destacar Temple (1999). Segundo este autor, a taxa de retorno das pesquisas nos Estados Unidos, de 1950 a 1960, era de aproximadamente $30 \%$ a 50\% ao ano. Apesar de alguns autores destacarem alguns problemas na mensuração da contribuição da pesquisa e desenvolvimento ( $P \& D$ ), os pesquisadores têm encontrado altos retornos privados de todo o investimento em $\mathrm{P} \& \mathrm{D} .^{36}$

O tema desenvolvimento e crescimento sempre causou e continua provocando muita controvérsia, justamente porque envolve uma conjugação de variáveis, conforme discutido nos parágrafos anteriores. Variáveis como o papel das instituições e os aspectos culturais, por exemplo, que se mantiveram à margem nessas análises, em alguns países podem ser os elementos-chave para entender, na plenitude, a

${ }^{35}$ Apesar de concordar com o autor, não se pretende incorporar a variável I nos modelos propostos na presente tese, devido a escassez de dados sobre infra-estrutura na agropecuária brasileira.

${ }^{36}$ Segundo Temple, duas referências particularmente úteis sobre o tema são:

GRILICHES, Z. Issues in assessing the contribution of R\&D to productivity growth. Bell Journal Economic, v.10, n.1, p.92-116, 1979.

GRILICHES, Z. The search for R\&D spillovers. Working Paper, wps 3768 (National Bureau of Economic Research), 1992. 
realidade de um país específico. Os pontos levantados por Stern e Harberger constituem nas pré-condições para alavancar o desenvolvimento dos países. A ausência desses determinantes nas análises econômicas, especialmente nos modelos econométricos, pode causar resultados distorcidos, e devem ser interpretados pelo pesquisador com muita cautela.

Trazendo o problema para o contexto brasileiro, fica evidente que algumas regiões brasileiras, como o Nordeste e Norte, possuem uma carência muito grande tanto de capital humano como também de capital físico, sem contar que os investimentos em $\mathrm{P} \& \mathrm{D}$ são, em termos relativos, muito menores nessas regiões se comparados às outras regiões mais desenvolvidas do país. Por essas razões, o setor agropecuário nas Regiões Norte e Nordeste é bem menos desenvolvido que o da Região Sul e Sudeste, conforme estudado no capítulo anterior.

\subsection{Algumas considerações a respeito do modelo de crescimento endógeno}

Ao final da década de 70, as análises de crescimento econômico estavam fundamentadas no modelo de Solow. Com a publicação, por exemplo, dos trabalhos de Lucas (1988) e Romer $(1986,1990)$, a teoria do crescimento sofreu grande impulso e rompeu com alguns pressupostos básicos do modelo de equilíbrio competitivo. Por exemplo, em Romer (1986), foi demonstrada a existência de equilíbrio dinâmico, com rendimentos crescentes à escala e ocorrência de externalidades. Esse artigo inaugurou uma nova vertente do estudo de crescimento econômico, pois passou a tratar o tema crescimento econômico também sobre uma perspectiva endógena. Apesar dos modelos de crescimento endógeno não serem o objeto primordial de estudo do presente trabalho, a seguir é apresentada uma análise, de forma resumida, desses modelos.

O propósito, em primeiro lugar, ao se realizar uma breve discussão acerca dos modelos de crescimento endógeno é mostrar como o capital humano, em tais modelos, tornou-se o insumo básico na alavancagem do crescimento econômico de 
qualquer país. Em segundo lugar, mesmo havendo indícios de que o capital humano é capaz de gerar externalidades positivas no setor agropecuário, procurou-se apresentar alguns argumentos a respeito das limitações teóricas de aplicar os modelos de crescimento endógeno em análises específicas do setor agropecuário brasileiro.

\subsubsection{A função de produção com progresso tecnológico endógeno}

Para Solow, segundo Jiménez (1998), o progresso tecnológico - que expressa o conhecimento ou capital humano aplicado na produção - é um bem livre, e todos os produtores podem acessá-lo sem nenhuma restrição. Desse modo, considerando que $a$, da equação (3), seja por pressuposição um bem livre, e que o preço do trabalho e do capital são positivos, então, no modelo de Solow ficam asseguradas as condições para a existência do equilíbrio geral, quer seja, um vetor de preço não negativo em cada mercado.

Entretanto, Arrow (1962) ${ }^{37}$, citado por Jiménez (1988), afirmou que a produção de informação ou conhecimento apresenta duas características: a) sua apropriabilidade é parcial; e b) os resultados da investigação são incertos. Assim, i) quem descobre a informação torna-se um monopolista dessa informação, mas se apropria de forma incompleta dos seus resultados; ii) quando uma firma inicia um processo de produção, de antemão se conhece a quantidade e o preço do insumo, mas os produtos que gera não podem ser prognosticados perfeitamente. Olhando pela ótica de mercado, nem todos os mercados estão definidos nos modelos que incorporam a produção de conhecimento, por exemplo, fica suprimido o mercado que a comercializa. Por essas duas características é que o equilíbrio de mercado não é ótimo.

\footnotetext{
${ }^{37}$ ARROW, K. J. El bienestar económico y la asignación de recursos para la invención. El Trimestre Econômico, v.31, p.151-167, 1962.
} 
Foi com o propósito de tentar ampliar a discussão sobre a importância do capital humano no processo de produção que os modelos de crescimento endógeno foram concebidos. A idéia era de que o modelo clássico de Solow poderia ser melhor ajustado ao incluir o capital humano, como argumento da função de produção, reconhecendo que os diversos países têm diferentes níveis de instrução e qualificação de sua força de trabalho. A premissa básica desse tipo de modelo é que o conhecimento é um bem não-rival e que, portanto, vários produtores poderiam usá-lo concomitantemente

Como já ressaltado, o conceito de crescimento endógeno surgiu a partir dos anos 80, quando a ênfase se voltou para a endogeneidade do progresso técnico, o qual, no modelo de Solow, era tratado como exógeno. Ao incluir o capital humano como argumento da função de produção, e endogeneizar o progresso tecnológico, admite-se que ocorram as externalidades geradas pela acumulação de capital humano. Tais externalidades podem, nos modelos de crescimento endógeno, ser compatíveis com as disparidades persistentes nos níveis de renda e nas taxas de crescimento entre os países. Admitindo que não haja impedimento para a livre circulação de bens entre os países, espera-se que os países venham a se especializar na produção de bens em que eles possuam alguma vantagem comparativa. Nos países com maior capital humano, esperase que a taxa de crescimento do seu produto per capita a longo prazo seja mais elevada do que naqueles com capital humano inferior em razão da possibilidade de usar, de forma mais economicamente rentável, as potencialidades das vantagens comparativas, inicialmente ali existente.

O recente desenvolvimento dos modelos de crescimento na linha endógena, como destaca Stern (1991), foi favorecido principalmente pela crescente documentação catalogada após a Segunda Guerra Mundial sobre os mais diversos indicadores econômicos e sociais. Este conjunto de informações tem permitido o desenvolvimento de modelos de crescimento endógeno de grande complexidade e com alto poder de explicação. Como exemplo, destacam-se os trabalhos de Romer (1986, 1990), Lucas 
(1988), Psacharopoulos (1985), Aghion \& Howitt (1992), Glomm \& Ravikumar (1992), Grossman \& Helpman (1994), e Pack (1994).

Segundo Klenow (1998), os modelos de crescimento endógeno podem ser divididos em duas classes. A primeira diz respeito aos modelos desenvolvidos com base em Romer (1990), Grossman \& Helpman (1991) e Aghion \& Howitt (1992). Nesses modelos, novos produtos ou processos de produção surgem de gastos em pesquisa e desenvolvimento. Os novos produtos englobam insumos de não-trabalho, como a maior qualidade dos bens intermediários ou maior especialização do capital. Conforme argumenta Romer, o conhecimento, ou o capital humano, não é um bem rival, o que permite que seja incluído em várias unidades de capital e bens intermediários sem precisar duplicar as pesquisas. A segunda classe de modelos de crescimento endógeno considera a rivalidade do capital humano, como o caso dos modelos de Jones \& Manuelli (1990) e Rebelo (1991). A rivalidade do capital humano significa que o conhecimento provém somente da pessoa que investe nele. Portanto, nesses modelos o conhecimento não é copiado pelos concorrentes.

Sob o ponto de vista de Romer (1994), existem duas aplicações para os modelos de crescimento endógeno. A primeira é a questão da controvérsia da convergência, onde as estimações servem para vislumbrar se a desigualdade entre os países está aumentando ou diminuindo.

A segunda aplicação se refere ao rompimento com alguns pressupostos dos modelos de competição perfeita e especifica que atualmente há evidências para rejeitar todos os modelos de crescimento desenvolvidos nos anos cinqüenta, sessenta e setenta. $\mathrm{O}$ progresso dos novos modelos de crescimento endógeno não veio da aplicação mecânica dos testes de hipóteses. Existe um processo criativo associado à construção desses novos modelos em que primordialmente se procura é explicar a essência do processo de crescimento econômico (Romer, 1994). 


\subsubsection{Os fundamentos dos modelos de crescimento endógeno}

Para Romer (1994, p.12), os economistas por longo tempo vêm enfrentando pelo menos cinco fatos básicos em suas análises de crescimento econômico. São eles:

1) há muitas firmas na economia de mercado competindo em uma estrutura de mercado concorrencial.

2) As descobertas diferem de outros insumos no sentido de que todas as pessoas podem, desde que permitido pelo inventor ou adotando o sistema de cópias, usá-las ao mesmo tempo. Uma vez criada a idéia, qualquer firma que a conheça pode tirar proveito dela. Em outras palavras, os bens ordinários são rivais e a informação de modo geral é um bem não-rival. A informação gera extemalidades positivas.

3) É possível replicar as atividades físicas. A replicação significa que a função de produção agregada deverá ser caracterizada pela homogeneidade de grau um para todos os seus insumos rivais. A função de produção ${ }^{38}$, dada pela equação (2), pressupõe que se dobrarem todos os insumos rivais, $K$ e $L$, o produto irá dobrar também. Entretanto, a tecnologia $A$ (insumo não-rival) não necessita dobrar, porque parte da informação poderá ser usada por todos os produtores ao mesmo tempo.

4) O avanço tecnológico deve vir das habilidades de cada indivíduo em desenvolver tarefas. O autor cita o exemplo da mineração de ouro. Quando mais pessoas decidem garimpar, mais metais serão encontrados.

5) Muitos indivíduos e firmas têm poder de mercado e obtêm rendas monopolistas sobre as descobertas. Os bens econômicos são, pelo menos em parte, excluíveis. Apesar de se ter visto anteriormente que as descobertas são potencialmente não-rivais,

\footnotetext{
${ }^{38}$ A qual é: $Y=A \cdot F(K, L)=A \cdot K^{\alpha} \cdot L^{1-\alpha}$, onde $0<\alpha<1$.
} 
6) descobertas importantes são parcialmente excludentes, porque as firmas detêm controle sobre os planos de utilização das idéias por elas produzidas. Apesar da informação ser um bem não-rival, os planos sobre como essas idéias serão colocadas em prática são rivais. Se as firmas podem controlar, de alguma maneira, o acesso aos planos e projetos de um novo produto, elas podem obter, pelo menos por algum tempo, ganhos monopolísticos.

Nos modelos de crescimento endógeno, como o proposto por Romer (1986), o conhecimento e o papel dos agentes econômicos, visando otimizar os resultados, guiam o processo de crescimento econômico. O conhecimento foi tratado como um capital, que é acumulável com o passar do tempo. Ele pode se acumular através do tempo de estudo formal ou pela forma de aprendizado consagrada pelo nome de learning-by-doing, vista anteriormente. De acordo com Sachs \& Larrain (1995), se ocorrer incremento nos níveis de investimento de uma determinada empresa, gerando incremento tecnológico, não apenas a capacidade produtiva e a produtividade da mãode-obra desta empresa irão aumentar, mas devido às inter-relações e ao fluxo de informações entre os diversos setores produtivos da economia, outras empresas e outros trabalhadores irão também se beneficiar daquele conhecimento, aumentando tanto a sua capacidade de produção, quanto a produtividade da mão-de-obra. Surgem assim, externalidades positivas do incremento tecnológico de uma firma. Essa é a essência dos modelos de crescimento endógeno. Isso ocorre porque o progresso técnico desenvolvido por uma empresa é copiado pelas firmas concorrentes. Assim, o investimento cria efeito externo positivo.

No caso específico da agropecuária, a singularidade do conhecimento humano, que o torna diferente dos demais insumos, pode ser facilmente percebida quando, por exemplo, um determinado agricultor, ou mesmo um pesquisador, inventa nova maneira de combater eficientemente uma praga, a qual tem devastado plantações inteiras. Todos os outros agricultores, que venham a conhecer a nova idéia, poderão tirar proveito dela. 


\subsubsection{A interpretação da taxa de crescimento do produto segundo o enfoque do modelo de crescimento endógeno}

O modelo de Romer discutido em Romer (1990), com mudança tecnológica endógena, apresenta duas partes fundamentais. A primeira é composta de uma função de produção descrita como segue:

$$
Y=F(Z, X)
$$

onde $Y$ representa o produto per capita, $Z$ são os insumos não-rivais e $X$ os insumos rivais $^{39}$.

Pode-se destacar, a exemplo do que foi feito para o modelo neoclássico, quatro propriedades associadas à equação (6): i) os produtos marginais do trabalho e do capital são positivos, mas decrescentes; ii) o produto marginal do capital humano é crescente; iii) todos os insumos são essenciais à produção; e iv) a função de produção exibe rendimentos crescentes à escala.

Comparando o modelo de crescimento endógeno com o modelo de crescimento neoclássico, visto no item 3.2, pode-se destacar pelo menos dois pontos em que o primeiro avança em relação ao segundo: i) introduzem-se rendimentos crescentes à escala devido ao conhecimento empregado na produção de bens finais; e ii) introduzemse as externalidades. Um novo conhecimento gerado por uma firma tem efeito externo positivo sobre a produção das outras empresas, visto que este não pode ser plenamente protegido contra a imitação por parte dos concorrentes (Jiménez, 1998).

Seguindo Romer (1990), se $Z$ na equação (6) é também insumo produtivo, pode-se dedurir que a equação (6) não pode ser uma função de produção côncava, pois $F(\lambda Z, \lambda X)>\lambda F(Z, X)$. Considerando as propriedades da função homogênea ${ }^{40}$, pode-se

\footnotetext{
${ }^{39}$ Acerca de bens rivais e não-rivais, ver Randall (1987, p.169 a 176).

${ }^{40}$ Para o leitor que desejar conhecer detalhadamente essas propriedades, ver Chambers (1988, p.8 a 17).
} 
facilmente perceber que uma empresa com essa característica não iria sobreviver como tomadora de preço em uma estrutura de mercado concorrencial. Nesse tipo de mercado, o equilíbrio da empresa seria alcançado quando o preço se tornasse igual à receita marginal. Entretanto, assumindo que $Z$ e $X$ são produtivos, e fazendo a derivada total da equação (6), tem-se que:

$$
F(Z, X)<Z \cdot \frac{\partial F}{\partial Z}(Z, X)+X \cdot \frac{\partial F}{\partial X}(Z, X)
$$

Se a empresa pagar por todos os insumos utilizados no processo produtivo, ela estará incorrendo em prejuízo ${ }^{41}$.

De acordo com Romer (1990), Solow (1956) contornou o problema mencionado no parágrafo anterior tratando $Z$ como um insumo exógeno. Shell (1966) tratou $Z$ como um insumo público provido pelo governo. $\mathrm{O}$ problema com essas pressuposições é que nenhuma empresa paga compensação monetária para explorar $Z$.

No modelo de Romer (1990), seguindo o enfoque dado por Jones (1995), a taxa de crescimento econômico pode ser interpretada com base na trajetória de crescimento equilibrado. A busca de novas idéias por pesquisadores origina a função de geração de novos conhecimentos, que pode ser formulada como:

$$
\Delta H=\delta L_{H}^{\lambda} H(t)^{\phi}
$$

com $\Delta H$ representando o acréscimo de conhecimento gerado no período $t ; H(t)$ é o estoque de conhecimento que foi inventado até o período $t ; \delta$ é a taxa de descobrimento

\footnotetext{
${ }^{41}$ Segundo Romer (1990), esta observação foi há muito tempo formulada, por exemplo, por: SCHUMPETER, J. A. Capitalism, socialism and democracy. New York: Harper, 1942. 168p. SHELL, K. Toward a theory of inventive activity and capital accumulation. American Economic Review, v.56, p.62-68, May 1966. Paper and Proceedings. NORDHAUS, W. D. Invention, growth and welfare: a theorical treatment of technological change. Cambridge: Mit Press, 1969.
} 
de novos conhecimentos; $L_{H}$ é o número de pessoas que tentam descobrir novos conhecimentos; $\phi$ e $\lambda$ são parâmetros. Se, por exemplo, $\phi>0$, a produtividade do conhecimento aumenta com o número de idéias já concebidas, gerando trasbordamento da pesquisa; se $\phi=0$, a produtividade das pesquisas não depende do estoque de conhecimento; o parâmetro $\lambda$ assume valores entre 0 e 1 e indica que a produtividade da pesquisa é dependente do número de pesquisadores.

No modelo original de Romer (1990), assume-se que $\lambda=1$ e $\phi=1$. Se a equação (8) fosse rescrita, considerando os valores desses parâmetros, o crescimento econômico dos países poderia ser sustentado no modelo de Romer na presença de esforço de pesquisa constante, isto é:

$$
\frac{\Delta H}{H}=\delta \cdot L_{H}
$$

Numa trajetória de crescimento equilibrado, a taxa de crescimento do produto per capita - representado pela notação $g_{Y}$ - é proporcional à taxa de crescimento da relação capital/trabalho $\left(g_{K}\right)$ e à taxa de crescimento do capital humano $\left(g_{H}\right)$, ou melhor ${ }^{42}, g_{Y}=g_{K}=g_{H}$.

A partir da equação (8), chega-se à seguinte equação ${ }^{43}$ (ver Apêndice 1)

$$
g_{Y}=\lambda n /(1-\phi)
$$

A equação (10) especifica que a taxa de crescimento da economia, $g_{Y}$, é determinada pela taxa de crescimento positiva do capital humano, $g_{H}$, cuja taxa acaba sendo determinada pela taxa de crescimento populacional (n). Dessa maneira, um país

\footnotetext{
${ }^{42}$ Somente quando se assume que a economia alcança o crescimento equilibrado, torna-se possivel assumir que a taxa de crescimento do produto se iguala à taxa de crescimento dos insumos.

${ }^{43}$ As principais hipóteses adotadas nessa transformação são: considera-se uma trajetória constante de crescimento equilibrado; a taxa de crescimento do número de pesquisadores é igual à taxa de crescimento populacional, à taxa de crescimento do produto e é igual à taxa de crescimento do capital humano.
} 
para manter taxa de crescimento positiva ao longo do tempo requer aumento no número de pesquisadores. Ao aumentar o número de pesquisadores, o estoque de conhecimento irá incrementar, sustentando, assim, o crescimento econômico (segundo o modelo em discussão). Em síntese, o conhecimento humano é o elemento fundamental no modelo de Romer, pois trata-se de um bem não-rival. $O$ incremento no estoque de conhecimento numa economia tem reflexos positivos sobre todos os indivíduos.

A equação (9), segundo Jones (1995), revela que a função de geração de novos conhecimentos varia proporcionalmente em relação ao estoque existente de idéias, ou seja, a produtividade dos pesquisadores incrementa ao longo do tempo, mesmo se o número de pesquisadores permanecer constante. Foi justamente nesse ponto que recaiu a crítica suscitada por Jones (1995) em relação ao modelo de Romer. Para Jones, as evidências empíricas não ajudam a ancorar o pressuposto do modelo de Romer, porque o esforço de pesquisa aumentou substancialmente nos últimos 100 anos, o que, de acordo com o modelo de Romer, deveria sustentar um crescimento econômico rápido dos países avançados. No entanto, o que se observou, segundo Jones (1995), foi que a taxa média de crescimento anual dos EUA foi de 1,8\% nos últimos 100 anos. Isto permite rejeitar a pressuposição de que $\phi=1$. Parece ser mais racional admitir que $\phi<1$. Segundo Jones (1995), esse raciocínio não exclui a existência de retornos crescentes para o conhecimento, sendo que $\phi$ deve ser positivo e com magnitude elevada. A crítica principal de Jones, enfim, recai sobre o valor arbitrário de $\phi=1$.

\subsection{Restrị̧ões em aplicar os modelos de crescimento endógeno em análises empíricas do setor agropecuário}

Vários pontos podem ser destacados a respeito da dificuldade em se utilizar os modelos de crescimento endógeno para analisar o crescimento de um setor específico da economia de um determinado país. Foi afirmado, no início do tópico anterior, que o modelo de crescimento endógeno rompe com alguns pressupostos dos modelos de concorrência perfeita. Em primeiro lugar, considerando o caso da agropecuária 
brasileira, fica difícil imaginar que a estrutura de mercado desse setor não se aproxima do modelo concorrencial, pois nenhum produtor, individualmente, é capaz de influenciar o comportamento dos preços de mercado. Portanto, não é possível que eles obtenham ganhos monopolísticos, alterando os preços dos produtos agrícolas. A empresa agrícola, ou o produtor rural, é tomador de preço no mercado.

Em segundo lugar, as informações a respeito de uma nova tecnologia desenvolvida por empresas de pesquisas públicas estão disponíveis para qualquer produtor. Dessa maneira, é difícil imaginar que um produtor rural, individualmente, possa desenvolver pesquisas capazes de incrementar tecnologicamente o seu sistema de produção a ponto de obter receitas adicionais. No tópico 3.3.2 foi dito que muitos indivíduos e firmas têm poder de mercado e obtêm rendas monopolísticas sobre as descobertas. É improvável que isso ocorra no setor agropecuário.

Em terceiro lugar, os produtos agrícolas são homogêneos e as regras para a padronização das commodities agrícolas são definidas internacionalmente. Assim, os ganhos monopolísticos não podem ser obtidos através da diferenciação dos produtos.

Em quarto lugar, os modelos de crescimento endógeno geralmente envolvem mais de um setor da economia. Como o propósito do presente estudo é avaliar o papel do capital humano especificamente na agropecuária brasileira, esse tipo de modelo dificulta o seu uso na forma como se encontra.

Em quinto lugar, como visto na equação (8), o acréscimo de capital humano gerado no período $t$ depende do número de pesquisadores. As limitações de dados existentes no Brasil acerca do número de pesquisadores que se dedicam à pesquisa agropecuária em cada estado também dificultam a aplicação do modelo de crescimento endógeno à agropecuária brasileira.

Devido às limitações apresentadas acima, optou-se pelo modelo neoclássico alternativo proposto por Benhabib \& Spiegel (1994) para avaliar o papel do capital 
humano no desenvolvimento da agropecuária brasileira. No tópico seguinte, discute-se de forma detalhada esse modelo.

\subsection{O modelo neoclássico alternativo}

Como foi visto anteriormente, existem várias abordagens que procuraram analisar a importância do capital humano para o crescimento econômico. Uma dessas abordagens ficou caracterizada, por exemplo, pelo modelo neoclássico aumentado proposto por Mankiw et al. (1992), onde o capital humano foi tratado como insumo ordinário e simplesmente adicionado na função de produção. A outra abordagem, estudada nos tópicos anteriores, denominada de modelo de crescimento endógeno, passou a tratar o capital humano como um insumo com características especiais, devido a sua capacidade de gerar rendimentos crescente à escala. Uma terceira abordagem é apresentada por Engelbrecht (1997), quando o autor argumenta que o modelo proposto

por Benhabib \& Spiegel (1994) questiona ambas as abordagens acima colocadas. O modelo proposto por esses dois últimos autores supõe que o crescimento do produto per capita é explicado, em parte, pelo nível de capital humano, o qual é assumido capturar as inovações endógenas domésticas, e com um termo adicional, denominado de catch-up, que captura o spillover da tecnologia internacional.

A forma como os modelos catch-up (ver Apêndice 2) foram especificados não contemplou o papel do capital humano. A proposta de Benhabib \& Spiegel (1994), aqui denominada de modelo neoclássico alternativo, é de certa forma inovadora porque procurou preencher esta lacuna. Ao especificar a equação de regressão, o crescimento do produto per capito passou a ser explicado pelas variáveis capital, trabalho e por um termo relacionado ao capital humano que estima a capacidade de um país em inovar domesticamente, e um outro termo denominado de catch-up. Este último sugere que tomando os níveis de capital humano como sendo constantes, os países com menores níveis de produto per capita poderão obter taxa de crescimento econômico mais alta se 
houver difusão tecnológica entre os países mais desenvolvidos e os menos desenvolvidos.

Como o estudo de Benhabib \& Spiegel (1994) é a referência básica para a segunda parte do presente estudo, acredita-se que seja útil apresentar de forma detalhada o modelo proposto por esses autores (o que será feito nos itens seguintes).

\subsubsection{Os funda mentos teóricos e quantitativos do modelo neoclássico alternativo}

Na concepção de Nelson \& Phelps (1966), a educação aumenta a habilidade do indivíduo em receber e entender as informações. O maior nível de educação permite que os administradores da produção agrícola adaptem melhor e mais rapidamente o seu processo de produção diante do progresso técnico. A hipótese dos autores é que a educação promove o processo de difusão tecnológica.

Os autores encontraram na agricultura norte-americana evidências para a hipótese mencionada no parágrafo anterior. Veja o que disseram os autores:

$$
\begin{aligned}
& \text { "...Está claro que o fazendeiro com alto nivel } \\
& \text { de educação tende a adotar inovações antes do } \\
& \text { fazendeiro com menor nivel de educação. Entende-se } \\
& \text { que isso se deve porque o maior nível de educação do } \\
& \text { fazendeiro incrementa a sua habilidade de entender e } \\
& \text { avaliar novos produtos, ou novos processos de } \\
& \text { produção disseminados pelo Departamento de } \\
& \text { Agricultura"(Nelson \& Phelps, p. 70, 1966). }
\end{aligned}
$$

O modelo de Nelson \& Phelps (1966) pode ser interpretado da seguinte maneira: o avanço tecnológico de um determinado país depende do hiato entre o nível de conhecimento desse país e um nível teórico de conhecimento que se poderia denominar fronteira do conhecimento dominada pelos países desenvolvidos. $\mathrm{O}$ seu modelo permite 
captar o processo de difusão de tecnologia entre os países, podendo ser representado como segue ${ }^{44}$ :

$$
\frac{\Delta A_{t}^{i}}{A_{t}^{i}}=m\left(H_{i}\right) \cdot\left(\frac{A_{t}^{\max }-A_{t}^{i}}{A_{t}^{i}}\right)
$$

onde o termo do lado esquerdo da equação representa a taxa de crescimento da tecnologia, $A_{t}^{\max }$ foi definido como o nível teórico de tecnologia no tempo $t$, disponível em um determinado país desenvolvido. $A_{t}^{i}$ é o nível de tecnologia existente no país $i$ observado no tempo $t, H_{i}$ é o nível de capital humano, e $m$ é o parâmetro da função. Assim, a taxa de crescimento da tecnologia no país $i$ é uma função crescente da educação obtida $(H)$, e proporcional ao termo $\left(\frac{A_{t}^{\max }-A_{t}^{i}}{A_{t}^{i}}\right)$.

O nível teórico de conhecimento é assumido pelos autores a crescer a uma taxa exponencial constante $\lambda$. A função exponencial é dada pela fórmula:

$$
A_{t}^{\max }=A_{o} \cdot e^{i s}, \operatorname{com} \lambda>0
$$

Segundo Benhabib \& Spiegel (1994), a equação (11) implica que o resíduo de Solow, ou crescimento da tecnologia, é influenciado por $H$ no curto prazo, mas no longo prazo o resíduo de Solow deve crescer à taxa $\lambda$ (conforme equação 12).

Benhabib \& Spiegel (1994) fizeram uma mudança importante no modelo de Nelson \& Phelps (1966) para permitir comparações entre países. Benhabib \& Spiegel (1994) redefiniram a equação (11) para permitir que o catch-up tecnológico tivesse como referência a tecnologia do país líder. Além disso, cabe ressaltar - em conformidade com os argumentos de Benhabib \& Spiegel (1994) - que, nos modelos de crescimento

\footnotetext{
${ }^{44}$ As nomenclaturas do modelo original de Nelson \& Phelps (1966) foram alteradas para preservar a uniformidade das fórmulas do presente estudo.
} 
endógeno, o incremento da tecnologia $(A)$ foi modelado como uma função do nível de educação, ou capital humano, ou conhecimento $(H)$. Em Romer (1990), por exemplo, o papel dos incentivos de mercado determina a alocação de $H$ entre a produção de bens e as atividades inovativas, as quais aceleram o crescimento da tecnologia. No modelo proposto por Benhabib \& Spiegel foi assumido que o capital humano é exógeno, contudo, o maior nível de $H$ causa maior nível de crescimento em $A$.

Considerando a reformulação na variável catch-up e fazendo as devidas adaptações no modelo básico de Benhabib \& Spiegel (1994), para permitir comparações entre os estados brasileiros, a taxa de crescimento da tecnologia dos iésimos estados pode ser dada por: ${ }^{45}$

$$
\frac{\Delta A_{t}^{i}}{A_{t}^{i}}=\delta_{H i}\left(H_{i}\right)+\delta_{H C}\left(H_{i}\right) \cdot\left(\frac{A_{t}^{\max }-A_{t}^{i}}{A_{t}^{i}}\right)
$$

onde o termo do lado esquerdo representa a taxa de crescimento da tecnologia nos iésimos estados brasileiros; $\left(H_{i}\right)$ relaciona-se ao estoque médio de capital humano nos respectivos estados; $\delta_{H i}$ e $\delta_{H C}$ são os parâmetros do capital humano e do termo catch$u p$, respectivamente; o termo $\delta_{H i}\left(H_{i}\right)$ diz respeito à capacidade de um estado em promover endogenamente sua própria inovação tecnológica; e, $A_{t}^{\max }$ e $A_{t}^{i}$ representam o nível tecnológico no estado mais desenvolvido do Brasil (São Paulo) e nos demais estados, respectivamente. $\mathrm{O}$ segundo termo do lado direito da equação (13) representa a capacidade que um determinado país ou estado possui de adaptar e implementar eficientemente tecnologias desenvolvidas em algum outro lugar.

A escolha de São Paulo como estado líder se justifica por pelo menos três motivos. O primeiro deles está relacionado ao fato deste estado concentrar os principais institutos de pesquisa na área agrícola do Brasil, como por exemplo, o Instituto

\footnotetext{
${ }^{45}$ Ver Apêndice 2 do porquê utilizar o conceito de catch-up nesse modelo.
} 
Agronômico de Campinas (IAC). Em segundo lugar, a existência de várias Universidades com elevados reconhecimentos acadêmico e científico no país e no exterior, às quais estão vinculados um grande número de cientistas ligados às pesquisas agropecuárias. Em terceiro lugar, pode-se dizer que o Estado de São Paulo é o que possui o maior número de pesquisadores no Brasil.

A tecnologia do estado líder $\left(A_{t}^{\max }\right)$ poderá ser alcançada, e até mesmo ultrapassada, por um outro estado com nível de tecnologia inferior, tal como $\left(A_{t}^{i}\right)$. Isto acontecerá, logicamente, se o nível de educação do iésimo estado for maior do que o verificado para o estado líder. Assume-se que o iésimo estado não poderá alcançar a tecnologia do estado líder se ele possuir estoque de capital humano inferior ao daquele estado.

Espera-se que o estado líder possua elevado estoque de capital humano e o maior nível de tecnologia entre todos os estados. Assim, o estado líder atinge um grau de desenvolvimento tecnológico, por exemplo, tal como $A_{0}^{\max }$, no tempo 0 . Teoricamente, algum outro estado $i$ poderá alcançar o nível tecnológico $A_{0}^{\max }$, desde que ele possua, também, elevado estoque de capital humano. Isso só será possível se a taxa de crescimento da tecnologia do estado líder, $\delta_{H L}$, for menor que aquela taxa de crescimento obtida pelo iésimo estado, com elevado estoque de capital humano $\left(\delta_{H i}\right)$.

Assim, a taxa de crescimento do incremento tecnológico do estado líder é dada por:

$$
A_{t}^{\max }=A_{0}^{\max } \cdot e^{\delta_{H L}\left(H_{t}^{L}\right)}
$$

enquanto a taxa de crescimento da tecnologia do iésimo estado, com elevado $H$, é definida por: 


$$
A_{t}^{i}=A_{0}^{i} \cdot e^{\delta_{H i}\left(H_{i}^{i}\right)}
$$

A taxa de crescimento do iésimo estado tende a ser maior devido ao fator catch-up, que capta a difusão de tecnologia. Ao substituir a equação (14) na equação (13), tem-se:

$$
\frac{\Delta A_{t}^{i}}{A_{t}^{i}}=\delta_{H i}\left(H_{i}\right)+\delta_{H C}\left(H_{i}\right) \cdot\left(\frac{A_{0}^{\max } e^{\delta_{H L}\left(H_{t}^{L}\right)}-A_{t}^{i}}{A_{t}^{i}}\right)
$$

Multiplicando a equação (16) por $A_{t}^{i}$ e fazendo algumas resoluções algébricas chega-se a:

$$
A_{t}^{i}-\left[\delta_{H i}\left(H_{i}\right)-\delta_{H C}\left(H_{i}\right)\right] A_{t}^{i}=\delta_{H C}\left(H_{i}\right) \cdot A_{0}^{\max } \cdot e^{\delta_{H L}\left(H_{t}^{L}\right)}
$$

A equação (17) representa uma estrutura de equação diferencial, onde a sua resolução geral é encontrada multiplicando-a pelo fator integrante $\mu_{t}$, dado por:

$$
\mu_{t}=e^{\int-\left[\delta_{H i}\left(H_{i}\right)-\delta_{H C}\left(H_{i}\right)\right] d t}=e^{-\left[\delta_{H i}\left(H_{i}\right)-\delta_{H C}\left(H_{i}\right)\right] t}
$$

Ao multiplicar a equação (17) pelo fator integrante, pode-se encontrar a solução geral:

$$
\mu_{t} \cdot A_{t}^{i}-\left[\delta_{H i}\left(H_{i}\right)-\delta_{H C}\left(H_{i}\right)\right] \cdot A_{t}^{i} \cdot \mu_{t}=\delta_{H C}\left(H_{i}\right) \cdot A_{0}^{\max } \cdot e^{\delta_{H L}\left(H_{t}^{L}\right)} \cdot \mu_{t}
$$

O método de resolução de equações diferenciais do tipo da equação (19) é apresentado por Bronson (1977, p.44), e consiste no seguinte: o membro esquerdo da equação (19) será a derivada de $A_{t}^{i} \mu_{t}^{i}$ em relação a $t$.

$$
\frac{\partial\left\{A_{t}^{i} \cdot e^{-\left[\delta_{H i}\left(H_{i}\right)-\delta_{H C}\left(H_{i}\right)\right]}\right\}}{\partial t}=\delta_{H C}\left(H_{i}\right) \cdot A_{0}^{\max } \cdot e^{\left[\delta_{H C}\left(H_{i}\right)-\delta_{H i}\left(H_{i}\right)+\delta_{H L}\left(H_{t}^{L}\right)\right] t}
$$


Calculando a integral da equação (20), chega-se à seguinte equação:

$$
A_{t}^{i} \cdot e^{-\left[\delta_{H i}\left(H_{i}\right)-\delta_{H C}\left(H_{i}\right)\right] t}=\delta_{H C}\left(H_{i}\right) \cdot A_{0}^{\max } \int e^{\left(\delta_{H C}\left(H_{i}\right)-\delta_{H i}\left(H_{i}\right)+\delta_{H L}\left(H_{t}^{L}\right)\right) t} d t+c
$$

Novamente calculando a integral da equação (21), utilizando a integração por partes, obtém-se:

$$
A_{t}^{i} \cdot e^{-\left[\delta_{H i}\left(H_{i}\right)-\delta_{H C}\left(H_{i}\right)\right] t}=\frac{\delta_{H C}\left(H_{i}\right)}{\delta_{H C}\left(H_{i}\right)-\delta_{H i}\left(H_{i}\right)+\delta\left(H_{t}^{L}\right)} A_{0}^{\max } \cdot e^{\left[\delta_{H C}\left(H_{i}\right)-\delta_{H i}\left(H_{i}\right)+\delta_{H L}\left(H_{t}^{L}\right)\right] t}+c
$$

Fazendo algumas simplificações na equação (22), e representando o primeiro termo do lado direito desta equação por $\Omega=\frac{\delta_{H C}\left(H_{i}\right)}{\delta_{H C}\left(H_{i}\right)-\delta_{H i}\left(H_{i}\right)+\delta_{H L}\left(H_{I}^{L}\right)}$, chega-se a:

$$
A_{t}^{i}=\Omega \cdot A_{0}^{\max } \cdot e^{\delta_{H L}\left(H_{i}^{L}\right)}+c \cdot e^{\left[\delta_{H i}\left(H_{i}\right)-\delta_{H C}\left(H_{i}\right)\right] t}
$$

O valor de c pode ser calculado fazendo $t=0$, isto é:

$$
c=A_{0}^{i}-A_{0}^{\max } \cdot \Omega
$$

Substituindo o valor de $c$ na equação (23), tem-se, finalmente, a solução esperada:

$$
A_{t}^{i}=\Omega \cdot A_{0}^{\max } \cdot e^{\delta_{H L}\left(H_{t}^{L}\right)}+\left[A_{0}^{i}-A_{0}^{\max } \Omega\right] \cdot e^{\left[\delta_{H i}\left(H_{i}\right)-\delta_{H C}\left(H_{i}\right)\right] t}
$$

Conforme argumentam Benhabib \& Spiegel (1994), a equação (25) difere da equação derivada por Nelson \& Phelps (1966) em razão da taxa de crescimento da tecnologia, para os dois últimos autores, ser determinada por fatores exógenos aliados à tecnologia. Já na equação acima, o efeito de $\delta_{H i} H_{i}$ sobre o incremento da tecnologia persiste a longo prazo. Se $\delta_{H i}>\delta_{H C}$, o catch-up será mais lento do que aquele resultante do modelo de Nelson \& Phelps. Entretanto, no longo prazo, o estado que detém a 
fronteira tecnológica, com o crescimento $\delta_{H L}$, irá determinar e, até mesmo, dominar o crescimento dos $\delta_{H i}$ nos demais estados. Benhabib \& Spiegel (1994) provam essa assertiva dividindo a equação (25) por $A_{t}^{\max }$, dado na equação (14). Assim:

$$
\frac{A_{t}^{i}}{A_{t}^{\max }}=\frac{\left[A_{0}^{i}-A_{0}^{\max } \cdot \Omega\right] \cdot e^{\left[\delta_{H i}\left(H_{i}\right)-\delta_{H C}\left(H_{i}\right)-\delta_{H L} H^{L}\right] t}}{A_{0}^{\max }}+\Omega
$$

Calculando o limite da equação (26) com o $t$ tendendo a infinito, chega-se ao seguinte resultado:

$$
\lim _{t \rightarrow \infty} \frac{A_{t}^{i}}{A_{t}^{\max }}=\Omega
$$

desde que $\left(\delta_{H i}\left(H_{i}\right)-\delta_{H C}\left(H_{i}\right)-\delta_{H L}\left(H_{t}^{L}\right)\right)<0$

Portanto, no longo prazo, conforme a equação (27) revela, a taxa de crescimento da tecnologia dos iésimos estados, em relação ao estado líder, cresce baseando-se nos argumentos de Benhabib \& Spiegel (1994) - assintoticamente à mesma taxa $\delta_{H L}$. O estado líder ocupa uma posição de destaque no cenário econômico brasileiro e deveria ser a esteira do desenvolvimento e puxar os demais estados através do efeito catch-up, o que, conseqüentemente, resultaria em taxas de crescimento, no longo prazo, equilibradas entre todos os estados brasileiros. Entretanto, ancorando-se nos argumentos de Benhabib \& Spiegel (1994), pode-se dizer que o período de transição para se obter o equilíbrio nas taxas de crescimento pode ser bastante longo, em razão de que estados com o nível tecnológico $A_{i}$ muito distante do líder poderão obter taxa de crescimento muito alta, acima da alcançada pelo estado líder. Contudo, aqueles que estão próximos da fronteira tecnológica do líder poderão ter taxa de crescimento menor do que o líder porque o efeito catch-up é insignificante. Dessa maneira, assume-se que quanto maior o estoque de capital humano maior o nível de tecnologia. Além disso, o progresso tecnológico nos iésimos estados pode também estar associado ao efeito catch- 
up. Por essa razão, nas regressões que se seguem irão aparecer, além da variável associada à capacidade dos estados inovarem endogenamente, também a variável introduzida no modelo para captar o efeito catch-up.

\subsubsection{O modelo neoclássico alternativo proposto por Benhabib \& Spiegel}

A partir de uma típica função de produção Cobb-Douglas, Benhabib \& Spiegel (1994) procuram avaliar o comportamento do capital humano num modelo de crescimento neoclássico com catch-up. Os autores consideram como variável dependente a taxa de crescimento do produto per capita do tempo 0 ao $t$. Assim, Benhabib \& Spiegel definem a seguinte equação:

$$
\begin{gathered}
\left(\ln Y_{t}^{i}-\ln Y_{0}^{i}\right)=\left(\ln A_{t}^{i} \cdot\left(H_{t}^{i}\right)-\ln A_{0}^{i} \cdot\left(H_{t}^{i}\right)\right)+\alpha\left(\ln K_{t}^{i}-\ln K_{0}^{i}\right)+ \\
\beta\left(\ln L_{t}^{i}-\ln L_{0}^{i}\right)+\left(\ln \varepsilon_{t}-\ln \varepsilon_{0}\right)
\end{gathered}
$$

onde $Y_{t}^{i}$ é o produto per capita do país $i$ no período $t, K_{t}^{i}$ é o estoque de capital físico no período $t$, e $L_{t}^{i}$ é o trabalho no período $t$. $A_{t}^{i} H_{t}^{i}$ é o progresso tecnológico associado ao capital humano em um determinado país $i$ no tempo $t$. $O$ termo $\left(\ln A_{t}^{i} \cdot\left(H_{t}^{i}\right)-\ln A_{0}^{i} \cdot\left(H_{t}^{i}\right)\right)$ representa o avanço tecnológico do país $i$ ao longo do período (de 0 a $t$ ), que se materializa na PTF. Os demais termos são o crescimento do estoque de capital físico, o crescimento do trabalho e do erro estocástico (que são, respectivamente, a segunda, a terceira e a quarta parcelas do segundo membro da equação acima).

Benhabib \& Spiegel (1994) argumentaram que, para poder comparar a adoção e implementação de novas tecnologias entre os países, não se pode ignorar a difusão tecnológica que ocorre entre eles. $\mathrm{O}$ resíduo de Solow depende da diferença de conhecimento entre a tecnologia de ponta, desenvolvida e utilizada pelos países desenvolvidos, e a tecnologia adotada pelos países menos desenvolvidos. Para captar o 
efeito catch-up, conforme já argumentado, eles redefiniram o modelo originalmente proposto por Nelson \& Phelps $(1966)^{46}$. A diferença de tecnologia entre os países tende a diminuir à medida que o estoque de $H$ entre esses países se torne mais ou menos equivalente.

O termo $\left(\ln A_{t}^{i} \cdot\left(H_{t}^{i}\right)-\ln A_{0}^{i} \cdot\left(H_{\imath}^{i}\right)\right)$, no modelo de Benhabib \& Spiegel (1994), reflete, em primeiro lugar, o progresso tecnológico exógeno; em segundo lugar, o efeito das inovações endógenas domésticas; e, em terceiro lugar, reflete também o efeito de um termo interativo que envolve o nível de capital humano e a defasagem tecnológica de um país em relação a um país líder, a chamada difusão de tecnologia ou spillover. Desse modo, a partir da readaptação do modelo de Nelson \& Phelps (1966), pode-se definir a taxa de crescimento da tecnologia no país $i$ como:

$$
\frac{\Delta A_{t}^{i}}{A_{t}^{i}}=g\left(H_{t}^{i}\right)+c\left(H_{t}^{i}\right) \cdot\left[\frac{A_{i}^{\max }-A_{i}^{t}}{A_{i}^{t}}\right]
$$

O termo do lado esquerdo da equação (29) significa que a taxa de crescimento da tecnologia materializada na produtividade total dos fatores, de um país $i$, depende da taxa de crescimento endógeno do capital humano $g\left(H_{t}^{i}\right)$ e do coeficiente catch-up, dado pela função $c\left(H_{i}\right)$. Esta função especifica que a taxa a qual a diferença tecnológica entre os países é diminuída depende do nível de capital humano. Os autores assumem que $g\left(H_{i}\right)$ e $c\left(H_{i}\right)$ são funções não-decrescente de $H i$, ou seja, $\frac{\partial g}{\partial H}>0$ e $\frac{\partial c}{\partial H}>0$

Desse modo, pode-se adaptar a equação (29) para redefinir o termo $\left[\ln _{t}^{i}\left(H_{t}^{i}\right)-\ln A_{0}^{i}\left(H_{t}^{i}\right)\right]$ para que esse passe a representar a especificação estrutural de um país i. Assim,

${ }^{46}$ Ver modelo original em Benhabib \& Spiegel (1994, p.155). 


$$
\left[\ln A_{t}^{i} \cdot\left(H_{t}^{i}\right)-\ln A_{0}^{i} \cdot\left(H_{t}^{i}\right)\right]=C+g H_{t}^{i}+m H \cdot\left[\frac{Y_{t}^{\max }-Y_{t}^{i}}{Y_{t}^{i}}\right]
$$

sendo $C$ o progresso tecnológico exógeno, a parcela $g\left(H_{t}^{i}\right)$ representa, no período $t$, o progresso tecnológico endógeno associado com a capacidade de um país de inovar domesticamente, sendo $g$ o parâmetro; o $Y_{t}^{\max }$ representa a renda per capita, no período $t$, do país com a tecnologia de ponta (país líder); o $Y_{t}^{i}$ é a renda per capita, no período $t$, do país com tecnologia mais atrasada. A parcela $m H \cdot\left[\frac{Y_{t}^{\max }-Y_{t}^{i}}{Y_{t}^{i}}\right]$ representa a difusão de tecnologia vinda do país líder para o país com a tecnologia mais atrasada, com $m$ sendo o parâmetro. Esta parcela foi denominada pelos autores de catch-up, o qual sugere que, tomando os níveis de capital humano como sendo constantes, os países com menores níveis de produtividade inicial poderão obter taxas de crescimento mais rapidamente do seu produto agregado se houver difusão da tecnologia entre os países.

Substituindo a equação (30) em (28) e simplificando, resulta em:

$$
\begin{aligned}
\left(\ln Y_{t}^{i}-\ln Y_{0}^{i}\right)=C & +(g-m) H_{t}^{i}+m H_{t}^{i} \cdot\left(\frac{Y_{t}^{\max }}{Y_{t}^{i}} \cdot\right)+\alpha\left(\ln K_{t}^{i}-\ln K_{0}^{i}\right)+ \\
& +\beta\left(\ln L_{t}^{i}-\ln L_{0}^{i}\right)+\left(\ln \varepsilon_{t}-\ln \varepsilon_{0}\right)
\end{aligned}
$$

O primeiro termo da equação (31) representa o crescimento do produto per capita; a parcela $(g-m) H_{i}^{i}$ reflete o efeito das inovações endógenas domésticas, isto é, incrementando de forma independente o estoque de capital humano, aumenta o progresso tecnológico; a parcela $\left[m H_{t}^{i} \cdot\left(\frac{Y_{t}^{\max }}{Y_{t}^{i}}\right)\right]$ é um termo interativo que representa a defasagem tecnológica de um país $i$ qualquer em relação a um país líder. As demais 
parcelas que explicam o crescimento do produto per capita são os crescimentos do estoque de capital físico e do trabalho e o erro estocástico.

A questão fundamental é saber se o modelo proposto por Benhabib \& Spiegel, que a princípio foi aplicado para países, poderia ser utilizado para avaliar o papel do capital humano em setores específicos dentro de um mesmo país. Pode-se enumerar alguns pontos que, acredita-se, venham a justificar a aplicação de tal modelo para análise de setores específicos. Em primeiro lugar, a parcela do catch-up na equação

(31) foi especificada por $\left[m H_{t}^{i} \cdot\left(\frac{Y_{t}^{\max }}{Y_{t}^{i}}\right)\right]$. Se está ocorrendo difusão de tecnologia dos setores industriais, ou mesmo de outros países, para a agropecuária brasileira, é sensato pensar que o setor agropecuário do estado líder seja o primeiro a incorporá-la aumentando o seu volume de produção. Posteriormente, é de se esperar que essa tecnologia seja difundida para os demais estados. Dependendo do nível de capital humano existente nos demais estados, alguns deles poderão atingir taxas de crescimento acima daquela obtida pelo estado líder, levando à diminuição do hiato econômico que os separam do estado líder. Em segundo lugar, se o progresso técnico é gerado no próprio setor agropecuário, mais uma vez, é sensato pensar que ele seja, na sua maioria, desenvolvido no estado mais rico economicamente. O maior nível de tecnologia irá impactar de forma positiva a produção desse estado. Posteriormente, é possível que esse incremento tecnológico se difunda para os demais estados. Em terceiro lugar, Nelson \& Phelps (1966), apesar de não apresentarem em seu artigo uma aplicação empírica da sua proposta metodológica, sinalizam que o estudo poderia ser aplicado para a agricultura norte-americana, conforme salientado no subitem (3.5.1).

\subsection{Modelos teóricos considerados para teste}

Como especificado anteriormente, existem várias maneiras de avaliar como o capital humano afeta o crescimento do produto. No presente trabalho serão consideradas duas delas. A primeira é considerar o capital humano numa função de 
produção neoclássica tradicional, como a equação (2). Foi este o recurso utilizado por Lau et. al. (1993). A segunda maneira é considerar o capital humano sob o enfoque neoclássico alternativo, onde se procura, de acordo com Benhabib \& Spiegel (1994), modelar o progresso tecnológico como uma função do estoque de capital humano dos países, como é o caso da equação (31).

No Quadro 2 estão resumidos os principais fundamentos dessas duas equações.

\begin{tabular}{|c|c|c|}
\hline & Modelo neoclássico tradicional & Modelo neoclássico alternativo \\
\hline Origem & Solow (1957) & $\begin{array}{l}\text { Nelson \& Phelps (1966) e } \\
\text { Benhabib \& Spiegel (1994) }\end{array}$ \\
\hline $\begin{array}{l}\text { Tipo de função } \\
\text { de produção }\end{array}$ & $\begin{array}{l}Y=A \cdot F(K, L, H) \\
Y \text { é o valor da produção, } A \text { é o } \\
\text { progresso tecnológico, } K \text { e } L \text { são os } \\
\text { estoques de capital e trabalho, } \\
\text { respectivamente, e } H \text { é o capital } \\
\text { humano }\end{array}$ & $\begin{array}{l}Y=F(A H, K, L) \\
Y \text { é o valor da produção, } A H \text { é o } \\
\text { progresso tecnológico asso- } \\
\text { ciado ao capital humano, } K \text { e } L \\
\text { são os estoques de capital e } \\
\text { trabalho, respectivamente }\end{array}$ \\
\hline $\begin{array}{l}\text { Papel da } \\
\text { tecnologia }\end{array}$ & $\begin{array}{l}\text { Neutro no sentido de Hicks e } \\
\text { exógeno }\end{array}$ & $\begin{array}{l}\text { A fronteira tecnológica é } \\
\text { determinada pelo país líder }\end{array}$ \\
\hline $\begin{array}{l}\text { Papel do capital } \\
\text { humano }\end{array}$ & $\begin{array}{l}\text { Foi considerado como uma das } \\
\text { explicações para o resíduo de } \\
\text { Solow }\end{array}$ & $\begin{array}{l}\text { E um argumento da função de } \\
\text { produção, sendo capaz de gerar } \\
\text { difusão de tecnologia }\end{array}$ \\
\hline $\begin{array}{l}\text { Rendimentos à } \\
\text { escala }\end{array}$ & Constante ou decrescente & Constante ou decrescente \\
\hline
\end{tabular}

Quadro 2 - Comparação entre os modelos de crescimento neoclássico e alternativo.

Fonte: Compilado pelo autor .

O presente trabalho considera essas duas abordagens e, nos próximos capítulos, aplica-as para verificar qual proporciona uma melhor explicação sobre a importância do capital humano no processo de crescimento da agropecuária brasileira. 


\section{METODOLOGIA}

O presente capítulo mostra, no item 3.1, as limitações e vantagens das funções de produção mais utilizadas na literatura, que são: a função de produção CobbDouglas, CES e translog. No item 3.2, desenvolve-se, com o intuito de verificar como o capital humano influencia a variação do produto agropecuário brasileiro, a formulação econométrica do modelo neoclássico básico a partir da função de produção CobbDouglas. No subitem 3.2.1, deriva-se, da função Cobb-Douglas, uma função de produção capaz de mensurar o efeito threshold para a educação dos trabalhadores no setor agropecuário brasileiro. No item 3.3, define-se a função de produção que será estimada para verificar o papel do capital humano no desempenho do setor agropecuário brasileiro sobre a perspectiva do modelo neoclássico alternativo. Finalmente, no item 3.4 são discutidos os dados a serem utilizados e as suas fontes.

\subsection{As funções de produção}

As funções de produção mais utilizadas nos estudos econômicos são a CobbDouglas, a função de produção que supõe Elasticidade de Substituição entre os fatores ser Constante (CES) e a Translogarítmica, conhecida como translog.

Originalmente, a função de produção Cobb-Douglas foi desenvolvida em 1928. Não obstante, a incorporação do progresso tecnológico neutro nesta função, no 
sentido de Hicks, ocorreu em 1946. A equação (2) do Capítulo 3 é a representação tradicional da função de produção Cobb-Douglas com progresso tecnológico ${ }^{47}$. A neutralidade do progresso técnico significa que a taxa marginal de substituição entre os fatores não sofre variação com o passar do tempo, isto é, as produtividades marginais dos fatores de produção crescem à mesma taxa (Barbosa, 1985, p.228). Segundo Dias (1998), a virtude da função de produção Cobb-Douglas decorre da sua simplicidade, o que a tornou amplamente empregada até os dias atuais. Para Beattie \& Taylor (1985, p.65), essa função pode ser uma boa aproximação para processos de produção nos quais os fatores são substitutos imperfeitos entre si. Além disso, segundo Beattie \& Taylor (1985), trata-se de uma função que pode ser convertida numa forma funcional logarítmica linear nos parâmetros, o que, conseqüentemente, facilita a sua estimação usando métodos econométricos. As restrições ao uso desta função - destacadas tanto por Dias (1998) quanto por Beattie \& Taylor (1985) - relacionam-se às hipóteses da elasticidade de substituição ser unitária e as elasticidades de produção e de demanda de fatores serem constantes. A busca da superação dessas limitações levou os economistas a desenvolverem funções alternativas, tais como: a CES e a translog, por exemplo.

A função de produção com elasticidade de substituição constante (CES) é uma generalização da Cobb-Douglas. Segundo Barbosa (1985), ela foi definida em 1961 por Arrow, Chenery, Minhas e Solow ${ }^{48}$. Matematicamente, ela pode ser representada como:

$$
Y=\gamma\left[\delta K^{-\rho}+(1-\delta) L^{-\rho}\right]^{-\nu / \rho}
$$

onde $Y$ é o produto; e $K$ e $L$ são, respectivamente, as quantidades de capital e trabalho. Os $\delta$, $\rho$ e $v$ são os parâmetros da função.

\footnotetext{
${ }^{47}$ Esta função é: $Y=A \cdot F(K, L)$.

${ }^{48}$ Arrow, K. J. et al. Capital-labor susbstitution and economic efficiency. Review of Economic and Statístics, v.43, p.225 a 250, 1961.
} 
A elasticidade de substituição $(\sigma)$ é dada por:

$$
\sigma=\frac{1}{1+\rho}
$$

Como se pode notar, a elasticidade de substituição é constante, pois $\rho$ é constante. Por isso o nome $\mathrm{CES}^{49}$. Essa função, como argumenta Barbosa (1985), é uma generalização de várias funções de produção. Por exemplo, se $\rho$ aproxima-se de -1 , a elasticidade de substituição tende para o infinito, o que implica que existe substituição perfeita entre os fatores de produção. Entretanto, se $\rho$ tende ao mais infinito, $\sigma$ tende a zero e a CES reduz-se a uma função de produção com proporções fixas, denominada de função de produção de Leontief. Quando $\rho$ tende a zero, $\sigma$ tende para 1 e a CES se converte numa função tipo Cobb-Douglas ${ }^{50}$.

A função CES, inicialmente concebida, era não-linear nos parâmetros. Tal característica impedia a utilização do método de regressão linear múltipla. Procurando facilitar a estimação da função CES, foi desenvolvida por Kmenta uma aproximação dessa função ${ }^{51}$, a qual permitiu obter uma função linear nos parâmetros, possibilitando usar o método dos mínimos quadrados ordinários para a sua estimação (Barbosa, 1985).

A principal restrição da função CES, conforme destaca Dias (1998, p.39), é que esse tipo de função apresenta, como o próprio nome indica, elasticidade de substituição constante, porém não-unitária. Esta característica torna a função CES inadequada para representar o comportamento econômico do setor produtivo.

O recurso dos economistas, quando não querem impor restrições à tecnologia, ao valor das elasticidades e nem pressupor a homogeneidade linear, é utilizar as formas flexíveis, como a função manslog. Segundo Chambers (1988, p.167), a função

\footnotetext{
${ }^{49}$ Ver dedução em Barbosa (1985, p. 231 a 232).

${ }^{50}$ A prova matemática dessas afirmações está em Barbosa (1985, p.233 a 236).

${ }^{51}$ A função seria: $\log Q_{1}=c+v \delta \log K_{1}+v(1-\delta) \log L_{1}-\frac{v \rho \delta(1-\delta)}{2}\left(\log K_{1}-\log L_{1}\right)^{2}+\varepsilon_{1}$.
} 
translog é a mais popular transformação de variável econômica. Esta função foi proposta em razão da função de produção Cobb-Douglas não ser suficientemente flexível para representar as variações tecnológicas na meta função de produção. Matematicamente, a translog pode ser representada por:

$$
\ln Y=C+\sum_{j=1}^{n} \delta_{j} \ln Z_{j}+\frac{1}{2} \sum_{i}^{n} \sum_{j}^{n} \Psi_{i j} \ln Z_{i} \cdot \ln Z_{j}
$$

onde, $C$ é uma constante, $Z_{i}$ e $Z_{j}$ representam as variáveis independentes, $\delta$ e $\psi$ são os parâmetros e $\psi_{i j}=\psi_{j i}$.

A função translog, como qualquer outra função de produção, pressupõe algumas propriedades. Halter et al. (1951) apresentam-nas de forma sistemática, o que dispensa repetir, no presente trabalho, deduções matemática ali feitas. Com o propósito de somente apresentar essas propriedades, sem se ater em suas implicações matemáticas, toma-se como referência o trabalho de Chambers (1988). Essas propriedades são: a aproximação numérica na vizinhança de um ponto arbitrário; a homogeneidade linear, isto é, $\sum_{j} \delta_{j}=1, \sum_{i} \psi_{i j}=\sum_{j} \psi_{j i}=0$; não é possível obter concavidade global; a separabilidade, ou seja, não é possível impor restrições.

No presente estudo será considerada apenas a função Cobb-Douglas para especificar as equações do modelo neoclássico tradicional e o alternativo. A escolha da Cobb-Douglas baseia-se na sua simplicidade e por ser recorrentemente utilizada em trabalhos que são as referências básicas do presente estudo ${ }^{52}$. Ao utilizar a mesma função de produção usada por Lau et al. (1993) e Gonçalves et al. (1998) para a economia

\footnotetext{
${ }^{52}$ Está se referindo ao trabalho de Lau et al. (1993), Gonçalves et al. (1998) e Benhabib \& Spiegel (1994).
} 
brasileira, torna-se possível comparar os resultados obtidos no presente trabalho com aqueles apresentados pelos autores mencionados.

\subsection{O modelo neoclássico tradicional aumentado}

No capítulo da introdução foi comentado, de forma sucinta, o modelo de Lau et al. (1993). O presente trabalho difere em pelo menos dois pontos daquele trabalho. Em primeiro lugar, pretende-se verificar, especificamente, o papel do capital humano no processo de crescimento da agropecuária, ao passo que os autores citados o fazem para a economia brasileira como um todo. Em segundo lugar, foi introduzida a terra como mais uma variável explicativa na metafunção de produção.

Na literatura tradicional, a importância do capital humano para determinar o nível de produto foi, geralmente, estimada utilizando-se uma metafunção de produção (MFP). O conceito MFP foi introduzido, segundo Lau \& Yotopoulos (1989), por Haymi e Ruttan no início da década de $70^{53}$. A pressuposição é que estando a tecnologia disponivel no mercado, todos os estados estariam utilizando a mesma MFP, contudo, dependendo do grau de desenvolvimento dos respectivos estados, eles poderiam operar em diferentes partes dela. Assim, a MFP mais adequada para o propósito da presente tese pode ser definida como:

$$
Y_{t}^{i^{*}}=F_{i}\left(K_{t}^{i^{*}}, L_{t}^{i^{*}}, H_{t}^{i^{*}}, T_{t}^{i^{*}}\right)
$$

onde $Y_{l}^{i^{*}}$ representa a quantidade de equivalente-eficiente do valor da produção agropecuária do iésimo estado no tempo $t ; K_{t}^{i^{*}}, L_{t}^{i^{*}}, H_{t}^{i^{*}}$ e $T_{t}^{i^{*}}$ representam, respectivamente, a quantidade de equivalente-eficiente do estoque de capital físico, o volume de trabalho empregado, o capital humano e a área de terra, respectivamente.

${ }^{53}$ HAYAMI, Y.; RUTTAN, R. W. Agricultural productivity differences among countries. American Economic Review, v.60, n.3, p.895-911, 1970. 
Equivalente-eficiente é entendido como uma medida padrão, comum a todos estados, a qual permite comparar a eficiência técnica dos insumos e do produto nos diferentes estados brasileiros. A especificação da equação (35) em termos de equivalente-eficiente significa preservar as diferenças na eficiência técnica da produção. Por várias razões, os fatores aumentadores diferem entre os estados. Nas palavras de Lau. et al. (1993, p.49):

"...diferenças no clima, topografia, infra-
estrutura e recursos naturais, diferenças na
qualidade, diferenças na composição do produto, e
diferenças na eficiência técnica de produção são
alguns exemplos. Os fatores aumentadores são
introduzidos precisamente para captar essas
diferenças entre os estados."

Considerando que os argumentos de Lau et al. (1993), realizados para o Brasil, sejam também aplicáveis para a agropecuária brasileira, pode-se dizer que as quantidades de equivalente-eficiente do valor da produção e dos insumos em cada estado não são diretamente observáveis. Considera-se que o equivalente-eficiente está associado às quantidades mensuradas do valor da produção e dos estoques de insumos $(K, L, H \mathrm{e}$ $T$ ), para os iésimos estados no tempo $t$.

O presente estudo irá pressupor, assim, que a conversão do valor da produção e dos insumos em equivalente-eficiente ocorre através da multiplicação de $Y_{t}^{i}$, $K_{t}^{i}, L_{t}^{i}$ e $T_{t}^{i}$ pelo fator aumentador denominado $\omega^{i}$ (onde $i$ indica cada estado do Brasil). Para o capital humano $\left(H_{t}^{i}\right)$, a conversão ocorre pela adição do fator aumentador $^{54}$. Ao pressupor que o fator aumentador fosse adicionado à variável $H$,

\footnotetext{
${ }^{54}$ Para mais informações acerca dos motivos de se usar a forma exponencial e linear, ver Lau et al. (1993, p.48 e
} 49). 
admitiu-se que, por exemplo, três anos médio de estudo em um determinado estado pode ser equivalente-eficiente a dois anos de estudo médio em um outro estado.

Ao realizar essa álgebra simples, obtém-se

$$
\begin{aligned}
& Y_{t}^{i^{*}}=\omega_{Y}^{i} Y_{t}^{i} \\
& K_{t}^{i^{*}}=\omega_{K}^{i} K_{t}^{i} \\
& L_{t}^{i^{*}}=\omega_{L}^{i} L_{t}^{i} \\
& T_{t}^{i^{*}}=\omega_{T}^{i} T_{t}^{i} \\
& H_{t}^{i^{*}}=\omega_{H}^{i}+H_{t}^{i}
\end{aligned}
$$

Substituindo a equação (36) na equação (35) chega-se a uma metafunção de produção agregada, definida por:

$$
Y_{t}^{i}=\left(\omega_{Y}^{i}\right)^{-1} \cdot F_{i}\left(K_{t}^{i^{*}}, L_{t}^{i^{*}}, T_{t}^{i^{*}}, H_{t}^{i^{*}}\right), \quad i=1, \ldots, \mathrm{n}
$$

O elemento $\omega_{Y}^{i}$, relacionado ao produto, permite que a eficiência na produção varie de um estado para outro. Ao pressupor-se que $\omega$ multiplica $Y_{\imath}^{i}, K_{t}^{i}, L_{t}^{i}$ e, $T_{t}^{i}$ e é adicionado ao $H_{t}^{i}$, então, os fatores aumentadores para as quatro primeiras variáveis estão assumindo a forma exponencial com relação ao tempo e para $H_{t}^{i}$ a forma linear com relação ao templo. Desse modo,

$$
\begin{aligned}
& Y_{t}^{i^{*}}=\omega_{Y}^{i} \cdot e^{\left(b_{Y}^{i}\right)_{t} Y_{t}^{i}} \\
& K_{t}^{i^{*}}=\omega_{K}^{i} \cdot e^{\left(b_{K}^{i}\right)_{t} K_{t}{ }^{\prime}}
\end{aligned}
$$




$$
\begin{aligned}
& L_{t}^{i^{*}}=\omega_{L}^{i} e \cdot{ }^{\left(b_{L}^{i}\right) L_{t}{ }^{i}} \\
& T_{t}^{i^{*}}=\omega_{T}^{i} e \cdot{ }^{\left(b_{T}^{i}\right) T_{t}{ }^{i}} \\
& H_{t}^{i^{*}}=H_{t}^{i}+\omega_{H}^{i}+\left(b_{H}^{i}\right)_{t}
\end{aligned}
$$

sendo que $\omega_{Y}^{i}, \omega_{K}^{i}, \omega_{L}^{i}, \omega_{T}^{i} e \omega_{H}^{i}$ são constantes específicas para cada estado (indicado pelo sobre-índice $i$ ), onde os $\omega$ 's representam a eficiência técnica do valor da produção e dos fatores de produção. $\left(b_{Y}^{i}\right)_{t} e\left(b_{J}^{i}\right)_{t} \operatorname{com}-j=K, L, T$ e $H$ - irão captar o progresso tecnológico, determinado exogenamente.

Sendo a equação (41) uma função de produção Cobb-Douglas, então, ela pode ser representada por:

$$
Y_{t}^{i^{*}}=\psi \cdot\left(K_{t}^{i^{*}}\right)^{\delta_{K}} \cdot\left(L_{t}^{i^{*}}\right)^{\delta_{L}} \cdot\left(T_{t}^{i^{*}}\right)^{\delta_{T}} \cdot\left(e^{\delta_{H} H_{t}^{i^{*}}}\right) \cdot u_{t}
$$

onde $\psi$ representa o termo constante e $\delta_{K}, \delta_{L}, \delta_{T}$ e $\delta_{H}$ são os coeficientes das variáveis $K, L$, e $H$, respectivamente, e $e$ é a base dos logarimos neperiano.

Ao logaritmizar a equação (47) e substituir os valores das equações (42) a (46), resulta em:

$$
\begin{aligned}
\ln \left(\omega_{Y}^{\mathrm{i}} \cdot e^{\left(b_{Y}^{i}\right)_{t} Y_{t}^{i}}\right)= & \ln \psi+\delta_{K} \ln \left(\omega_{K}^{i} \cdot e^{\left(b_{K}^{i}\right)_{t} K_{t}^{i}}\right)+\delta_{L} \ln \left(\omega_{L}^{i} \cdot e^{\left(b_{L}^{i}\right)_{t} L_{t}^{i}}\right)+\delta_{T} \ln \left(\omega_{T}^{i} \cdot e^{\left(b_{T}^{i}\right)_{t} T_{t}^{i}}\right) \\
& +\delta_{H}\left(\omega_{H}^{i}+\left(b_{H}^{i}\right)_{t}+H_{t}^{i}\right)+\ln \varepsilon_{t}
\end{aligned}
$$

Resolvendo e simplificando a equação (48), tem-se:

$$
\begin{aligned}
& \ln Y_{t}^{i}=\ln \psi-\ln \omega_{Y}^{i}+\delta_{K} \ln \omega_{k}^{i}+\delta_{L} \ln \omega_{L}^{i}+\delta_{T} \ln \omega_{T}^{i}+\delta_{H} \omega_{H}^{i}+\delta_{K} \ln K_{t}^{i}+\delta_{L} \ln L_{t}^{i}+ \\
& +\delta_{T} \ln T_{t}^{i}+\delta_{H} H_{t}^{i}-\left(b_{Y}^{i}\right)_{t}+\delta_{K}\left(b_{K}^{i}\right)_{t}+\delta_{L}\left(b_{L}^{i}\right)_{t}+\delta_{T}\left(b_{T}^{i}\right)_{t}+\delta_{H}\left(b_{H}^{i}\right)_{t}+\ln \varepsilon_{t}
\end{aligned}
$$


Alguns termos da equação (49) são constantes em relação ao tempo. Assume-se que estes termos possam ser representados por:

$$
\ln G_{i}=+\delta_{K} \ln \left(\omega_{K}^{i}\right)+\delta_{L} \ln \left(\omega_{L}^{i}\right)+\delta_{T} \ln \left(\omega_{T}^{i}\right)-\ln \left(\omega_{Y}^{i}\right)+\ln \psi+\delta_{H}\left(\omega_{H}^{i}\right)
$$

Ao substituir a equação (50) na equação (49), chega-se à seguinte especificação:

$$
\begin{aligned}
\ln Y_{t}^{i}= & \ln G_{i}+\delta_{K} \ln K_{t}^{i}+\delta_{L} \ln L_{t}^{i}+\delta_{T} \ln T_{t}^{i}+\delta_{H} H_{t}^{i}+\left(-b_{Y}^{i}+\delta_{k} b_{K}^{i}+\right. \\
& \left.\delta_{L} b_{L}^{i}+\delta_{T} b_{T}^{i}+\delta_{H} b_{H}^{i}\right)_{t}+\ln \varepsilon_{t}
\end{aligned}
$$

O termo entre parênteses no segundo membro da equação (51) é responsável pela incorporação do progresso tecnológico em cada um dos fatores. Como esse termo sofre variação ao longo do tempo ${ }^{55}$, ele pode ser representado por:

$$
A_{t}^{i}=\left(-b_{Y}^{i}+\delta_{K} b_{K}^{i}+\delta_{L} b_{L}^{i}+\delta_{T} b_{T}^{i}+\delta_{H} b_{H}^{i}\right)_{t}
$$

Substituindo a equação (52) na equação (51) e procedendo à primeira diferença para expressar a nova equação em termos de taxa de crescimento, tendo como referência o ano de 1970, obtém-se:

$$
\begin{aligned}
\left(\ln Y_{t}^{i}-\ln Y_{t-1}^{i}\right)= & A_{t}^{*}+\delta_{K}\left(\ln K_{t}^{i}-\ln K_{t-1}^{i}\right)+\delta_{L}\left(\ln L_{t}^{i}-\ln L_{t-1}^{i}\right)+ \\
& +\delta_{T}\left(\ln T_{t}^{i}-\ln T_{t-1}^{i}\right)+\delta_{H}\left(H_{t}^{i}-H_{t-1}^{i}\right)+\ln \varepsilon_{t}
\end{aligned}
$$

onde $A_{t}^{*}=\left(\ln A_{t}^{i}-\ln A_{t-1}^{i}\right)$ com $i$ representando os 25 estados do Brasil. Trata-se, portanto, de uma equação de regressão clássica com $A_{t}^{*}$ especificando o progresso tecnológico determinado exogenamente no modelo.

${ }^{55}$ Observe que apenas as variáveis $b_{J}(J=Y, K, L, T$ e $H)$ variam ao longo do tempo. Os valores de $\delta_{J}$ não se alteram ao longo do tempo. 
Para estimar a equação (53), pode-se utilizar dados dos Censos Agropecuários para os anos censitários de 1970, 1975, 1980, 1985 e 1995/96. Há informações para 25 estados em cada ano censitário. A existência de dados com características de cross-section e de série temporal, dados em painel, possibilita recorrer ao uso da técnica conhecida como pooling, que consiste em "empilhar" os dados. Com cinco anos censitários e 25 estados, as regressões contarão com 100 observações, pois, foi calculada a taxa de crescimento das variáveis dependentes e independentes $(K, L \mathrm{e} T)$ tendo como base o ano de 1970. Para a variável $H$, como ela não está em logaritmo, fezse apenas a primeira diferença, tomando como base o ano de 1970 .

Além da estimação do pooling, procede-se também à estimação dos crosssection . Nesse caso, mais quatro regressões foram estimadas considerando a equação (53). Cada uma dessas regressões refere-se a um determinado período. Ao todo, são quatro períodos que são especificados com base em $1970^{56}$. Assim, tem-se o período de 1975 com base 1970, 1980 com base 1970, 1985 com base 1970, e 1995/96 com base em 1970. A justificativa para a manutenção da mesma base para o cálculo das taxas de crescimento (ou seja, 1970) é que os efeitos do capital humano são cumulativos ao longo do tempo.

A questão com que se depara o trabalho neste estágio diz respeito ao seguinte: qual é o método econométrico mais apropriado para estimar a equação (53)?

Como os dados estão em pooling, dispostos em série de tempo e crosssection, o método mais recomendado seria o de $\mathrm{Parks}^{57}$, se existir correlação contemporânea. Caso não exista esse problema econométrico e nem heteroscedasticia, os modelos deverão ser estimados pelo Método dos Mínimos Quadrados (OLS).

O método de Parks é usado para estimar modelo do tipo:

\footnotetext{
${ }^{56}$ As estimativas por período estão no Apêndice 4.

${ }^{57}$ Ver Parks (1967).
} 


$$
u_{i t}=\rho_{i} u_{i, t-1}+\varepsilon_{i t}
$$

Nesse tipo de modelo assume-se que o modelo é auto-regressivo de primeira ordem (ARl) com correlação contemporânea entre cross-sections. Infelizmente, esse tipo de cálculo exige que o tamanho da série temporal seja bem maior que o número de parâmetros, o que, logicamente, inviabiliza o seu uso na estimação de todas as equações propostas nesse estudo.

Se não for diagnosticado heteroscedasticia na equação (53), deve-se utilizar o Método dos Mínimos Quadrados Ordinários (OLS), caso contrário, deve-se recorrer ao recurso econométrico proposto por White $(1980)^{58}$ - apresentado por Johnston \& DiNardo (1997). A natureza do estimador OLS de White pode ser mais facilmente entendida quando comparada com o estimador OLS convencional. A fórmula convencional da matriz de variância $\operatorname{var}(\boldsymbol{b})$ no OLS é dada por $\sigma^{2}\left(X^{\prime} \boldsymbol{X}\right)^{-1}$, enquanto a matriz de variância correta na presença de heteroscedasticia deveria, segundo Johnston \& DiNardo (1997), apresentar a seguinte formulação:

$$
\operatorname{var}(b)=\left(X^{\prime} X\right)^{-1} X^{\prime} \sigma^{2} u u^{\prime} X\left(X^{\prime} X\right)^{-1}
$$

Esta alteração matemática na especificação da fórmula da variância no modelo OLS permite obter estimativas consistentes da variância levando em consideração a heteroscedasticia. No presente trabalho, essa forma de estimação será referida como ECVH de White. Cabe ressaltar que a magnitude dos parâmetros da equação (53) não é alterada ao proceder a estimação desta equação utilizando ECVH de White. O que modifica são as significâncias estatísticas dos parâmetros da respectiva equação.

58 WHITE, H. A heteroscedasticity-consistent covariance matrix estimator and a direct test for heteroscedasticity. Econometrica, v.48, n.4, p.817-838, 1980. 


\subsubsection{O modelo econométrico para a estimação do efeito threshold}

Como visto no capítulo de introdução, pode-se definir o efeito threshold como sendo o efeito que surge sobre o crescimento do produto per capita quando o número médio de anos de educação atinge certa magnitude. Este efeito sobre o produto não surge quando o nível médio de educação está abaixo ou acima deste valor crítico. A existência desse efeito manifestar-se-ia na significância estatística de alguma classe específica de anos de educação (indicada por $H J$, onde $J$ é a classe de anos de estudo). É esperado que os parâmetros associados às primeiras classes iniciais de anos de estudo (por exemplo, $\mathrm{H} 1$ e H2), não sejam significativos. O efeito threshold só deveria ocorrer em uma das classes intermediárias (por exemplo, $\mathrm{H} 3$ ou H4); sendo que as demais classes (por exemplo, H5 e H6) não teriam, também, os seus parâmetros estatisticamente significativos. Isso se explica pelo seguinte fato: as classes iniciais de anos de estudo constituem a base educacional em um determinado período. A idéia é a de que se os trabalhadores rurais de todos os estados brasileiros tivessem, por exemplo no período de 1970 a 1980, em média até dois anos de estudo, o efeito da educação sobre o valor da produção seria mais ou menos equivalente. Contudo, se de repente, no próximo período (1980-1985), essa média aumenta consideravelmente, para a classe de 3 a 4 anos de estudo em média, em alguns estados importantes do ponto de vista da produção agropecuária, é esperado, então, que o efeito marginal desse incremento adicional de educação cause impactos altamente positivos e estatisticamente significativos sobre o valor da produção. Entretanto, com o passar do tempo, quando todos os outros estados alcançarem também essa média, é esperado que diminua o impacto, dessa classe específica, sobre a formação do valor da produção.

Um exemplo fictício permite entender melhor o efeito threshold. Se um pesquisador estiver analisando o resultado da regressão de um país $\mathrm{X}$ (onde as variáveis foram tomadas em logarimos), e verificar que a magnitude do parâmetro associado à educação média foi de 0,20 (um ano adicional de educação média afeta o produto per capita em 20\%), o pesquisador poderá concluir - com base em outros estudos, ou em seu 
próprio entendimento da dinâmica econômica daquele país - que a magnitude desse parâmetro está muito alta para os padrões daquela economia, e que possivelmente o efeito da educação daquele país no longo prazo deverá ser menor. Para verificar se a educação da força de trabalho do país $\mathrm{X}$ alcançou um nível de threshold crítico, então $\mathrm{o}$ pesquisador, neste exemplo fictício, desagrega a educação média em três classes: H1, H2 e H3 que correspondem às classes de 1 a 2,2 a 3 e 3 a 4 anos de estudos, respectivamente. Ao incorporar esse conjunto de variáveis artificiais na equação de regressão - que fora anteriormente estimada - e reestimá-la, o pesquisador pode perceber que o único parâmetro associado à educação média que se apresentou estatisticamente significativo foi H2. Então, ele pode concluir que, realmente, houve o efeito threshold, já que o efeito de $20 \%$ da educação média sobre o produto foi explicado apenas pela classe de 2 a 3 anos de estudo. No longo prazo, o pesquisador espera que esse efeito diminua.

Para estimar o efeito threshold, procede-se à remodelagem da equação (53) com a introdução de um conjunto de variáveis artificiais construídas a partir da desagregação da variável capital humano $H(H 1, H 2, H 3, H 4, H 5$ e $H 6)$. Utilizou-se o mesmo recurso matemático de Lau et al. (1993), mas adaptando-o aos propósitos do presente estudo. Essas variáveis são:

$$
\begin{aligned}
& H 1_{t}^{i}= \begin{cases}H_{t}^{i}-0,3, & \text { se } 0,3 \leq H_{t}^{i}<1 \\
1, & \text { se } \quad H_{t}^{i} \geq 1\end{cases} \\
& H 2_{t}^{i}= \begin{cases}0, & \text { se } H_{t}^{i} \leq 1 \\
H_{t}^{i}-1, & \text { se } 1<H_{t}^{i}<2 \\
1, & \text { se } H_{t}^{i} \geq 2\end{cases} \\
& H 3_{t}^{i}= \begin{cases}0, & \text { se } H_{t}^{i} \leq 2 \\
H_{t}^{i}-2, & \text { se } 2<H_{t}^{i}<3 \\
1, & \text { se } H_{t}^{i} \geq 3\end{cases}
\end{aligned}
$$




$$
\begin{aligned}
& H 4_{t}^{i}=\left\{\begin{array}{lll}
0, & \text { se } & H_{t}^{i} \leq 3 \\
H_{t}^{i}-3, & \text { se } & 3<H_{t}^{i}<4 \\
1, & \text { se } & H_{t}^{i} \geq 4
\end{array}\right. \\
& H 5_{t}^{i}=\left\{\begin{array}{lll}
0, & \text { se } & H_{t}^{i} \leq 4 \\
H_{t}^{i}-4, & \text { se } & 4<H_{t}^{i}<5 \\
1, & \text { se } & H_{t}^{i} \geq 5
\end{array}\right. \\
& H 6_{t}^{i}=\left\{\begin{array}{lll}
0, & \text { se } & H_{t}^{i} \leq 5 \\
H_{t}^{i}-5, & \text { se } & H_{t}^{i}>5
\end{array}\right.
\end{aligned}
$$

Por exemplo, considerando a variável $H 2$ : se o ano de estudo médio for menor ou igual a 1 , no vetor coluna correspondente à essa variável coluna aparecerá 0 ; se o ano de estudo estiver entre 1 e dois anos incompletos, aparecerá, nesse mesmo vetor, o número médio de anos de estudo deduzido de 1 , mas se o ano de estudo for maior do que 2, o valor que aparecerá no vetor será 1 . O mesmo raciocínio poderá ser feito para todas as outras variáveis.

A equação (53) pode ser remodelada a partir da incorporação do conjunto de variáveis artificiais dado por (56), resultando em um modelo adaptado para estimar a presença do efeito threshold. Adicionando a equação (56) como variável explicativa na equação (53), considerando 1970 como base, resulta em:

$$
\begin{aligned}
\left(\ln Y_{t}^{i}-\ln Y_{t-1}^{i}\right)= & A_{t}^{*}+\delta_{K}\left(\ln K_{t}^{i}-\ln K_{t-1}^{i}\right)+\delta_{L}\left(\ln L_{t}^{i}-\ln L_{t-1}^{i}\right)+\delta_{T}\left(\ln T_{t}^{i}-\ln T_{t-1}^{i}\right)+ \\
& \sum_{j=1}^{6} \delta_{E J}\left(H j_{t}^{i}-H j_{t-1}^{i}\right)+\ln \varepsilon_{t}
\end{aligned}
$$

A identificação do efeito threshold pode ser feita examinando os parâmetros $\delta_{E j}$ da equação (57). Se realmente existir este efeito, espera-se a ocorrência de significância estatística de algum parâmetro intermediário $\left(\delta_{E j}\right)$, sendo os demais 
parâmetros não significativos em termos estatísticos. Assim, por exemplo, se $H 3$ - nível de educação de 2 a 3 anos de escolaridade - for significativo, então, o efeito positivo e estatisticamente significativo do capital humano sobre a taxa de crescimento do valor da produção seria explicado apenas pela classe de anos de estudo de dois até três anos de escolaridade, conforme já argumentado no início deste tópico. Nesse caso, pode-se dizer que surgem evidências da existência de um nível de threshold para o conjunto dos trabalhadores rurais.

Como no caso da equação de regressão (53), se for constatada a presença da heteroscedasticia, irá recorrer-se ao método ECVH de White. Contudo, se não for detectado esse problema, o método OLS convencional será utilizado.

\subsection{O modelo econométrico para considerar o capital humano numa perspectiva de crescimento neoclássico alternativo}

A proposta de Benhabib \& Spiegel (1994), de como avaliar a influência do capital humano no crescimento do produto, foi apresentada no Capítulo 3. O ponto de partida de Benhabib \& Spiegel (1994) foi a função de produção Cobb-Douglas, conforme visto anteriormente. No presente trabalho, estima-se essa função com algumas adaptações. Em primeiro lugar, Benhabib \& Spiegel (1994) procuram analisar o papel do capital humano no desenvolvimento econômico de diversos países e, para tanto, fazem estimativas cross-country. No presente trabalho, estuda-se o papel do capital humano no desenvolvimento da agropecuária brasileira utilizando-se estimativas cross-state. Em segundo lugar, a proxy do capital humano, utilizada por aqueles autores, era a formação escolar da força de trabalho. No presente estudo, esta proxy é constituída pelos anos de estudo da população economicamente ativa ligada ao setor agropecuário composta por pessoas com 10 anos ou mais de idade trabalhando ou procurando emprego. Em terceiro lugar, é introduzida na função de produção proposta pelos autores a variável $T$ (terra), já que o foco de estudo do presente trabalho é a agropecuária. 
Assim, remodelando a proposta de Benhabib \& Spiegel (1994), para atender ao propósito deste estudo, definiu-se a seguinte função de produção:

$$
Y_{t}^{i}=\left(A_{t}^{i} \cdot H_{t}^{i}\right) \cdot\left(K_{t}^{i}\right)^{\delta_{K}} \cdot\left(L_{t}^{i}\right)^{\delta_{L}} \cdot\left(T_{t}^{i}\right)^{\delta_{T}} \cdot u_{t}^{i}
$$

onde $Y_{t}^{i}$ é o valor da produção agropecuária do iésimo estado no tempo $t ; K_{t}^{i}, L_{t}^{i}$ e $T_{t}^{i}$ representam o estoque de capital, a força de trabalho em equivalente-homem e a área de terras exploradas no iésimo estado no tempo $t$, respectivamente; e $A_{t}^{i} H_{t}^{i}$ é o progresso tecnológico associado ao capital humano nos iésimos estados no tempo $t$. Após o desenvolvimento matemático da equação (58), o termo $A_{t}^{i} H_{t}^{i}$, como já visto, passará a representar, por sua vez, três efeitos sobre o produto: i) o efeito exógeno do capital humano, ii) o efeito endógeno do capital humano, e iii) o efeito catch-up. Os $\delta_{K}, \delta_{L}$ e $\delta_{T}$ são os parâmetros das variáveis $K, L$ e $T$, respectivamente. O $u_{t}^{i}$ representa o vetor de resíduo.

Expressando a função (58) em termos de taxa de crescimento do tempo $t-1$ até $t$, resulta em:

$$
\begin{aligned}
\left(\ln Y_{t}^{i}-\ln Y_{t-1}^{i}\right)= & \left(\ln A_{t}^{i} \cdot\left(H_{t}^{i}\right)-\ln A_{t-1}^{i} \cdot\left(H_{t}^{i}\right)\right)+\delta_{K}\left(\ln K_{t}^{i}-\ln K_{t-1}^{i}\right)+ \\
& +\delta_{L}\left(\ln L_{t}^{i}-\ln L_{t-1}^{i}\right)+\delta_{T}\left(\ln T_{t}^{i}-\ln T_{t-1}^{i}\right)+\ln \varepsilon_{t}
\end{aligned}
$$

Benhabib \& Spiegel (1994) sugeriram que o crescimento do resíduo de Solow num país $i$ depende do gap entre o seu nível de educação e o nível de educação do país líder. No presente estudo, considera-se que a taxa de crescimento da produção no estado $i$ depende do hiato entre o nível de educação do setor rural daquele estado e o maior nível de educação no setor rural do estado líder (São Paulo). 
A porção do valor da produção agropecuária influenciada pelo estoque de capital humano está representada pela primeira parcela do lado direito da equação (59). Ela pode ser genericamente escrita como ${ }^{59}$ :

$$
\left(\ln A_{t}^{i} \cdot\left(H_{t}^{i}\right)-\ln A_{t-1}^{i} \cdot\left(H_{t}^{i}\right)\right)=C_{H}+\delta_{H}\left(H_{t}^{i}\right)+\delta_{H C} H_{t}^{i} \cdot\left(\frac{Y_{t}^{\max }}{Y_{t}^{i}}\right)
$$

Na equação (60), o $C_{H}$ representa o efeito exógeno do capital humano sobre o crescimento do produto. A segunda parcela do lado direito da equação (60), $\delta_{H} H_{t}^{i}$, é o efeito endógeno da educação média sobre o crescimento do produto - esse fator representa a capacidade que um estado $i$ possui de promover endogenamente o avanço tecnológico, utilizando-se, somente, do seu capital humano. A última parcela do segundo termo da expressão (60) diz respeito ao efeito catch-up, isto é, a capacidade que o estado $i$ possui de assimilar a difusão da tecnologia vinda do estado líder.

Cabe ressaltar que as variáveis $H, Y_{t}^{\max }$ e $Y_{t}^{i}$ do termo catch-up não estão na forma de taxas de crescimento. Na construção do vetor $H$ (educação média) e do termo catch-up, pressupôs que a taxa de crescimento do valor da produção, de um determinado período, depende do estoque de capital humano e do nível de catch-up do início daquele respectivo período. Portanto, para construir as observações para o período de 1970 a 1975, por exemplo, calculou-se a taxa de crescimento da variável dependente $(Y)$ e das independentes $(K, L e T)$ de 1970 a 1975; com relação às variáveis $H, Y_{t}^{\max }$ e $Y_{t}^{i}$, considerou-se os seus valores no início do período (1970). O mesmo critério foi adotado para os demais períodos.

\footnotetext{
59 A equação (60) é similar à equação (31) do capítulo 3, havendo apenas mudanças na nomenclatura de alguns parâmetros.
} 
O modelo neoclássico alternativo a ser estimado foi obtido da substituição da equação (60) na equação (59). A equação resultante, tendo como base o ano de 1970, a ser estimada, pode ser escrita como:

$$
\begin{aligned}
\left(\ln Y_{t}^{i}-\ln Y_{t-1}^{i}\right)= & C_{H}+\delta_{H} H_{t}^{i}+\delta_{H C} H_{t}^{i} \cdot\left(\frac{Y_{t}^{\max }}{Y_{t}^{i}}\right)+\delta_{K}\left(\ln K_{t}^{i}-\ln K_{t-1}^{i}\right)+ \\
& +\delta_{L}\left(\ln L_{t}^{i}-\ln L_{t-1}^{i}\right)+\delta_{T}\left(\ln T_{t}^{i}-\ln T_{t-1}^{i}\right)+\ln \varepsilon_{t}
\end{aligned}
$$

Seguindo o mesmo procedimento adotado nas equações (53) e (57), uma vez verificada a presença da heteroscedasticia, recorre-se ao método ECVH de White. Caso esse problema não seja detectado, a equação (61) será estimada pelo método OLS convencional.

Para a estimação da equação (61), adotou-se o mesmo critério utilizado na estimação da equação (53). Essa equação foi estimada, em primeiro lugar, recorrendo-se à técnica do pooling. Em segundo lugar, foram feitas estimativas para cada crosssection.

Com o propósito de apresentar ao leitor um panorama geral acerca das equações a serem estimadas, elaborou-se o Quadro 3. 


\begin{tabular}{|c|c|}
\hline $\begin{array}{l}\text { Modelo neoclássico } \\
\text { tradicional }\end{array}$ & $\begin{array}{l}\text { Equação (53) } \\
\begin{aligned}\left(\ln r_{t}^{i}-\ln Y_{t-1}^{i}\right)= & A_{t}^{*}+\delta_{K}\left(\ln K_{t}^{i}-\ln K_{t-1}^{i}\right)+\delta_{L}\left(\ln h_{t}^{i}-\ln \mathcal{L}_{t-1}^{i}\right)+\delta_{T}\left(\ln T_{t}^{i}-\ln T_{t-1}^{i}\right)+ \\
& +\delta_{H}\left(H_{t}^{i}-H_{t-1}^{i}\right)+\ln \varepsilon_{t}\end{aligned}\end{array}$ \\
\hline $\begin{array}{l}\text { Modelo neoclássico } \\
\text { com efeito threshold }\end{array}$ & $\begin{array}{l}\text { Equação (57): } \\
\begin{aligned}\left(\ln Y_{t}^{i}-\ln Y_{t-1}^{i}\right)=A_{t}^{*}+\delta_{K}\left(\ln K_{t}^{i}-\ln K_{t-1}^{i}\right)+\delta_{L}\left(\ln L_{t}^{i}-\ln L_{t-1}^{i}\right)+ \\
\quad+\delta_{T}\left(\ln T_{t}^{i}-\ln T_{t-1}^{i}\right)+\sum_{j=1}^{6} \delta_{E J}\left(H j_{t}^{i}-H j_{t-1}^{i}\right)+\ln \varepsilon_{t}\end{aligned}\end{array}$ \\
\hline $\begin{array}{l}\text { Modelo neoclássico } \\
\text { alternativo }\end{array}$ & $\begin{array}{l}\text { Equação (61) } \\
\begin{aligned}\left(\ln Y_{t}^{i}-\ln Y_{t-1}^{i}\right) & =C_{H}+\delta_{H} H_{t}^{i}+\delta_{H C} H_{t}^{i} \cdot\left(\frac{Y_{t}^{\max }}{Y_{t}^{i}}\right)+\delta_{K}\left(\ln K_{t}^{i}-\ln K_{t-1}^{i}\right)+ \\
& +\delta_{L}\left(\ln L_{t}^{i}-\ln L_{t-1}^{i}\right)+\delta_{T}\left(\ln T_{t}^{i}-\ln T_{t-1}^{i}\right)+\ln \varepsilon_{t}\end{aligned}\end{array}$ \\
\hline
\end{tabular}

Quadro 3 - Equações a serem estimadas.

Fonte: Compilado pelo autor.

\section{4 $\mathrm{A}$ base de dados $\mathrm{e}$ as suas fontes}

Todas as equações expressas no Quadro 3 são estimadas considerando os dados agregados em nível de cada estado e território da Federação, de acordo com a divisão geográfica existente no Brasil em 1970. Assim, os dados do Estado da Guanabara foram anexados aos do Rio de Janeiro; os de Tocantins, aos de Goiás; e os de Mato Grosso do Sul, aos de Mato Grosso. Com essas agregações, cada ano censitário passou a apresentar 25 observações. Como são utilizados cinco anos censitários (1970, 1975, 1980, 1985 e 1995/96), há um conjunto de 125 observações amostrais. Como os dados estão em taxa de crescimento, tendo como base o ano de 1970, o número de observações reduziu-se para 100.

Os dados sobre o valor da produção total $(Y)$ de cada estado correspondem ao valor da produção animal (animal de médio e grande porte, aves e pequenos animais) e o valor da produção vegetal (lavouras permanentes e temporárias, horticultura, floricultura, silvicultura e extração vegetal). Essas informações foram coletadas junto aos Censos Agropecuários, para os anos censitários mencionados anteriormente. 
As informações do valor da produção total estavam em valores nominais. Para convertê-las em valores reais, na data base de agosto de 1994, recorreu-se ao índice de preço recebido pelos agricultores em cada estado. Para os estados da Região Norte, a Revista Conjuntura Econômica não publicava esse índice até o início da década de 90 . Buscando contornar esse problema, utilizou-se o índice médio da Região Nordeste para todos os estados da Região Norte nos anos censitários de 1970, 1975 e 1980. Os dados relativos a esses índices foram obtidos junto à Revista Conjuntura Econômica. Os valores de $Y$, em termos reais, estão no Apêndice 3, Tabela 3.1.

Para mensurar o capital $(K)$, utilizou-se como proxy a potência dos tratores de roda, medida em número de cavalos (c.v.). $\mathrm{O}$ número de cavalos foi dimensionado a partir de quatro classes de potência: i) tratores com até 10 c.v's; ii) de 10 a 50 c.v's; iii) 50 a 100 c.v's; e iv) com 100 c.v's ou mais. Para calcular o número total de c.v. acumulado de cada ano censitário, multiplicou-se o número total de tratores pelo valor representativo em cada classe de potência. Assim, para a primeira classe, admitiu-se o limite superior, ou seja, 10 c.v's; para a segunda e terceira classes, foram adotados os valores médios em cada grupo, ou seja, 30 e 75 c.v's, respectivamente; para a última classe, considerou-se o limite inferior (100 c.v's). De posse desse procedimento, obtevese o estoque físico de capital medido em número total de cavalos. Esses dados estão no Apêndice 3, Tabela 3.1, e foram coletados junto aos Censos Agropecuários.

Os dados relacionados ao trabalho $(L)$ também foram coletados nos Censos Agropecuários. Entretanto, eles exigiram algumas transformações. A força de trabalho empregada na agricultura foi convertida em equivalente-homem-ano (EH), que diz respeito a um homem adulto trabalhando durante 300 dias por ano. Segundo Dias (1998), esse critério foi utilizado por diversos pesquisadores, como: Silva \& Kageyama (1983), Hoffmann et al. (1985) e o próprio Dias (1998). Este critério considera os seguintes fatores de conversão (que também foram usados no presente estudo). 
“...i) homem adulto, em qualquer situação, correspondeu a 1,0 EH; ii) não-empregados (responsável e membros não-remunerados da familia), se mulher, 0,6 EH, se criança de qualquer sexo, 0,4 EH; iii) empregados nãoassalariados (parceiro e outra condição), se mulher, 0,66 $\mathrm{EH}$, se criança (ambos os sexos), 0,5 EH; e iv) empregados assalariados (permanentes e temporários) se mulher, 1,0 EH, se criança (ambos os sexos), 0,5 EH.

Como nos Censos Agropecuários de 1975, 1980, 1985 não se discrimina o pessoal ocupado de 'outra condição' por sexo e idade, como no Censo de 1970, adota-se, aqui, o critério proposto por Hoffmann et al. (1985, v.3, p.654), que consiste na consideração da mesma proporção de crianças observadas para 'parceiros.'”(Dias, 1998, p.57).

Os resultados dessa conversão da força de trabalho em EH estão na tabela 3.1 no Apêndice 3.

Para a educação média $(H)$, a proxy usada foi o número médio de anos de estudo de pessoas com 10 anos ou mais ocupadas no meio rural. O Censo Demográfico de 1970 classificou as pessoas ocupadas de acordo com o número de anos de estudo em seqüência linear $(1,2,3, \ldots$ até 17 anos de estudo), resultando em 17 intervalos de anos de estudo. Para calcular a média de anos de estudo formal, multiplicou-se o número de pessoas em cada intervalo pelo número respectivo de anos de estudo. $\mathrm{O}$ somatório desse resultado foi dividido pelo número total de pessoas. Com isso, foram obtidos os valores de $H$ que aparecem no Apêndice 3, Tabela 3.1. 
Praticamente, a mesma sistemática de cálculo foi utilizada para 1980, com duas diferenças. Em primeiro lugar, o número de pessoas pertencente à classe sem instrução, apresentada no Censo Demográfico de 1970, foi incorporado, nos demais censos (1980 e 1991), em uma outra classe que recebeu a denominação de sem instrução e menos de um ano de estudo. Para homogeneizar os dados dos censos, considerou-se que quem tem menos de um ano de estudo é analfabeto. Portanto, para a classe com menos de um ano de estudo, nos demais censos, multiplicou-se o número de pessoas por zero. Em segundo lugar, no Censo de 1980 está disponível o intervalo de 17 anos ou mais de estudo. Para homogeneizar com o Censo de 1970, considerou-se o limite inferior de 17 anos como sendo representativo deste intervalo.

A sistemática de apresentação dos dados no Censo Demográfico de 1991 muda sensivelmente em relação aos censos anteriores. No Censo de 1991 foram definidos seis intervalos de anos de estudo, a saber: sem instrução e menos de 1 ano, 1 a 3 anos, 4 a 7 anos, 8 a 10 anos, 11 a 14 anos e 15 anos ou mais. Com o propósito de padronizar o Censo Demográfico de 1991 com os censos anteriores, procedeu-se à multiplicação do intervalo sem instrução e menos de um ano de estudo por zero. Nos demais, tomou-se a média. Para o último intervalo, considerou-se o valor de 17 anos de estudos. Com essas adaptações, o cálculo da média de $H$ foi semelhante ao realizado nos outros censos.

Os dados para a proxy $H$ foram coletados junto aos Censos Demográficos de 1970, 1980 e 1991. O complemento da série, ou seja, os dados de $H$ para os anos de 1975, 1985 e 1995/96 foram calculados recorrendo-se à taxa de crescimento exponencial, dada pela fórmula: $V_{A}=V_{O}(1+i)^{n}$. Assim, para calcular o valor de $H$ para 1975, considera-se o $V_{A}$ de 1980 , o $V_{O}$ de 1970 e $n=10$. Substituindo esses valores na fórmula anterior e resolvendo-a para $i$, chega-se ao quanto a educação média estava crescendo ao ano no período de 1970 a 1980 . De posse desse dado, calculou-se a taxa de crescimento acumulada durante cinco anos. Ao multiplicar-se essa taxa pelos valores de 
$H$ de 1970 , obtêm-se, finalmente, os valores de $H$ para 1975. A mesma sistemática de cálculo foi aplicada também para 1985, considerando $V_{A}$ de 1991 e $V_{O}$ de 1980 , com n $=$ 11. Entretanto, surgiu uma complicação quando se foi calcular o vetor coluna $H$ para 1995/96, porque o Censo Demográfico de 2000 ainda não estava disponível. Por essa razão, admitiu-se que a taxa de crescimento dos anos médio de educação de 1990 a 1995 foi a mesma da ocorrida na década anterior. Esses dados de $H$ para cada estado estão no Apêndice 3, Tabela 3.1.

Na construção da variável terra $(T)$, utilizou-se o seguinte critério: somaramse as áreas de lavouras permanentes e temporárias mais as áreas de pastagens naturais e plantadas e, ainda, as áreas de matas e florestas naturais e plantadas. Esses dados foram coletados nos Censos Agropecuário de 1970, 1975, 1980, 1985 e 1995/96 e estão apresentados no Apêndice 3, Tabela 3.1. 


\section{RESULTADOS E DISCUSSÃO}

Este capítulo foi dividido em duas partes. Na primeira, item 4.1, abordam-se as questões gerais relacionadas aos modelos de regressão propostos, tais como os testes de heteroscedasticia, autocorrelação e correlação contemporânea, por exemplo. A segunda parte, item 4.2, por sua vez, foi dividida em três subitens. No subitem 4.2.1, utilizou-se o método ECVH de White para estimar o modelo de regressão neoclássico padrão em que a educação média foi simplesmente adicionada na função de produção. No subitem 4.2.2 foi estimada a equação relacionada ao efeito threshold. A estimativa do modelo de crescimento neoclássico alternativo foi realizada no subitem 4.2.3.

\subsection{Comentários gerais acerca do modelo de regressão e as violações dos seus pressupostos}

O conjunto de dados desse estudo está disposto em múltiplas unidades crosssections e múltiplas unidades de séries de tempo. Os dados dispostos em série de tempo e cross-sections (TSCS) são conhecidos como dados em painel.

Antes de apresentar os resultados das regressões, faz-se necessário testar: i) se a variância do erro é constante. A violação desse pressuposto origina modelos heterocedástico; ii) se o modelo apresenta os resíduos autocorrelacionados entre as séries temporais; e iii) se o modelo apresenta correlação contemporânea. 
Em relação ao problema da autocorrelação dos resíduos, pode-se dizer que ele está mais relacionado aos modelos de séries temporais. Se há autocorrelação é porque os resíduos entre as diferentes séries estão correlacionados. Para se determinar a existência desse problema, no presente estudo, faz-se necessário defasar as variáveis dependentes e independentes. Isto significa que cada estado passará a ter três observações, com os modelos contendo no mínimo quatro parâmetros. Trata-se, portanto, de uma série temporal muito pequena comprometendo, dessa maneira, a realização do Teste de Durbin-Watson.

Em modelos do tipo TSCS, normalmente, aparece o problema de correlação serial, ou contemporânea, ou seja, os erros das iésimas equações estão correlacionadas no tempo. Se existe correlação contemporânea, o ajustamento dos modelos de regressão melhora significativamente quando se leva em conta esse problema. Quando se tem pooling dos dados com esse tipo de problema, é recomendável utilizar o método de estimação conhecido como Parks. Entretanto, a limitação destacada anteriormente impossibilita a utilização desse método de estimação.

O problema da heteroscedasticia é mais comum em modelos cross-sections. Como os modelos de regressão propostos no presente estudo apresentam também essa característica, tornou-se imprescindível verificar a existência ou não de heteroscedasticia.

Existem vários testes para detectar heteroscedasticia, como por exemplo, o Teste de Glesjer, o Teste de Goldfeld-Quandt, o Teste de Breusch-Pagan e o Teste de White, que é equivalente ao Teste de Breusch-Pagan. Optou-se pelo Teste de White devido a sua simplicidade. Esse teste consiste em fazer a regressão dos resíduos ao 
quadrado contra as variáveis independentes, e o produto entre as variáveis ${ }^{60}$. Segundo Greene (1997, p.553), deve-se considerar a distribuição $\chi^{2}$ com graus de liberdade iguais ao número de variáveis independentes.

A Tabela 10 apresenta os resultados do Teste de White para todas as equações estimadas no presente trabalho.

Tabela 10. Teste de heteroscedasticia usando o Teste de White.

\begin{tabular}{|c|c|c|c|c|c|c|c|}
\hline Equação & & Val & r calcul & & & $\begin{array}{l}\text { Valor } \\
\text { crítico do } \\
\chi^{2} \text { tabelado } \\
\text { a } 5 \%\end{array}$ & $\begin{array}{l}\text { Graus de } \\
\text { liberdade }\end{array}$ \\
\hline & Pooling & $\begin{array}{l}1975- \\
1970\end{array}$ & $\begin{array}{l}1980- \\
1970\end{array}$ & $\begin{array}{l}1985- \\
1970\end{array}$ & $\begin{array}{l}1996- \\
1970\end{array}$ & & \\
\hline Equação (53) & 52,084 & 17,132 & 8,503 & 14,773 & 22,642 & 23,685 & 14 \\
\hline Equação (57)** & 82,062 & - & - & - & - & $67,505^{*}$ & 53 \\
\hline Equação (61) & 41,926 & 20,612 & 18,794 & 21,693 & 23,733 & 31,410 & 20 \\
\hline
\end{tabular}

Fonte: dados da pesquisa, valores calculados pelo autor .

* Corresponde ao valor tabelado de 50 graus de liberdade (gl.), já que a Tabela do $\chi^{2}$ não apresenta o valor correspondente a $53 \mathrm{gl}$.

** Para os períodos não foi possível calcular o valor do chi-quadrado porque o número de variáveis (53 variáveis) é maior do que o número de observações em cada período (25 observações).

Pode-se constatar que, a $5 \%$ de significância estatística, as estimativas das três equações com pooling apresentaram problema de heteroscedasticia. $\mathrm{O}$ teste de heteroscedasticia de White evidenciou que, para todos os períodos, tanto o modelo neoclássico tradicional quanto o modelo neoclássico alternativo não apresentaram problema de heteroscedasticia. Contudo, não se pode afirmar com conviç̧ão que esses

${ }^{60}$ Este teste é apresentado em Judge et al. (1988) e a fórmula do teste é:

$$
\sigma_{t}^{2}=h\left(z_{t}^{\prime} \alpha^{\prime}\right)=h\left(\alpha_{1}+z_{t}^{*} \alpha^{*}\right)
$$

onde $h$ é uma função independente de $t, z_{t}^{\prime}=\left(1, z_{t}^{*^{\prime}}\right)=\left(1, z_{t 2}, z_{t 3} \ldots . z_{t S}\right)$ é o vetor de variáveis explicativas e $\alpha^{\prime}=\left(\alpha_{1}, \alpha^{*}\right)=\left(\alpha_{1}, \alpha_{2} \ldots \alpha_{S}\right)$ é um vetor de coeficientes não-conhecidos. 
períodos não são heteroscedásticos, porque o poder do teste de heteroscedasticia diminui significativamente quando o número de observações é reduzido. Os resultados das estimativas por período para os modelos neoclássicos tradicional e alternativo estão no Apêndice $4^{61}$.

Qual o problema quando se estima por mínimos quadrados uma regressão na presença de heteroscedasticia? Em uma regressão múltipla com esse problema, o estimador continua sendo linear e não-viesado, mas deixa de ser eficiente, ou seja, a variância não é mais mínima, ela pode apresentar viés positivo ou negativo. A implicação disso para a regressão é que o intervalo de confiança gerado por um modelo heterocedástico pode ser maior ou menor do que o obtido por uma regressão homoscedástica. Como conseqüência, a variância resultante é incorreta e o teste estatístico baseado não é válido. Em outras palavras, o resultado da regressão pode gerar parâmetros não-significativos, quando de fato eles o são, ou vice-versa ${ }^{62}$.

Como provavelmente a heteroscedasticia está presente nas regressões estimadas, conforme Tabela 10, a estimação das respectivas equações pelo método OLS representaria viés na significância estatísticas dos parâmetros. Por essa razão, utiliza-se o ECVH de White para a estimação dessas três equações especificadas no presente estudo.

\subsection{Análise dos resultados das regressões}

No item 4.2.1 estão os resultados das estimativas da equação (53). No item 4.2.2 está o resultado da estimativa da equação (57). Finalmente, o item 4.2.3 apresenta o resultado da estimativạa da equação (61).

\footnotetext{
${ }^{61}$ A explicação do motivo dessas regressões estarem em apêndices está no item 5.2.

${ }^{62}$ Baseado em Judge et al. (1988, p.356 a 358).
} 


\subsubsection{Os resultados da estimação do modelo neoclássico tradicional}

Na Tabela 11 estão os resultados da estimação da equação (53). Conforme se pode verificar, a regressão, com os dados em pooling, apresenta $\mathrm{R}^{2}$ igual a 0,668 , o que significa dizer que o conjunto de variáveis independentes explica, aproximadamente, $67 \%$ da variação do valor bruto da produção agropecuária brasileira. Os dados das estimações para cada período, tendo como base o ano de 1970, estão na Tabela 4.1, no Apêndice 4. A opção por apresentar ao leitor somente os dados relativos à estimação em pooling deve-se ao fato de que essa regressão, por ter maior grau de liberdade, apresentou melhor ajustamento dos parâmetros.

Tabela 11. Resultados da estimativa da equação de regressão (53) ajustada pelo método ECVH de White.

\begin{tabular}{ccc}
\hline Parâmetro & Coeficiente & Estatística $t$ \\
\hline Progresso tecnológico $\left(A_{t}^{*}\right)$ & $0,180^{\mathrm{b}}$ & 2,237 \\
Capital $\left(\delta_{K}\right)$ & $0,059^{\mathrm{f}}$ & 1,186 \\
Trabalho $\left(\delta_{L}\right)$ & $0,337^{\mathrm{c}}$ & 1,891 \\
Terra $\left(\delta_{T}\right)$ & $0,198^{\mathrm{NS}}$ & 0,845 \\
Capital humano $\left(\delta_{H}\right)$ & $0,413^{\mathrm{a}}$ & 6,787 \\
$\mathrm{R}^{2}$ & 0,668 & \\
\hline
\end{tabular}

Fonte: Valores calculados usando dados da Tabela 3.2 (Apêndice 3). Os sobreíndices a, b, c e f indicam que os parâmetros são significativos a até $1 \%, 5 \%, 10 \%$ e $25 \%$ de probabilidade, respectivamente. NS indica o parâmetro ser não-significativo estatisticamente.

O parâmetro $A_{t}^{*}$, na equação (53), relacionado ao progresso técnico, foi significativo a $5 \%$ e apresentou efeito positivo sobre a taxa de crescimento do valor bruto da produção. A magnitude encontrada deste parâmetro, igual a 0,180 , é bem inferior à elasticidade de 0,44 encontrada por Lau et al. (1993) para o crescimento da economia brasileira. Isto pode estar sinalizando que o papel do progresso técnico na economia brasileira como um todo foi mais expressivo do que o verificado na agropecuária brasileira. 
Pode-se perceber que o efeito apresentado pelo capital humano sobre a taxa de crescimento do valor da produção é estatisticamente diferente de zero a $1 \%$ e com o sinal positivo, como esperado. Isto indica que um ano adicional de educação média deve incrementar a taxa de crescimento do valor da produção em aproximadamente 0,41 , ou seja, em 41 pontos percentuais. A magnitude do parâmetro $\delta_{H}$ na regressão estimada superou bastante a elasticidade de 0,21 encontrada por Lau et al. (1993), para a economia brasileira. Esse resultado é interessante porque sugere que o papel da educação foi estatisticamente mais significativo na agropecuária do que na economia brasileira como um todo.

A estimativa do parâmetro $\delta_{K}$, associada ao fator $K$ foi baixa, conforme se pode verificar na Tabela 11 . O ajustamento da equação (53) resultou em elasticidade de 0,059, mas com sinal positivo como era esperado. Este resultado está coerente com os obtidos por Lau- et al. (1993), cuja elasticidade de produção em relação ao capital foi de 0,098 .

Uma explicação que talvez ajude a entender a reduzida magnitude do parâmetro $\delta_{K}$ relaciona-se à proxy usada potência dos tratores (medida em número de cavalos). A forma como foi construída essa variável deve ter subestimado o peso real do capital. A proxy mais aconselhável seria o valor dos bens, mas, infelizmente, o Censo Agropecuário não publicou o seu valor em 1995/96. Isto inviabilizou a utilização dos valores dos bens como medida de $K$ no presente estudo.

Observa-se também que o parâmetro $\delta_{L}$, associado à variável $L$, apresentouse estatisticamente diferente de zero a $10 \%$. O sinal positivo está coerente, pois, se esperava que quanto maior fosse a quantidade de força de trabalho empregada no processo produtivo maior seria a taxa de crescimento do valor da produção. A magnitude da elasticidade dos coeficientes de $L$ é 0,337 , como se pode ver na Tabela 11 . Isso significa que se a taxa de crescimento da mão-de-obra aumentar em 1\%, a taxa de crescimento do valor da produção irá aumentar em aproximadamente 0,34\%. Essa 
estimativa de $L$ é um pouco inferior à elasticidade de 0,42 obtida por Lau. et al. (1993), para essa variável na economia brasileira.

O parâmetro relativo à variável terra, $\delta_{T}$, não é estatisticamente significativo, conforme a Tabela 11. Esse dado está sinalizando que a variação na taxa de crescimento do valor da produção, ao longo do período analisado, não está estatisticamente relacionada à expansão da área produtiva do setor agropecuário. Esse resultado deve estar sendo influenciado pelo fato de que, na maioria dos estados do Brasil, o incremento na produção, no período de 1985 a 1995, foi acompanhado de redução da área explorada (ver tabela 3.1 no apêndice 3).

\subsubsection{Os resultados da estimação do efeito threshold da educação média na agropecuária brasileira}

No trabalho Lau et al. (1993, p.59-61) foi diagnosticada a existência de um nível de threshold da educação média entre três e quatro anos na economia brasileira. A existência desse efeito no Brasil fez despertar o interesse dessa pesquisa. A preocupação em diagnosticar a existência do efeito threshold justifica-se devido à magnitude do parâmetro $\delta_{H}$ de aproximadamente 0,41 , apresentado no tópico anterior. Conforme já argumentado, a existência do efeito threshold irá manifestar-se através da significância de alguns coeficientes associados às variáveis definidas na equação (57).

Observando a Tabela 12, pode-se constatar que ao desagregar o capital humano em seis estratos, três parâmetros $\left(\delta_{H 1}, \delta_{H 2}\right.$ e $\left.\delta_{H 3}\right)$ apresentam-se altamente significativos em até $1 \%$; enquanto $\delta_{H 5}$ é estatisticamente diferente de zero somente a 0,25 . Os outros dois parâmetros, $\delta_{H 4}$ e $\delta_{H 6}$, apesar de apresentarem os sinais positivos, como esperado, não se apresentaram estatisticamente significativos.

De acordo com Lau et al. (1993, p.60), se há efeito threshold da educação média, então, o incremento do número médio de anos de estudo irá refletir-se, 
primeiramente, em aumento da magnitude dos coeficientes estimados, e posteriormente, quando se atingir um determinado nível médio de educação, as magnitudes dos demais parâmetros deverão cair. Isto é, a inclinação do produto com relação ao número de anos de educação aumentará entre três e quatro anos e os demais intervalos de anos de estudo não seriam significativos. Observa-se que as estimativas dos parâmetros não é compatível com a definição do efeito threshold, vista anteriormente. Os resultados deste estudo sinalizam que, ao invés de ter-se apenas um nível crítico, têm-se três, demonstrando que o papel do capital humano se distribui por diversas classes. $\mathrm{O}$ efeito da educação apresentou-se significativo logo nos três intervalos iniciais, ao passo que se existisse o efeito threshold ele deveria ocorre em apenas um certo intervalo. Portanto, não existem indícios de que a educação média brasileira tenha atravessado um nível crítico de threshold. Entretanto, Lau et al. (1993) avaliaram que a magnitude do parâmetro associado ao capital humano para a economia brasileira de 0,208 era relativamente alta. Os autores esperavam magnitude próxima a 0,05 . A magnitude de $\delta_{H}$ de aproximadamente 0,41 , estimada para a agropecuária, pode ser considerada muito elevada frente ao que foi estimado para toda a economia brasileira. Isso permite inferir que o estoque de capital humano na agropecuária brasileira é tão baixo que um ano médio de escolaridade, não importando o intervalo de anos de estudo, tem impactos muito significativos sobre o valor da produção.

No longo prazo, é esperado que o efeito marginal da educação média no setor agropecuário amorteça e se aproxime mais do nível estimado para a economia brasileira. Isso irá ocorrer quando a escolaridade no setor rural atingir um determinado nível mínimo de educação mínima capaz de permitir ao produtor rural não apenas o desempenho do seu trabalho em um sistema agropecuário com tecnologia moderna, mas também com conhecimento razoável do funcionamento dos mercados, e das flutuações de preços dos produtos e insumos. 
Ao desagregar a educação média em intervalos pré-determinados e reestimar a regressão, conforme Tabela 12, foi possível constatar que o parâmetro $\delta_{T}$, que na equação estimada sem o efeito threshold não fora estatisticamente diferente de zero, tornou-se estatisticamente significativo a $25 \%$ e com a elasticidade de 0,297. Contudo, houve diminuição no nível de significância estatística do parâmetro $\delta_{L}$, que na equação (53) era diferente de zero a $10 \%$ e apresentou-se nessa regressão significativo a $20 \%$.

Tabela 12. Resultado do ajustamento da equação (57) usando o método ECVH de White.

\begin{tabular}{ccr}
\hline Parâmetro & Coeficiente & Estatística t \\
\hline Progresso tecnológico $\left(A_{t}^{*}\right)$ & $0,131^{\mathrm{b}}$ & 1,798 \\
Capital $\left(\delta_{K}\right)$ & $0,060^{\mathrm{e}}$ & 1,268 \\
Trabalho $\left(\delta_{L}\right)$ & $0,267^{\mathrm{e}}$ & 1,401 \\
Terra $\left(\delta_{T}\right)$ & $0,297^{\mathrm{f}}$ & 1,227 \\
Até 1 ano de escolaridade $\left(\delta_{H 1}\right)$ & $0,632^{\mathrm{a}}$ & 5,600 \\
De 1 a 2 anos de escolaridade $\left(\delta_{H 2}\right)$ & $0,286^{\mathrm{a}}$ & 3,106 \\
De 2 a 3 anos de escolaridade $\left(\delta_{H 3}\right)$ & $0,632^{\mathrm{a}}$ & 5,417 \\
De 3 a 4 anos de escolaridade $\left(\delta_{H 4}\right)$ & $0.115^{\mathrm{NS}}$ & 0,814 \\
De 4 a 5 anos de escolaridade $\left(\delta_{H 5}\right)$ & $0,684^{\mathrm{f}}$ & 1,212 \\
De 5 a 6 anos de escolaridade $\left(\delta_{H 6}\right)$ & $0,174^{\mathrm{NS}}$ & 0,131 \\
$\mathrm{R}^{2}$ & 0,685 & \\
\hline
\end{tabular}

Fonte: Valores calculados usando os dados da Tabela 3.3 (Apêndice 3). Os sobreíndices a, b, e, e findicam que os parâmetros são significativos a até $1 \%, 5 \%, 20 \%$ e $25 \%$ de probabilidade, respectivamente.

Em relação ao parâmetro $\delta_{K}$, pode-se constatar que a magnitude desse parâmetro não difere estatisticamente em ambas as regressões estimadas, equações (53) e (57). Entretanto, o ajustamento da variável capital através da equação (57) melhorou estatisticamente a significância desse parâmetro. Para o parâmetro $A_{t}^{*}$ que capta o progresso técnico exógeno, não houve mudanças significativas em termos estatísticos. De modo geral, pode-se dizer que o ajustamento dos dados através da equação (57) melhorou, de forma muito tênue, as estimativas dos parâmetros. 


\subsubsection{Os resultados da estimação do modelo de crescimento neoclássico alternativo}

O efeito exógeno do capital humano, representado na equação (61) pelo termo $C_{H}$, não foi estatisticamente significativo - conforme Tabela 13. Era esperado que o parâmetro $C_{H}$ apresentasse sinal positivo e fosse significativo. Como a estimativa da equação (61) não conseguiu captar o efeito exógeno do capital humano, a interpretação que poderia ser dada é a de que os avanços tecnológicos, desenvolvidos pelo capital humano nos demais setores da economia, não se apresentaram significativos em termos estatísticos para a agropecuária brasileira. Entretanto, este resultado é surpreendente, pois a agropecuária brasileira pertence a um complexo agro-industrial no qual acreditava-se que a maior parte da sua dinâmica econômica estaria sendo determinada pelos setores industrial e financeiro.

O termo catch-up estimado na regressão (61) apresentou efeito positivo sobre o crescimento do valor bruto da produção. Contudo, o parâmetro $\delta_{H C}$ aponta de forma muito tênue para a hipótese da difusão tecnológica em termos agregados na agropecuária brasileira, ou seja, há pouco indício de que tenha ocorrido efeito catch-up, devido ao baixo nível de significância estatística desse parâmetro e a sua reduzida magnitude. Por trás desse raciocínio, pode estar embutida a seguinte idéia: não ocorrendo diminuição do hiato de produção entre os iésimos estados e o estado mais desenvolvido, não estaria havendo transferência de tecnologia de São Paulo para o resto dos estados. Cabe ressaltar que este resultado não exclui a possibilidade de transferência de tecnologia de São Paulo para os demais estados em alguns produtos específicos como por exemplo, o algodão, a soja, o café. Ele apenas sinaliza que em termos agregados o modelo não conseguiu captar a difusão de tecnologia. 
Várias razões podem ter influenciado para que o efeito catch-up não fosse captado pela regressão. Uma delas é a já comentada proxy do capital que pode não estar refletindo, em toda a sua extensão, o verdadeiro montante de capital existente no setor agropecuário brasileiro. A outra é talvez a mais provável. É possível que em termos agregados realmente não tenha ocorrido efeito catch-up na agropecuária brasileira. Esse resultado acaba reforçando aquele apresentado no Capítulo 2, item 2.2, onde foi mostrado que a distribuição regional do valor da produção per capita vem piorando ao longo dos anos. Esse resultado contrapõe-se ao $-0,743$ obtido por Gonçalves et al. (1998) para toda a economia brasileira, quando os autores puderam confirmar a hipótese de difusão tecnológica. ${ }^{63}$

Tabela 13. Coeficientes da equação (61) usando o método ECVH de White.

\begin{tabular}{|c|c|c|}
\hline Parâmetro & Coeficientes* & Estatística $t$ \\
\hline Capital humano exógeno $\left(C_{H}\right)$ & $(0,015)^{\mathrm{NS}}$ & $(0,147)$ \\
\hline Capital humano endógeno $\left(\delta_{H}\right)$ & $0,196^{\mathrm{a}}$ & 3,680 \\
\hline Catch-up $\left(\delta_{H C}\right)$ & $0,0004^{\mathrm{NS}}$ & 1,132 \\
\hline Capital $\left(\delta_{K}\right)$ & $0,223^{\mathrm{a}}$ & 3,874 \\
\hline Trabalho $\left(\delta_{L}\right)$ & $0,173^{\mathrm{NS}}$ & 0,904 \\
\hline \multirow[t]{2}{*}{ Terra $\left(\delta_{T}\right)$} & $0,259^{\mathrm{NS}}$ & 1,009 \\
\hline & 0,510 & \\
\hline
\end{tabular}

Fonte: Valores calculados usando os dados da Tabela 3.4 (Apêndice 3). $\mathrm{O}$ sobreíndice a indica significativo a até $1 \%$, de probabilidade, e NS não significativo. ${ }^{*}$ Os valores entre parênteses indicam que o número é negativo.

Ao interpretar a equação (27), argumentou-se que no longo prazo o Estado de São Paulo deveria ser a esteira do desenvolvimento e, através do spillover efects, puxar o crescimento dos demais estados. Como o efeito catch-up apresentou pouca significância estatística (ver tabela 13), a explicação teórica, conforme argumentado

${ }^{63} \mathrm{O}$ valor encontrado por Gonçalves et al. é negativo devido, possivelmente, à forma como os autores construíram a variável catch-up, isto é $Y i / Y^{m a x}$, ao passo que a utilizada aqui foi $Y^{m a x} / Y^{i}$. 
anteriormente, para esse fato decorre do pressuposto de que os estados que estão muito próximos da fronteira tecnológica, com elevado nível de $H$, poderão obter taxas de crescimento menores do que aquelas obtidas por São Paulo (estado líder), isto porque o efeito catch-up é insignificante. Desse modo, é possível concluir, a partir desse aporte teórico, que só não haverá o mencionado efeito, se o hiato entre o valor da produção dos iésimos estados for mantido no mesmo nível, ou aumentado ao longo do período analisado. Neste caso, $\delta_{H L}>\delta_{H i}$. Essa inequação satisfaz a condição de que o termo $\left(\delta_{H i}\left(H_{i}\right)-\delta_{H C}\left(H_{i}\right)-\delta_{H L}\left(H_{L}^{t}\right)\right)$ deveria ser menor que zero. De posse da equação (27) ${ }^{64}$, pode-se observar que dependendo do grau de difusão de tecnologia dada por $\delta_{H C}$ e do crescimento de $\delta_{H L}$, deduz-se que o hiato entre os níveis do valor da produção dos iésimos estados e o estado líder deve-se manter sem muitas alterações ao longo do período analisado, ou mesmo aumentar se $\delta_{H C}$ tender a zero.

O outro caso ocorre quando, por exemplo, os estados distantes tecnologicamente do estado líder obtêm taxa de crescimento maior do que a alcançada por aquele estado, ou seja, $\delta_{H i}>\delta_{H L}$. Isso é possível em razão da difusão da tecnologia que foi incorporada pelos iésimos estados. Desse modo, admite-se $\delta_{H C}>\left(\delta_{H i}-\delta_{H L}\right)^{65}$. Neste caso, o hiato tecnológico entre os demais estados e o estado líder estaria diminuindo devido ao efeito catch-up, e ele deveria apresentar parâmetro significativo estatisticamente na regressão estimada.

Entretanto, no presente caso, o parâmetro associado ao catch-up não foi significativo. Isso sinaliza que o incremento de tecnologia no estado líder, ou nos estados que estão próximos da fronteira tecnológica, não está sendo difundido para os demais estados. A explicação que poderia ser dada para isso é a seguinte: os trabalhadores e

${ }^{64} \lim _{t \rightarrow \infty} \frac{A_{t}^{i}}{A_{t}^{\max }}=\frac{\delta_{H C}\left(H_{i}\right)}{\left(\delta_{H C}\left(H_{i}\right)-\delta_{H i}\left(H_{i}\right)+\delta_{H L}\left(H_{t}^{L}\right)\right)}$

${ }^{65}$ Vários autores, como por exemplo, Frantzen (2000), têm argumentado que a difusão tecnológica é mais importante para o crescimento da produtividade dos fatores do que o esforço de pesquisa doméstico. 
empresários agrícolas dos iésimos estados que estão mais distantes da fronteira tecnológica - por possuírem um nível muito baixo de capital humano - tendem a resistir à incorporação de novas técnicas de produção ou de novos equipamentos. Como já comentado, quanto menor o nível de educação do produtor rural, mais resistente ele estaria na adoção e implementação de pacotes tecnológicos. Talvez, esse fato e a própria cultura do produtor rural brasileiro ajude a explicar a não significância do parâmetro $\delta_{H C}$.

A interação do conhecimento do produtor rural, juntamente com as informações que recebem dos órgãos de pesquisa do próprio estado, com as informações recebidas de outros estados determina o grau de desenvolvimento do setor em cada estado. O coeficiente do capital humano responsável pelo efeito endógeno do capital humano, $\delta_{H}$ (cujo valor estimado é de 0,196 , significativo a $1 \%$ e com o sinal positivo), apenas confirma aquela idéia intuitiva de que o grau de instrução do produtor rural é, realmente, o fator diferenciador do desenvolvimento do setor agropecuário nos estados. Dessa maneira, a estimação da regressão dada pela equação (61), apesar de não ter captado de forma significativa o efeito catch-up, revelou que o capital humano endogenamente desempenhou um papel ativo na determinação da taxa de crescimento do valor da produção agropecuária. $\mathrm{O}$ efeito endógeno do capital humano materializa-se na capacidade dos produtores - nos iésimos estados - em promoverem inovações endógenas nos seus sistemas de produção.

Os parâmetros referentes às variáveis $L$ e $T$ apresentam sinais positivos como esperado, mas não são estatisticamente significativos. Em relação ao parâmetro $\delta_{L}$, o resultado apresentado na Tabela 13 contrapõe-se às estimativas obtidas pelas duas regressões anteriores (53) e (57).

Para o parâmetro $\delta_{K}$, relativo ao capital, o sinal positivo está coerente com o processo de modernização da agricultura no período analisado. Trata-se de um período em que a agropecuária brasileira passou a utilizar intensivamente os insumos modernos e 
o estoque de máquinas aumentou substancialmente, conforme apresentado na Tabela 7. A magnitude desse parâmetro, igual a 0,223 , é bem superior aos 0,059 do modelo neoclássico tradicional, maior do que a elasticidade de 0,167 obtida por Gonçalves et al. (1998) para a economia brasileira como um todo. Não se encontrou uma explicação plausível do porque as estimativas do capital foram tão distintas em ambos os modelos neoclássicos. 


\section{CONCLUSÕES}

O presente trabalho teve como propósito avaliar a contribuição do capital humano na formação do produto agropecuário brasileiro no período de 1970 a 1996. Para isso, estimaram-se várias equações de funções de produção, tanto sob a ótica neoclássica padrão quanto sob a perspectiva alternativa. A participação do capital humano, sob a perspectiva neoclássica tradicional, foi estudada a partir do nível de educação média $(H)$ da força de trabalho agrícola nos estados brasileiros. Enquanto sob a perspectiva do modelo neoclássico alternativo, duas variáveis estiveram relacionadas ao capital humano. Além de $H$, o modelo foi especificado também com a variável que capta a difusão tecnológica definida como catch-up.

Procurou-se inicialmente avaliar o desenvolvimento desigual que ocorreu na agropecuária entre os estados. Verificou-se que a maioria dos estados apresentou taxa de crescimento exponencial elevada de produtividade do trabalho. Com base apenas nesta variável, ficou difícil imaginar quão gritante era a diferença econômica do setor agropecuário brasileiro entre os estados. Para dar ao leitor uma visão mais acurada dos desequilíbrios regionais, foi mostrado que um trabalhador rural médio, por exemplo, em São Paulo e Mato Grosso gera um valor da produção dez vezes maior do que a média dos trabalhadores das Regiões do Norte e Nordeste.

Um indicador que chama atenção relaciona-se ao crescimento do processo de intensificação do uso de capital na agropecuária brasileira, no período de 1970 a 1995/96. A relação $K / L$ vem crescendo praticamente em todos os estados brasileiros. Em alguns estados tal crescimento foi mais intenso, casos típicos de Acre, Roraima, 
Maranhão, Paraná, Santa Catarina e Mato Grosso, com variação anual superior a 10\% no período de 1970 a 1995/96.

As estatísticas dos níveis de educação média na economia brasileira e na agricultura, especificamente, revelam um quadro de forte desequilíbrio. A população rural, em 1970, era em grande parcela analfabeta. No período compreendido entre 1970 a 1991, verificou-se uma tendência de crescimento da escolaridade média no setor rural e de diminuição de sua diferença em relação à média brasileira.

Parcela do nível de desenvolvimento da agropecuária dos estados brasileiros está relacionada às habilidades e conhecimento médio dos seus trabalhadores e dos seus empresários. Dessa maneira, pode-se argumentar que quanto maior o estoque médio conhecimento dos trabalhadores rurais e dos pequenos e médios empresários agropecuaristas, maior serão os seus níveis de abstração e mais dinâmicos eles se tornam, tanto no aprendizado e no desenvolvimento das tarefas quanto na tomada de decisões de investimentos e na realocação de recursos frente às mudanças conjunturais.

Duas abordagens teóricas foram consideradas para analisar o papel do capital humano no crescimento econômico. Com base na teoria neoclássica padrão, especificouse a forma funcional Cobb-Douglas tradicional aumentada ${ }^{66}$. A equação derivada dessa função foi ajustada pelo método OLS com o estimador consistente de variância levando em consideração a heteroscedasticia (estimador de White). Essa mesma equação foi remodelada para permitir a estimação do efeito threshold.

Os resultados do ajustamento do modelo de regressão neoclássico tradicional revelaram que o capital humano teve efeito altamente significativo, em termos estatísticos, e positivo sobre a taxa de crescimento do valor da produção agropecuária. Além disso, o incremento no valor da produção está positivamente relacionado com o progresso técnico e com o incremento no uso de trabalho e do capital físico.

\footnotetext{
${ }^{66}$ Recebe essa denominação porque o capital humano foi simplesmente adicionado à essa função.
} 
Ao ajustar o modelo neoclássico tradicional para captar o efeito threshold, as regressões não apontaram indícios de a agropecuária brasileira ter experimentado tal efeito. Os parâmetros associados aos primeiros três intervalos de anos de estudos apresentaram-se altamente significativos. Como o estoque de educação no setor rural era muito baixo, o incremento de um ano de escolaridade médio resultou em impactos significativos sobre o valor da produção. A tendência de longo prazo é que o efeito da educação amorteça e se aproxime daquele verificado para o conjunto da economia brasileira. Isso irá ocorrer quando o setor agropecuário atingir um determinado nível mínimo de escolaridade compatível com o desempenho das funções dos trabalhadores rurais em um setor agropecuário moderno. Nessa situação o produtor rural terá noções mínimas acerca do comportamento do mercado e das flutuações de preços dos insumos e dos produtos.

O ajustamento da regressão neoclássica alternativa permite avaliar a importância do capital humano através de três variáveis. Em primeiro lugar, o efeito exógeno do capital humano sobre o crescimento do valor da produção. $\mathrm{O}$ parâmetro associado a esta variável não foi estatisticamente significativo. Em segundo lugar, através de uma variável atrelada à capacidade de um estado inovar domesticamente, captada na regressão através do parâmetro $\delta_{H}$. Ela é altamente significativa e tem sinal positivo, como esperado. Em terceiro lugar, por meio da variável associada à difusão de tecnologia, a qual apresentou efeito positivo sobre a taxa de crescimento do valor da produção. Entretanto, a estimativa do parâmetro relacionado a esta variável ficou comprometida, na regressão, devido a sua pouca significância e à magnitude do seu parâmetro (muito próxima de zero). Os resultados da regressão apontaram também que o capital teve efeito significativo e positivo sobre a taxa de crescimento do valor da produção, ao passo que os parâmetros relacionados às variáveis terra e trabalho não se apresentaram significativos. Este último resultado deve ser associado ao fato da terra não ter sido estatisticamente significativa na regressão referente ao modelo neoclássico tradicional, e o fator trabalho apresentar pequena significância estatística nos dois 
modelos anteriores. Isto prova que a expansão extensiva da agropecuária perdeu importância no período analisado no presente trabalho.

Os resultados das regressões, tanto no modelo neoclássico padrão como o alternativo, confirmam o papel positivo do capital humano sobre o crescimento do valor bruto da produção. Entretanto, o modelo neoclássico alternativo não conseguiu captar a difusão de tecnologia entre os estados brasileiros, o que poderia levar em longo prazo a um processo de convergência, ou de catch-up, entre as taxas de crescimentos do valor bruto da produção agropecuária entre os estados.

Em termos gerais, o ajustamento do modelo neoclássico padrão parece melhor do que o obtido pelo modelo neoclássico alternativo. A única exceção está relacionada à variável $K$, com maior elasticidade e nível de significância estatística no modelo alternativo.

A maior importância do capital humano em relação ao capital físico (conforme os resultados do modelo neoclássico padrão) em explicar o crescimento do produto agropecuário no período de 1970 a 1996 permite, ex post, uma reflexão crítica sobre a política agrícola executada desde 1970. Esta política enfatiza a modernização agropecuária por meio do uso de insumos modernos, muitas vezes materializados em maquinaria. Pouca atenção foi dada à melhoria do nível educacional do trabalhador rural. No entanto, o resultado acima permite sugerir, a partir de agora, uma maior atenção das políticas públicas na formação de recursos humanos no setor agropecuário.

Como sempre acontece em estudos que utilizam modelos econométricos, os resultados devem ser interpretados com cautela. Além dessa limitação de ordem geral, outras limitações existem neste estudo. Entre elas, destacam-se: i) a proxy do capital utilizada - conforme argumentado em diversas oportunidades - talvez tenha subestimado o verdadeiro estoque do capital; ii) a incorporação da variável infraestrutura nos modelos econométricos poderá contribuir para o melhor ajustamento dos 
parâmetros; e iii) a pequena série temporal impossibilitou a utilização do método Parks, que levaria em conta a possível correlação contemporânea entre os erros.

À medida que novos dados sejam disponibilizados, futuros trabalhos podem ser realizados de modo a superar as deficiências acima mencionadas. Somente assim, os resultados desta pesquisa poderão ser confrontados com os obtidos no futuro. 


\section{REFERÊNCIAS BIBLIOGRÁFICAS}

AGHION, P.; HOWITT, P. A model of growth through creative destruction. Econometrica, v.60, n.2, p.323-351, 1992.

AHMAD, S. On the induced invention. Economic Journal, v.76, n.302, p.344-57, 1966.

ARNADE, C. A. Productivity and technical change in brazilian agriculture. New York: US Department of Agriculture. Economic Research Service, 1992b. (Technical Bulletin Number, n.1811)

ARROW, K. J. The economic implications of learning by doing. Review of Economic Studies, v.29, p.155-173, 1962.

ÁVILA, A. F. D.; EVENSON, R. E. Total factor productivity growth in the brazilian agriculture and the role of agricultural research. In: CONGRESSO BRASILEIRO DE ECONOMIA E SOCIOLOGIA RURAL, 33., Curitiba, 1995. Anais. Brasília: SOBER, 1995. p.631-657.

BACHA, C. J. C. Alguns aspectos dos modelos de análise dos impactos de mudança tecnológica no comportamento do setor agrícola. Revista de Economia e Sociologia Rural, v.30, n.1, p.41-62, jan./mar.1992. 
BACHA, C. J. C.; ROCHA, M. T. O comportamento da agropecuária brasileira, no período de 1987 a 1996. Revista de Economia e Sociologia Rural, v.36, n.1, p.3559, jan./mar.1998.

BARBOSA, F. H. Microeconomia: teoria, modelos econométricos e aplicações à economia brasileira. Rio de Janeiro: IPEA/INPES, 1985. 556p.

BARRETO, F.; SCHYMURA, L. G. Aplicação de um modelo de gerações superpostas para a reforma da previdência no Brasil: uma análise de sensibilidade no estado estacionário. In: ENCONTRO NACIONAL DE ECONOMETRIA, 17., Bahia. Anais. Rio de Janeiro: SBE, 1995. p.75-91.

BARRO, R. Economic growth in a cross-section of countries. Quartely Journal of Economics, v.106, n.2, p.407-433, 1991.

BARRO, R.; SALA-I-MARTIN, X. Convergence acros states and regions. In: CUKIERMAM, A. et al. (Ed.). Political economy, growth, and business cycle. Cambridge: MIT Press, 1992.

BARRO, R.; SALA-I-MARTIN, X. Convergence. Journal of Political Economy, v.100, n.2, p.222-251, $1992 b$.

BARRO, R.; SALA-I-MARTIN, X. Economic growth. New York: McGraw-Hill, 1995. 539p. (Advanced Series in Economics)

BARROS, A. L. M. Capital, produtividade e crescimento da agricultura: o Brasil de 1970 a 1995. Piracicaba, 1999. 149p. Tese (Doutorado) -- Universidade de São Paulo, Escola Superior de Agricultura "Luiz de Queiroz".

BARROS, J. R. M. Política e desenvolvimento agrícola no Brasil. In: VEIGA, A. (Coord.) Ensaios sobre política agrícola brasileira. São Paulo: Secretaria da Agricultura, 1979. p.9-36. 
BARROS, J. R. M.; GRAHAM, D. H. A agricultura brasileira e o problema da produção de álimentos. Pesquisa e Planejamento Econômico, v.8, n.3, p.695-726, 1978.

BARROS, R. P. ; MENDONÇA, R. S. P. de ; DUARTE, R. P. N. Bem-estar, pobreza e desigualdade de renda: uma avaliação da evolução histórica e das disparidades regionais. Rio de Janeiro: IPEA, 1997. 60p. ( Texto para Discussão, n.454)

BEATTIE, B. R; TAYLOR, C. R. The economics of production. New York: John Wiley \& Sons, 1985. 258p.

BECKER, G. S. Human capital. Chicago: The University of Chicago Press, 1993. 390 p.

BENHABIB, J; SPIEGEL, M. The hole of human capital in economic development, evidence from aggregate cross-country data. Journal of Monetary Economics, v.34, p.143-173, 1994.

BRONSON, R. Moderna introdução às equações diferenciais. São Paulo: McGrawHill do Brasil, 1977. 387p.

BUENO, N. P. A nova teoria neoclássica do crescimento e o problema do subdesenvolvimento econômico brasileiro. Revista Brasileira de Economia, v.18, n.2, p.5-19, abril/jun.1998.

CASHIN, P. Economic growth and convergence across the seven colonies of Australasia: 1861- 1991. The Economic Record, v.71, n.213, p.132-144, June 1995.

CHAMBERS, R. G. Applied production analysis: a dual approach. New York: Cambridge University Press, 1988. 330p. 
CHAMLEY, C. The last shall be first: eficient constraints on foreign borrowing in a model of endogenous growth. Journal of Economic Theory, v.58, p.335-354, 1992.

DIAS, R. S. Mudança tecnológica e viés de produção na agropecuária brasileira - 1970 a 1985. Piracicaba, 1998. 128p. Tese (Doutorado), Universidade de São Paulo, Escola Superior de Agricultura "Luiz de Queiroz".

DIAS, R. S.; BACHA, C. J. C. Produtividade e progresso tecnológico na agricultura brasileira: 1970-1985. In: CONGRESSO BRASILEIRO DE ECONOMIA E SOCIOLOGIA RURAL, 36., Poços de Caldas, 1998. Anais. Brasília: SOBER, 1998. p.211-221.

DOWRICK, S.; NGUYEN, D. T. OECD comparative economic growth 1950-85: catchup and convergence. The American Economic Review, v.79, n.5, p.1011-1029, 1989.

DRYSDALE, P.; HUANG, Y. Technological catch-up and economic growth in East Asia and the Pacific. The Economic Record, v.73, n.222, p.201-211, Sep.1997.

FAGERBERG, J. Convergence or divergence? The impact of technology on "why growth rates differ”, Journal Evolucionary Economic, v.5, p.269-284, 1995

ELLERY JUNIOR, R. G. Aprendizado prático e nível de escolaridade. Brasília: IPEA, 1999. 18p. (Texto para discussão, n.661)

ENGELBRECHT, H. J. International R\&D spillovers, human capital and produtivity in OECD economies: an empirical investigation. European Economic Review, v.41, p.1479-1488, 1997.

ENGLER, J. J. C. O capital humano numa função de produção da agricultura de São Paulo. Pesquisa e Planejamento Econômico, v.9, n.3, p.845-884, 1979. 
FERREIRA FILHO, J. B. S. Notas a respeito do desempenho agregado da agricultura brasileira no período 1980-1991. Revista de Economia e Sociologia Rural, v.32, n.3, p.225-235, jul./set.1994.

FERREIRA, P. C. G.; ELLERY JR. Convergência entre a renda per-capita dos estados brasileiros. Revista de Econometria, v.16, n.1, p.83-103, abril 1996.

FISCHER, S.; BLANCHARD, J. O. Lectures on macroeconomics. 7.ed. London: MIT Press, 1993. 650p.

FONSECA, E. G. O capital humano na filosofia social de Marshall. Revista de Economia Política, v.12, n.2, p.65-87, abril/jun.1992.

FRANTZEN, D. Innovation, international technological diffusion and the changing influence of R\&D on productivity. Cambridge Journal of Economics, v.24, p.193$210,2000$.

GALOR, O. Convergence ? Inferences from theorical models. The Economic Journal, v.106, p.1056-1069, July 1996.

GASQUES, J. G.; CONCEIÇÃO, J. C. P. R. Crescimento da produtividade da agricultura brasileira. Brasília: IPEA, 1997. 21p. (Texto para Discussão, n.520)

GASQUES, J. G.; CONCEIÇÃO, J. C. P. R. Produtividade da agricultura brasileira. In. AGUIAR, D. R. D.; PINHO, J. B. Agronegócio brasileiro: desafios e perspectivas. Brasília: SOBER, 1998. v.2: p.425-437.

GASQUEZ, J.G.; VILLA VERDE, C. M. Crescimento da agricultura brasileira e política agrícola nos anos oitenta. Brasília: IPEA, 1990. 22p. (Texto para discussão, n.204) 
GLOMM, G.; RAVIKUMAR, B. Public versus private investiments in human capital: endogenous growth on income inequality. Journal of Political Economy, v.100, n.4, p.818-834, 1992.

GOLDIN, I.; RESENDE, G. C. Agricultura brasileira na década de 80: crescimento numa economia em crise. Rio de Janeiro: IPEA, 1993. 119p.

GONÇALVES, F. O; SEABRA, F.; TEIXEIRA, J. R. O capital humano em um modelo de crescimento endógeno da economia brasileira. Análise Econômica, v.16, n.29, p.139-148, 1998.

GREENE, W. H. Econometric analysis. 3.ed. New Jersey: Mcmillian Publishing Company, 1997. 1075p.

GROSSMAN, G; HELPMAN, E. Innovation and growth in the global economy. Cambridge: MIT Press, 1991. 552p.

GROSSMAN, G; HELPMAN, E. Endogenous innovation in the theory of growth. Journal of Economic Perspectives, v.8, n.1, p.23-44, Winter 1994.

HAHN, F. H; MATTHEWS, R. C. O. The theory of economic growth. Economic Journal, v.74, n.296, p.779-902, 1964.

HALTER, A. N. et al. A note on the transcendental production function. Journal of Farm Economics, v.39, n.3, p.966-974, Aug.1951.

HARBERGER, A. C. A vision of the growth process. The American Economic Review, v.88, n.1, p.1-32, 1998.

HOFFMANN, R. et al. Modernização e produtividade da agropecuária brasileira em 332 microrregiões do Brasil em 1975 e 1980. Piracicaba: ESALQ, 1990. 146p. (Relatório de pesquisa) 
HOFFMANN, R. et al. Inovações tecnológicas e transformações recentes na agricultura brasileira. Piracicaba: ESALQ, 1985. p.520-778. (Relatório de pesquisa, 3)

ILHA, A. S.; Lima, J. E. Impacto da educação na pequena produção agrícola em Minas Gerais. Pesquisa e Planejamento Econômico, v.19, n.1, p.183-202, 1989.

ISTAKE, M.; BACHA, J. C. Comportamento do emprego na agropecuária do Paraná período de 1970 a 1996. Revista de Economia e Sociologia Rural, v.37, n.4, p.71$101,1999$.

JMÉNEZ, R. T. Crescimiento y desarrollo: la visión endógena. Investigación Económica, v.58, n.223, p.15-46, 1998.

JOHNSTON, J.; DINARDO J. Econometric methods. 4.ed. New York: McGraw-Hill, 1997. 531p.

JONES, L.; MANUELLI, R. A convex model of equilibrium growth. Journal of Political Economy, v.98, n.5, p.1008-1038, 1990.

JONES, C. I. Introdução à teoria do crescimento econômico. São Paulo: Campus, 1997. 178p.

JONES, C, I. R\&D-based models of economic growth. Journal of Political Economy, v.103, n.4, p.759-784, 1995.

JUDGE, G. et al. Introduction to the theory and practice of econometrics. 2.ed. New York: John Wiley \& Sons, 1988. 1002p.

KAGEYAMA, A. A; SILVA, J. G. Os resultados da modernização agrícola dos anos 70. Estudos Econômicos, v.13, n.03, p.537-559, set./dez. 1983. 
KALDOR, N. A model of economic growth. Economic Journal, v.67, n.268, p.591$624,1957$.

KALDOR, N; MIRRLEES, J. A. A new model of economic growth. Review of Economic Studies, v.29, n.286, p.174-190, 1962.

KASSOUF, A. L. Retornos à educação e treinamento nos setores urbano e rural do Brasil. In: CONGRESSO BRASILEIRO DE ECONOMIA E SOCIOLOGIA RURAL, n.34, Aracajú, 1996. Anais. Brasília: SOBER, 1996. p.771-783.

KAZNAR, J. Programa de estudos de estados e municípios. Rio de Janeiro: FGV, 1996.

KENNEDY, C. Induced bias in innovation and the theory of distribution. Economic Journal, v.74, n.295, p.541-547, 1964.

KLENOW, P. J. Ideas versus rival human capital: industry evidence on growth models. Journal of Monetary Economics, v.42, p.3-23, 1998.

LAU, L. J; YOTOPOULOS, P. A. The meta-production function approach to technological change in world agriculture. Journal of Development Economics, v.31, n.2, p.241-269, 1989.

LAU, L. J. et al. Education and economic growth: some cross-sectional evidence from Brazil. Journal of Development Economics, v.41, p.45-70, 1993.

LAVINAS, L.; GARCIA, H.E.; AMARAL, M. R. de. Desigualdades regionais: indicadores socioeconômicos nos 90. Rio de Janeiro: IPEA, 1993. 83p. (Texto para discussão, n.460)

LUCAS, R. E. On the mecanics of economic development. Journal of Monetary Economics, v.22, n.1, p.3-42, 1988. 
MANKIW, G.; ROMER, D.; WEIL, D. A contribution to the empirics of economic growth. Quartely Journal of Economics, v.107, n.2, p.407-307, 1992.

MANOEL, A.; BARROS, J. R. M. Agricultura brasileira: transformações e perspectivas na década de 80. In: ENCONTRO NACIONAL DE ECONOMIA, 16, Salvador, 1987. Anais. São Paulo: ANPEC, 1987, p.103-128.

MELLO, F. H. O crescimento agrícola brasileiro dos anos 80 e as perspectivas para os anos 90. Revista de Economia Política, v.10, n.03, p.22-30, jul./set.1990.

NELSON, R.; PHELPS, E. Investment in humans, technological diffusion, and economic growth. American Economic Review, v.56, n.2, p.69-75, 1966.

ORTIGUEIRA, S.; SANTOS M. S. On the speed of convergence in endogenous growth models. The American Economic Review, v.87, n.3, p.383-399, June 1997.

PACK, H. Endogenous growth theory: intellectual appeal and empirical short-comings. Journal of Economic Perspectives, v.8, n.1, p.55-72, Winter 1994.

PARKS, R. W. Efficiente estimation of a system of regression equations when disturbances are both serially and contemporaneously correlated. Journal of the American Statistical Association, v.62, p.500-509, 1967.

PATRICK, G. F.; KEHRBERG, E. W. Custos e retornos da educação em cinco áreas agrícolas da região leste do Brasil. In: ARAÚJO, P. F. C.; SCHUH, G. E. Desenvolvimento da agricultura. São Paulo: Pioneira, 1975. p.17-34.

PINTO, L. C. G. Notas sobre a política agrícola brasileira. Encontro com a Civilização Brasileira, v.7, p.193-206, jan.1979.

PSACHAROPOULOS, G. Returns to education: a further international update and implications. The Journal of Human Resources, v.20, p.584-604, 1985. 
RANDALL, A. Resource economics: an economic approach to natural resource and environmental policy. New YorK: John Wiley \& Son, 1987. 434p.

REBELO, S. Long-run policy analysis and long run growth. Journal of Political Economic, v.99. n.31, p.519-550, 1991.

REZENDE, G. C. Política econômica e a agricultura na década de 80. In: CONGRESSO BRASILEIRO DE ECONOMIA E SOCIOLOGIA RURAL, 28., Piracicaba, 1989. Anais. Brasília: SOBER, 1989. p.284-309.

ROMER, P. M. Increasing returns and long run growth. Journal of Political Economic, v.94, n.5, p.1002-1037, 1986.

ROMER, P. M. Human capital and growth: theory e evidence. Carnegie Rochester Conference Series on Public Policy, v.32, p.251-286, 1990.

ROMER, P. M. Endogenous technological change. Journal of Political Economic, v.98, n.5, p.71-102, 1990a.

ROMER, P. M. The origins of endogenous growth. Journal of Political Economics, v.94, n.1, p.3-22, 1994.

SACHS, J. D.; LARRAIN, F. B. Macroeconomia. São Paulo: Makron Books, 1995. $904 \mathrm{p}$.

SILVA, G. L. S. P. Transforming brazilian agriculture. In: CONGRESSO BRASILEIRO DE ECONOMIA E SOCIOLOGIA RURAL, 29., Campinas, 1991. Anais. Brasília: SOBER, 1991.p.254-278.

SILVA, J. G.; KAGEYAMA, A. Emprego e relações de trabalho na agricultura brasileira: uma análise dos dados censitários de 1960, 1970, e 1975. Pesquisa e Planejamento Econômico, v.13, n.1, p.235-266, abril 1983. 
SILVA, L. A. C. A função de produção da agropecuária brasileira: diferenças regionais e evolução no período 1975-1985. Piracicaba, 1996. 157p. Tese (Doutorado) Escola Superior de Agricultura "Luiz de Queiroz", Universidade de São Paulo.

SOLOW, R. A contribution to the theory of economic growth. Quartely Journal of Economics, v.70, n.1, p.65-91, 1956.

SOLOW, R. Technical change and the agregate production function. Review of Economic and Statistics, v.39, n.3, p.312-320, 1957.

STERN, N. The determinants of growth. The Economic Journal, v.101, p.122-133, 1991.

TARGETTI, F.; FOTI, A. Growth and productivity: a model of cumulative growth and catching-up. Cambridge Journal of Economics, v.21, p.27-43, 1997.

TEMPLE, J. The new growth evidence. Journal of Economic Literature, v.37, n.1, p.112-156, 1999. 
APÊNDICES 
APÊNDICE 1: Desenvolvimento da equação (10)

Considere a equação (8): $\Delta H=\delta \cdot L_{H}^{\lambda}(H)^{\phi}$. Dividindo ambos os membros por $H$, resulta em:

$$
\frac{\Delta H}{H}=\frac{\left(\delta \cdot L_{H}^{\lambda}\right)}{H^{(1-\phi)}}
$$

A taxa de crescimento só será equilibrada se o numerador e o denominador do lado direito da equação (8.1) crescerem à mesma taxa. Nesse caso, $\frac{\Delta H}{H}=g_{H}$. Assim:

$$
g_{H}=\frac{\left(\delta \cdot L_{H}^{\lambda}\right)}{H^{(1-\phi)}}
$$

Tirando o logarimo da equação (8.2), tem-se:

$\ln g_{H}=\ln \delta+\lambda \ln L_{H}-(1-\phi) \ln H$

Fazendo a derivada da equação (8.3) com relação ao tempo, e dado que $g_{H} \mathrm{e}$ $\delta$ são constantes:

$$
0=\lambda \frac{d \ln L_{H}}{d t}-(1-\phi) \frac{d \ln H}{d t}
$$

O que implica em:

$$
0=\lambda \frac{\Delta L_{H}}{L_{H}}-(1-\phi) \frac{\Delta H}{H}
$$

Considerando que a taxa de crescimento da pesquisa é igual à taxa de crescimento populacional $\frac{\Delta L_{H}}{L_{H}}=n$, e que $\frac{\Delta H}{H}=g_{H}$. Então:

$$
\lambda n-(1-\phi) g_{H}=0
$$

Isolando $g_{H}$,chega-se à seguinte equação:

$$
g_{H}=\frac{\lambda n}{(1-\phi)}
$$


Como $g_{H}=g_{K}=g_{Y}$, tem-se: $g_{Y}=\frac{\lambda n}{(1-\phi)}$ 
APÊNDICE 2: Alguns estudos a respeito do catch-up e convergência

A distinção entre convergência e catch-up está bem argumentada em Dowrick \& Nguyen (1989). Convergência pode ser definida como sendo a tendência para que determinados grupos de países pobres, em razão da difusão de tecnologia, alcancem taxas de crescimento do seu produto per capita acima daquelas alcançadas pelos países desenvolvidos. O conceito de catch-up caminha no mesmo sentido da convergência, mas com uma diferença: os modelos de catch-up possuem como variável dependente a produtividade total dos fatores. Assim, pode-se definir os modelos de catch-up como sendo a tendência para que determinados grupos de países pobres apresentem catching-up nos níveis da produtividade total dos fatores. Entretanto, como argumentam Dowrick \& Nguyen (1989), o catch-up da produtividade total dos fatores leva os níveis de renda a convergirem.

A teoria do catch-up rompe com a pressuposição de que os países possuem o mesmo nível de tecnologia. Esse ponto constitui a principal diferença em relação ao modelo neoclássico, já que para esse modelo, conforme argumenta Fagerberg (1995), o veículo para o crescimento econômico é a diferença na acumulação de capital e não na diferença de tecnologia. Para a teoria do catch-up, os países avançados têm como motor do seu crescimento as inovações tecnológicas, e os países menos desenvolvidos as imitam e as adaptam. Neste sentido, está admitindo-se que os países menos desenvolvidos não possuem aporte de recursos financeiros suficientes para financiar projetos de pesquisas de fronteira tecnológica. Assim, a transferência de tecnologia, ou a difusão de tecnologia entre os dois grupos de países, constitui-se em uma das variáveis fundamentais na determinação do crescimento econômico dos países menos desenvolvidos. Portanto, pode-se definir o catch-up como sendo um processo, derivado da difusão de tecnologia, que leva os países que estão atrás da fronteira tecnológica a crescerem mais rápido do que os países da fronteira tecnológica. Por exemplo, considerando que o termo catch-up $H_{i}\left(Y_{\text {Lider }} / Y_{i}\right)$, especificado em uma regressão, seja uma variável definida pela interação entre $\left(H_{i}\right)$ no país $i$ e a razão entre a produtividade 
total dos fatores entre os países líder e atrasados $\left(Y_{L i d e r} / Y_{i}\right)$, então, quanto maior for o estoque de capital humano nos países menos desenvolvidos maior será a possibilidade de redução do hiato que separa $Y_{i}$ e $Y_{\text {Lider }}$.

O efeito catch-up esteve no centro das preocupações de Targetti \& Foti (1997). Esses autores procuraram contribuir com o debate acerca da convergência econômica entre países economicamente líder e atrasados. A equação de regressão proposta pelo autor, a qual denominou de versão neoclássica da teoria do catching-up, especifica como variável dependente a variação do produto per capita para os iésimos países; e como variável independente, a razão entre a produtividade do país líder e dos países atrasados. Os autores utilizaram, para tanto, um modelo econométrico com pooling e cross-section, para um grupo de nove países da OECD, nove países da América Latina e sete países da Ásia Oriental. O processo de difusão de tecnologia entre os países foi estimado através da variável catch-up. O resultado da estimação, do modelo proposto pelos autores, foi o seguinte: o efeito catch-up foi relevante na explicação do crescimento da produtividade na área OECD e na Ásia Oriental, mas não foi estatisticamente significativo para os países da América Latina.

Em outro estudo, Drysdale \& Huang (1997) examinaram os fatores que contribuíram para o rápido crescimento econômico da Ásia Oriental, em relação aos membros da APEC. A variável dependente estimada foi a taxa média de crescimento do produto nacional bruto dos iésimos países, tendo como variáveis independentes $o$ crescimento da força de trabalho, o investimento médio e mais três dummies representando períodos específicos. Os autores encontraram que o aumento na produtividade foi um fator importante para o rápido crescimento da Ásia Oriental. Em vários países, como por exemplo, Japão, Coréia, Taiwan e Hong-Kong, grande parte deste crescimento pode ser atribuído à variável especificada no modelo como catch-up tecnológico.

Frantzen (2000) analisou a relação entre o esforço de incrementar o estoque de P\&D e o aumento da produtividade total dos fatores entre os países da OECD. A 
equação de regressão, proposta pelo autor, especifica como variável dependente a produtividade total dos fatores em logaritmos; e como variáveis independentes, o estoque de capital destinado à $\mathrm{P} \& \mathrm{D}$ dos iésimos países e o estoque de capital em P\&D dos países estrangeiros, ${ }^{67} \mathrm{e}$ variáveis dummies para representar os sete maiores países. A difusão tecnológica foi captada através das variáveis P\&D. Fazendo uso de estimações econométricas, o autor mostrou que a influência da difusão tecnológica internacional foi, em média, maior do que o esforço interno dos países em promover o incremento do estoque de P\&D.

Apesar dos modelos com difusão tecnológica, captada através do termo catch-up, terem sido aplicados em análises envolvendo países líderes e atrasados, conforme apresentado anteriormente, é possível verificar o processo de difusão de tecnologia dentro de um mesmo país através dos modelos de convergência na tradição do modelo apresentado por Barro \& Sala-in-Martin (1992b) ${ }^{68}$. Um dos estudos pioneiros foi o de Barro \& Sala-in-Martin (1992a). A equação estimada por estes autores, derivada após algumas manipulações matemática, ficou especificada como:

$$
T^{-1} \ln \left(y_{T} / y_{0}\right)=\left(1-e^{-\beta T}\right) T^{-1} \ln \left(\hat{y}^{*} / \hat{y}\right)+x
$$

onde $\beta$ é a velocidade de convergência, $T$ é a extensão do intervalo de tempo, $\hat{y}$ é o produto por unidade de trabalho, o subscrito * denota o valor no estado estacionário e $x$ é a taxa exógena do progresso técnico

Ao estimar a equação (2.1) para os estados norte-americanos, Barro \& Salain-Martin (1992a) encontraram que, realmente, tem ocorrido convergência entre os estados norte-americanos. Entretanto, a velocidade de convergência é muito lenta, de aproximadamente $2 \%$ ao ano.

\footnotetext{
${ }^{67} \mathrm{O}$ estoque de capital dos países estrangeiros foi calculado como a média ponderada do estoque de capital em P\&D de todos os outros países pertencentes à amostra.

${ }^{68}$ Para o processo de convergência entre países, ver, por exemplo, Barro (1991), Galor (1996) e Ortigueira \& Santos (1997).
} 
Os modelos neoclássicos de crescimento, segundo Galor (1996) e Gonçalves et al. (1998), permitem formular três hipóteses relacionados à convergência. A primeira foi denominada de hipótese da convergência absoluta, ou seja, economias consideradas similares, com divergência nos estoques de capital inicial, tendem a convergir no longo prazo para uma mesma renda per capita, independente das suas condições iniciais. De acordo com Galor, a hipótese da convergência absoluta foi refutada, por exemplo, por Barro (1991), Quah (1996) ${ }^{69}$ e Barro \& Sala-i-Martin (1995). Estes autores apoiaram-se na hipótese denominada convergência condicional. Se os países são similares em suas características estruturais, tecnologias, crescimento populacional, políticas econômicas, mas divergirem, apenas, nos níveis de crescimento do produto per capita, então é esperado que em longo prazo haja convergência entre o produto dos diferentes países, independente das suas condições iniciais ${ }^{70}$. Segundo Galor (1996), quando o capital humano foi incluído nos modelos de crescimento, esses se tornaram modelos de crescimento com múltiplos equilíbrios do steady state. Países que são idênticos em suas características estruturais, mas diferem em seus níveis de capital humano, podem se agrupar em diferentes equilíbrios no estado estacionário, na presença de retornos crescentes à escala. Essas características passaram a sustentar a hipótese de clube de convergência.

Recorrendo à mesma equação (2.1), mas adicionando a constante, Cashin (1995) estimou o processo de convergência entre sete colônias da Astralásia (Austrália e Nova Zelândia). $\mathrm{O}$ autor encontrou que o nível de renda per capita entre as colônias está convergindo, ou seja, as colônias mais pobres estão crescendo mais rapidamente do que as colônias mais ricas.

\footnotetext{
${ }^{69}$ QUAH, D. Convergence empirics across countries with (some) capital mobility. Journal of Economic Growth, v.1, n.1 p.95-124, 1996.

${ }^{70}$ Se o leitor desejar mais informações sobre a convergência absoluta, ver Romer (1986), Lucas (1988) e Barro (1991).
} 
Estudos de convergência no Brasil, nos moldes do modelo proposto por Barro \& Sala-in-Martin (1992a), foram desenvolvidos por Ferreira \& Ellery Jr. (1996), quando esses autores estudaram a convergência entre a renda per capita dos estados brasileiros. Os resultados das estimativas apontaram evidências de que os estados mais pobres estão diminuindo a distância que o separa dos estados mais ricos. Contudo, a velocidade de convergência, medida pelo parâmetro $\beta$ (equação 2.1 ), ficou em torno de 0,013; enquanto a dos estados americanos, estimada por Barro \& Sala-in-Martin (1992a), foi de 0,02. Isto leva a concluir que a convergência entre os estados brasileiros é bem mais lenta do que aquela verificada para os estados norte-americanos.

Um outro teste de convergência para o Brasil foi aplicado por Gonçalves et al. (1998). Os resultados encontrados pelos autores apoiam a hipótese da convergência. A velocidade de convergência estimada pelos autores foi de $1,2 \%$ ao ano, muito próximo ao 1,3\% encontrado por Ferreira \& Ellery Jr. (1996). 
APÊNDICE 3: Dados utilizados no estudo

Tabela 3.1. Dados básicos da Pesquisa'.

\begin{tabular}{|c|c|c|c|c|c|}
\hline UF & $Y^{A}$ & $K^{A}$ & $L^{\mathrm{A}}$ & $H^{\mathrm{B}}$ & $T^{A}$ \\
\hline RO70 & 12675,84 & 2005,00 & 15789,06 & 0,77 & $\overline{1281312,00}$ \\
\hline RO75 & 30317,36 & 3350,00 & 72039,76 & 1,12 & 3015647,00 \\
\hline RO80 & 48746,63 & 34920,00 & 131964,24 & 1,64 & 5110767,00 \\
\hline R085 & 124006,78 & 68515,00 & 239135,12 & 2,12 & 5858740,00 \\
\hline R095/96 & 209549,82 & 166625,00 & 235014,64 & 3,71 & 8584594,00 \\
\hline AC70 & 31636,42 & 800,00 & 48594,32 & 0,46 & 4038735,00 \\
\hline AC75 & 44204,33 & 2705,00 & 57207,98 & 0,53 & 4227129,00 \\
\hline AC80 & 46211,48 & 13665,00 & 70929,34 & 0,61 & 5547952,00 \\
\hline AC85 & 51825,96 & 16490,00 & 84722,62 & 0,89 & 5087439,00 \\
\hline AC95/96 & 67214,25 & 24420,00 & 69609,82 & 2,03 & 3082824,00 \\
\hline AM70 & 131648,66 & 1590,00 & 210152,58 & 0,79 & 4012172,00 \\
\hline AM75 & 138235,24 & 2795,00 & 286579,46 & 0,92 & 5919254,00 \\
\hline AM80 & 159640,11 & 30425,00 & 325007,24 & 1,07 & 6380411,00 \\
\hline AM85 & 201045,99 & 27935,00 & 377934,98 & 1,32 & 5325834,00 \\
\hline AM95/96 & 229791,84 & 25660,00 & 259448,46 & 2,10 & 3008160,00 \\
\hline RR70 & 11075,29 & 135,00 & 6343,90 & 1,05 & 1566588,00 \\
\hline RR75 & 20497,67 & 1460,00 & 13172,42 & 1,27 & 1778409,00 \\
\hline RR80 & 26857,28 & 8480,00 & 12499,02 & 1,53 & 2381460,00 \\
\hline RR85 & 39916,33 & 10480,00 & 16790,00 & 2,08 & 2052325,00 \\
\hline RR95/96 & 40050,66 & 22710,00 & 26298,58 & 3,85 & 2833255,00 \\
\hline PA70 & 190905,48 & 36440,00 & 414373,02 & 1,02 & 8311796,00 \\
\hline PA75 & 278485,65 & 74465,00 & 563488,98 & 1,21 & 13899181,00 \\
\hline PA80 & 509519,30 & 261335,00 & 749491,30 & 1,43 & 17487254,00 \\
\hline PA85 & 722474,87 & 270435,00 & 863140,08 & 1,67 & 21429340,00 \\
\hline PA95/96 & 751130,12 & 345095,00 & 673711,06 & 2,34 & 20586537,00 \\
\hline AP70 & 8270,63 & 1350,00 & 7837,96 & 1,21 & 556402,00 \\
\hline AP75 & 11442,29 & 2055,00 & 13546,30 & 1,34 & 645567,00 \\
\hline AP80 & 18223,82 & 4270,00 & 11424,84 & 1,47 & 604645,00 \\
\hline AP85 & 25413,89 & 6085,00 & 15607,00 & 1,81 & 1068695,00 \\
\hline AP95/96 & 44428,27 & 9300,00 & 12878,16 & 2,73 & 662526,00 \\
\hline MA70 & $64677 ; 27$ & 7250,00 & 901361,74 & 0,45 & 6850755,00 \\
\hline MA75 & 75767,43 & 25070,00 & 1137100,44 & 0,57 & 8350923,00 \\
\hline MA80 & 110487,23 & 162295,00 & 1269572,66 & 0,72 & 10245974,00 \\
\hline MA85 & 126210,74 & 198610,00 & 1257061,70 & 0,93 & 10507369,00 \\
\hline MA95/96 & 481517,60 & 237535,00 & 1075154,86 & 1,67 & 9503325,00 \\
\hline PI70 & 73321,20 & 10715,00 & 414830,08 & 0,33 & 7050100,00 \\
\hline PI75 & 102591,46 & 22765,00 & 465812,08 & 0,44 & 7610418,00 \\
\hline PI80 & 117614,96 & 101575,00 & 622336,20 & 0,59 & 7307701,00 \\
\hline PI85 & 170341,81 & 122830,00 & 635157,26 & 0,83 & 8117924,00 \\
\hline PI95/96 & 250392,07 & 141530,00 & 524977,14 & 1,79 & 7082220,00 \\
\hline CE70 & 151270,62 & 29420,00 & 841809,50 & 0,35 & 10371952,00 \\
\hline CE75 & 210937,22 & 77530,00 & 768806,92 & 0,46 & 8965452,00 \\
\hline CE80 & 268619,42 & 235270,00 & 889713,60 & 0,59 & 10623516,00 \\
\hline CE85 & 482653,34 & 226875,00 & 1025038,76 & 0,84 & 8934775,00 \\
\hline CE95/96 & 675643,27 & 245425,00 & 956903,04 & 1,63 & 7274173,00 \\
\hline
\end{tabular}


Tabela 3.1. Dados básicos da Pesquisa.

\begin{tabular}{|c|c|c|c|c|c|}
\hline$\overline{\mathrm{UF}}$ & $Y^{\mathrm{A}}$ & $K^{\mathrm{A}}$ & $\overline{L^{\mathrm{A}}}$ & $H^{\mathrm{B}}$ & $T^{A}$ \\
\hline$\overline{R N 70}$ & 70696,98 & 23470,00 & 260727,48 & 0,51 & 3926426,00 \\
\hline RN75 & 99613,23 & 68520,00 & 294800,42 & 0,63 & 4109118,00 \\
\hline RN80 & 111885,31 & 184880,00 & 357115,22 & 0,78 & 4245581,00 \\
\hline RN85 & 204940,23 & 170135,00 & 350231,12 & 1,06 & 3949785,00 \\
\hline RN95/96 & 263180,24 & 192950,00 & 281534,12 & 2,05 & 3124032,00 \\
\hline PB70 & 144507,43 & 37470,00 & 474165,30 & 0,43 & 4056849,00 \\
\hline PB75 & 212169,88 & 76875,00 & 591200,48 & 0,54 & 4080785,00 \\
\hline PB80 & 193223,60 & 191095,00 & 536939,80 & 0,67 & 4277845,00 \\
\hline PB85 & 383823,61 & 169860,00 & 609752,84 & 0,87 & 4235658,00 \\
\hline PB95/96 & 409566,47 & 171890,00 & 394507,80 & 1,54 & 3447947,00 \\
\hline PE70 & 362634,28 & 70965,00 & 901819,26 & 0,44 & 5076963,00 \\
\hline PE75 & 470583,38 & 153400,00 & 869016,52 & 0,55 & 5187849,00 \\
\hline PE80 & 524008,87 & 313650,00 & 994286,78 & 0,68 & 5813986,00 \\
\hline PE85 & 862694,85 & 284340,00 & 1052791,22 & 0,96 & 5685372,00 \\
\hline PE95/96 & 991653,10 & 295640,00 & 803362,94 & 2,08 & 4873890,00 \\
\hline AL70 & 182182,35 & 53400,00 & 339246,22 & 0,32 & 1729491,00 \\
\hline AL75 & 293426,95 & 155165,00 & 376173,26 & 0,41 & 1847338,00 \\
\hline AL80 & 409458,75 & 244870,00 & 428049,28 & 0,51 & 2061802,00 \\
\hline AL85 & 470347,78 & 232225,00 & 496904,96 & 0,97 & 2094479,00 \\
\hline AL95796 & 528027,46 & 214765,00 & 360489,64 & 1,67 & 1947178,00 \\
\hline SE70 & 83461,35 & 23510,00 & 214005,38 & 0,38 & 1490377,00 \\
\hline SE75 & 116535,82 & 60530,00 & 231074,38 & 0,50 & 1656334,00 \\
\hline SE80 & 200375,43 & 115960,00 & 235171,62 & 0,66 & 1764639,00 \\
\hline SE85 & 185434,75 & 112840,00 & 277791,88 & 0,94 & 1793525,00 \\
\hline SE95/96 & 234766,28 & 146075,00 & 258702,12 & 2,10 & 1626955,00 \\
\hline BA70 & 837030,29 & 84120,00 & 1612211,58 & 0,45 & 18424860,00 \\
\hline BA75 & 1074175,03 & 258625,00 & 1865480,82 & 0,54 & 20951789,00 \\
\hline BA80 & 1179815,46 & 792570,00 & 2082350,76 & 0,65 & 25652858,00 \\
\hline BA85 & 1979693,00 & 896210,00 & 2497946,40 & 0,90 & 28348417,00 \\
\hline BA95/96 & 1992005,72 & 1367610,00 & 2002045,90 & 1,84 & 26701200,00 \\
\hline MG70 & 1991848,38 & 458325,00 & 1668979,86 & 1,20 & 39898623,00 \\
\hline MG75 & 2867045,66 & 1327790,00 & 1799483,48 & 1,50 & 42569482,00 \\
\hline MG80 & 3441046,58 & 3053225,00 & 1951391,88 & 1,88 & 44309625,00 \\
\hline MG85 & 4803304,58 & 3600000,00 & 2278649,46 & 2,32 & 44109893,00 \\
\hline MG95/96 & 6073015,45 & 5564755,00 & 1731837,56 & 3,74 & 39047085,00 \\
\hline ES70 & 444536,96 & 47840,00 & 247318,70 & 1,28 & 3353742,00 \\
\hline ES75 & 511292,11 & 105080,00 & 253667,64 & 1,66 & 3481260,00 \\
\hline ES80 & 601400,35 & 304770,00 & 298751,84 & 2,16 & 3567662,00 \\
\hline ES85 & 961854,42 & 445315,00 & 349005,04 & 2,74 & 3677458,00 \\
\hline ES95/96 & 1192476,12 & 540145,00 & 298852,28 & 4,31 & 3343891,00 \\
\hline RJ70 & 281531,60 & 178695,00 & 230545,10 & 1,35 & 3062429,00 \\
\hline RJ75 & 347251,84 & 324835,00 & 242793,54 & 1,61 & 3199761,00 \\
\hline RJ80 & 437878,70 & 445550,00 & 261859,50 & 1,93 & 3017171,00 \\
\hline RJ85 & 545549,44 & 178695,00 & 283853,48 & 2,48 & 3092064,00 \\
\hline RJ95/96 & 592258,58 & 434885,00 & 156790,00 & 4,39 & 2338813,00 \\
\hline
\end{tabular}


Tabela 3.1. Dados básicos da Pesquisa.

\begin{tabular}{|c|c|c|c|c|c|}
\hline $\mathrm{UF}$ & $Y^{\mathrm{A}}$ & $K^{\mathrm{A}}$ & $L^{\mathrm{A}}$ & $H^{\mathrm{B}}$ & $T^{\mathrm{A}}$ \\
\hline$\overline{\text { SP70 }}$ & 2171351,65 & 3028540,00 & 1238884,48 & 1,87 & 19291301,00 \\
\hline SP75 & 2938009,64 & 5744020,00 & 1191764,64 & 2,24 & 19685756,00 \\
\hline SP80 & 5154642,40 & 8959835,00 & 1251666,70 & 2,68 & 19648144,00 \\
\hline SP85 & 7440337,96 & 10273250,00 & 1238011,28 & 3,22 & 19747466,00 \\
\hline SP95/96 & 7902877,10 & 11173425,00 & 843489,20 & 4,81 & 16986550,00 \\
\hline PR70 & 2240086,17 & 819020,00 & 1566669,32 & 1,39 & 12421805,00 \\
\hline PR75 & 2365437,82 & 3309640,00 & 1609062,96 & 1,81 & 13767718,00 \\
\hline PR80 & 3165720,86 & 5503975,00 & 1470752,02 & 2,36 & 15080400,00 \\
\hline PR85 & 3773720,66 & 6800835,00 & 1535441,40 & 2,92 & 15680776,00 \\
\hline PR95/96 & 5015974,90 & 9135490,00 & 1075787,92 & 4,62 & 15297488,00 \\
\hline SC70 & 509567,63 & 183540,00 & 578028,10 & 2,31 & 5915358,00 \\
\hline SC75 & 676167,85 & 606115,00 & 622416,72 & 2,72 & 5916062,00 \\
\hline SC80 & 952695,10 & 1458600,00 & 638538,68 & 3,20 & 6795526,00 \\
\hline SC85 & 1428985,22 & 2128295,00 & 690532,96 & 3,78 & 6844692,00 \\
\hline SC95/96 & 2821347,71 & 3251460,00 & 569764,44 & 5,47 & 6318987,00 \\
\hline RS70 & 1688309,95 & 2001330,00 & 1183373,04 & 2,53 & 22622112,00 \\
\hline RS75 & 2357288,42 & 4777595,00 & 1409680,92 & 2,84 & 22763169,00 \\
\hline RS80 & 2379578,40 & 7766740,00 & 1371626,50 & 3,19 & 23274624,00 \\
\hline RS85 & 3087183,24 & 9095075,00 & 1388096,96 & 3,71 & 22934050,00 \\
\hline RS95/96 & 5374487,35 & 10398600,00 & 1118224,26 & 5,21 & 20939027,00 \\
\hline MT70 & 292948,83 & 223235,00 & 296274,30 & 1,16 & 43358028,00 \\
\hline MT75 & 404169,32 & 1067905,00 & 394713,74 & 1,50 & 47288548,00 \\
\hline MT80 & 699678,55 & 2624220,00 & 440875,72 & 1,95 & 61526444,00 \\
\hline MT85 & 1165422,76 & 3780330,00 & 506114,06 & 2,46 & 65562642,00 \\
\hline MT95/96 & 3937239,44 & 5367045,00 & 456454,56 & 4,10 & 78329841,00 \\
\hline GO70 & 347204,54 & 289460,00 & 462361,26 & 1,01 & 31913195,00 \\
\hline GO75 & 489215,94 & 851445,00 & 566577,44 & 1,31 & 39986038,00 \\
\hline GO80 & 729754,05 & 1910290,00 & 633459,70 & 1,70 & 44195636,00 \\
\hline G085 & 997835,73 & 2240720,00 & 703314,24 & 2,18 & 43311922,00 \\
\hline G095/96 & 2735111,17 & 3631040,00 & 566400,36 & 3,78 & 41772148,00 \\
\hline DF70 & 5470,10 & 5155,00 & 5890,32 & 1,79 & 152328,00 \\
\hline DF75 & 6990,84 & 12495,00 & 6802,88 & 2,36 & 148181,00 \\
\hline DF80 & 19290,59 & 65250,00 & 12710,84 & 3,12 & 245368,00 \\
\hline DF85 & 37992,43 & 99890,00 & 15722,42 & 3,56 & 292446,00 \\
\hline DF95/96 & 125945,62 & 120215,00 & 13190,32 & 4,81 & 228486,00 \\
\hline
\end{tabular}

Fonte: Dados da pesquisa retirados: A, dos Censos Agropecuários e B, dos Censos Demográficos. ' $\mathrm{Os}$ valores de $Y$ estão em mil Reais, $K$ em número de cavalos, $L$ em equivalente-homem, $H$ em número de anos educação e $T$ área de terra medida em hectares. 
Tabela 3.2. Dados utilizados no processo de estimação da equação $(53)^{(\mathrm{A})}$. Brasil

\begin{tabular}{|c|c|c|c|c|c|}
\hline UF & $\ln Y_{t}^{i}-\ln Y_{t-1}^{i}$ & $\ln K_{t}^{i}-\ln K_{t-1}^{i}$ & $\ln L_{t}^{i}-\ln L_{t-1}^{i}$ & $H_{t}^{i}-H_{t-}^{i}$ & $\ln T_{t}^{i}-\ln T_{t-1}^{i}$ \\
\hline RO75-70 & 0,87 & 0,51 & 1,52 & 0,35 & 0,86 \\
\hline RO80-70 & 1,35 & 2,86 & 2,12 & 0,87 & 1,38 \\
\hline RO85-70 & 2,28 & 3,53 & 2,72 & 1,34 & 1,52 \\
\hline RO95/96-70 & 2,81 & 4,42 & 2,70 & 2,93 & 1,90 \\
\hline AC75-70 & 0,33 & 1,22 & 0,16 & 0,07 & 0,05 \\
\hline AC80-70 & 0,38 & 2,84 & 0,38 & 0,16 & 0,32 \\
\hline AC85-70 & 0,49 & 3,03 & 0,56 & 0,43 & 0,23 \\
\hline AC95/96-70 & 0,75 & 3,42 & 0,36 & 1,58 & $-0,27$ \\
\hline AM75-70 & 0,05 & 0,56 & 0,31 & 0,13 & 0,39 \\
\hline AM80-70 & 0,19 & 2,95 & 0,44 & 0,27 & 0,46 \\
\hline AM85-70 & 0,42 & 2,87 & 0,59 & 0,53 & 0,28 \\
\hline AM95/96-70 & 0,56 & 2,78 & 0,21 & 1,30 & $-0,29$ \\
\hline RR75-70 & 0,62 & 2,38 & 0,73 & 0,22 & 0,13 \\
\hline RR80-70 & 0,89 & 4,14 & 0,68 & 0,48 & 0,42 \\
\hline RR85-70 & 1,28 & 4,35 & 0,97 & 1,03 & 0,27 \\
\hline RR95/96-70 & 1,29 & 5,13 & 1,42 & 2,80 & 0,59 \\
\hline PA75-70 & 0,38 & 0,71 & 0,31 & 0,19 & 0,51 \\
\hline PA80-70 & 0,98 & 1,97 & 0,59 & 0,41 & 0,74 \\
\hline PA85-70 & 1,33 & 2,00 & 0,73 & 0,65 & 0,95 \\
\hline PA95/96-70 & 1,37 & 2,25 & 0,49 & 1,32 & 0,91 \\
\hline AP75-70 & 0,32 & 0,42 & 0,55 & 0,13 & 0,15 \\
\hline AP80-70 & 0,79 & 1,15 & 0,38 & 0,26 & 0,08 \\
\hline AP85-70 & 1,12 & 1,51 & 0,69 & 0,60 & 0,65 \\
\hline AP95/96-70 & 1,68 & 1,93 & 0,50 & 1,52 & 0,17 \\
\hline MA75-70 & 0,16 & 1,24 & 0,23 & 0,12 & 0,20 \\
\hline MA80-70 & 0,54 & 3,11 & 0,34 & 0,28 & 0,40 \\
\hline MA85-70 & 0,67 & 3,31 & 0,33 & 0,49 & 0,43 \\
\hline MA95/96-70 & 2,01 & 3,49 & 0,18 & 1,22 & 0,33 \\
\hline PI75-70 & 0,34 & 0,75 & 0,12 & 0,11 & 0,08 \\
\hline PI80-70 & 0,47 & 2,25 & 0,41 & 0,26 & 0,04 \\
\hline PI85-70 & 0,84 & 2,44 & 0,43 & 0,50 & 0,14 \\
\hline PI95/96-70 & 1,23 & 2,58 & 0,24 & 1,46 & 0,00 \\
\hline CE75-70 & 0,33 & 0,97 & $-0,09$ & 0,10 & $-0,15$ \\
\hline CE80-70 & 0,57 & 2,08 & 0,06 & 0,24 & 0,02 \\
\hline CE85-70 & 1,16 & 2,04 & 0,20 & 0,49 & $-0,15$ \\
\hline CE95/96-70 & 1,50 & 2,12 & 0,13 & 1,28 & $-0,35$ \\
\hline RN75-70 & 0,34 & 1,07 & 0,12 & 0,12 & 0,05 \\
\hline RN80-70 & 0,46 & 2,06 & 0,31 & 0,27 & 0,08 \\
\hline RN85-70 & 1,06 & 1,98 & 0,30 & 0,55 & 0,01 \\
\hline RN95/96-70 & 1,31 & 2,11 & 0,08 & 1,55 & $-0,23$ \\
\hline PB75-70 & 0,38 & 0,72 & 0,22 & 0,11 & 0,01 \\
\hline PB80-70 & 0,29 & 1,63 & 0,12 & 0,24 & 0,05 \\
\hline
\end{tabular}


Tabela 3.2. Dados utilizados no processo de estimação da equação $(53)^{(\mathrm{A})}$. Brasil

\begin{tabular}{|c|c|c|c|c|c|}
\hline UF & $\ln Y_{t}^{i}-\ln Y_{t-1}^{i}$ & $\ln K_{t}^{i}-\ln K_{t-1}^{i}$ & $\ln L_{t}^{i}-\ln L_{t-1}^{i}$ & $H_{l}^{i}-H_{t-}^{i}$ & $\ln T_{t}^{i}-\ln T_{t-1}^{i}$ \\
\hline $\begin{array}{l}\text { PB85-70 } \\
\end{array}$ & 0,98 & 1,51 & 0,25 & 0,44 & 0,04 \\
\hline PB95/96-70 & 1,04 & 1,52 & $-0,18$ & 1,10 & $-0,16$ \\
\hline PE75-70 & 0,26 & 0,77 & $-0,04$ & 0,11 & 0,02 \\
\hline PE80-70 & 0,37 & 1,49 & 0,10 & 0,24 & 0,14 \\
\hline PE85-70 & 0,87 & 1,39 & 0,15 & 0,52 & 0,11 \\
\hline PE95/96-70 & 1,01 & 1,43 & $-0,12$ & 1,63 & $-0,04$ \\
\hline AL75-70 & 0,48 & 1,07 & 0,10 & 0,08 & 0,07 \\
\hline AL80-70 & 0,81 & 1,52 & 0,23 & 0,18 & 0,18 \\
\hline AL85-70 & 0,95 & 1,47 & 0,38 & 0,65 & 0,19 \\
\hline AL95/96-70 & 1,06 & 1,39 & 0,06 & 1,34 & 0,12 \\
\hline SE75-70 & 0,33 & 0,95 & 0,08 & 0,12 & 0,11 \\
\hline SE80-70 & 0,88 & 1,60 & 0,09 & 0,28 & 0,17 \\
\hline SE85-70 & 0,80 & 1,57 & 0,26 & 0,56 & 0,19 \\
\hline SE95/96-70 & 1,03 & 1,83 & 0,19 & 1,72 & 0,09 \\
\hline BA75-70 & 0,25 & 1,12 & 0,15 & 0,09 & 0,13 \\
\hline BA80-70 & 0,34 & 2,24 & 0,26 & 0,20 & 0,33 \\
\hline BA85-70 & 0,86 & 2,37 & 0,44 & 0,45 & 0,43 \\
\hline BA95/96-70 & 0,87 & 2,79 & 0,22 & 1,39 & 0,37 \\
\hline MG75-70 & 0,36 & 1,06 & 0,08 & 0,30 & 0,06 \\
\hline MG80-70 & 0,55 & 1,90 & 0,16 & 0,68 & 0,10 \\
\hline MG85-70 & 0,88 & 2,06 & 0,31 & 1,12 & 0,10 \\
\hline MG95/96-70 & 1,11 & 2,50 & 0,04 & 2,55 & $-0,02$ \\
\hline ES75-70 & 0,14 & 0,79 & 0,03 & 0,38 & 0,04 \\
\hline ES80-70 & 0,30 & 1,85 & 0,19 & 0,89 & 0,06 \\
\hline ES85-70 & 0,77 & 2,23 & 0,34 & 1,46 & 0,09 \\
\hline ES95/96-70 & 0,99 & 2,42 & 0,19 & 3,03 & 0,00 \\
\hline RJ75-70 & 0,21 & 0,60 & 0,05 & 0,26 & 0,04 \\
\hline RJ80-70 & 0,44 & 0,91 & 0,13 & 0,58 & $-0,01$ \\
\hline RJ85-70 & 0,66 & 0,00 & 0,21 & 1,13 & 0,01 \\
\hline RJ95/96-70 & 0,74 & 0,89 & $-0,39$ & 3,04 & $-0,27$ \\
\hline SP75-70 & 0,30 & 0,64 & $-0,04$ & 0,37 & 0,02 \\
\hline SP80-70 & 0,86 & 1,08 & 0,01 & 0,81 & 0,02 \\
\hline SP85-70 & 1,23 & 1,22 & 0,00 & 1,36 & 0,02 \\
\hline SP95/96-70 & 1,29 & 1,31 & $-0,38$ & 2,94 & $-0,13$ \\
\hline PR75-70 & 0,05 & 1,40 & 0,03 & 0,42 & 0,10 \\
\hline PR80-70 & 0,35 & 1,91 & $-0,06$ & 0,96 & 0,19 \\
\hline PR85-70 & 0,52 & 2,12 & $-0,02$ & 1,52 & 0,23 \\
\hline PR95/96-70 & 0,81 & 2,41 & $-0,38$ & 3,23 & 0,21 \\
\hline SC75-70 & 0,28 & 1,19 & 0,07 & 0,41 & 0,00 \\
\hline SC80-70 & 0,63 & 2,07 & 0,10 & 0,89 & 0,14 \\
\hline SC85-70 & 1,03 & 2,45 & 0,18 & 1,47 & 0,15 \\
\hline SC95/96-70 & 1,71 & 2,87 & $-0,01$ & 3,16 & 0,07 \\
\hline
\end{tabular}


Tabela 3.2. Dados utilizados no processo de estimação da equação (53) ${ }^{(\mathrm{A})}$. Brasil

\begin{tabular}{|c|c|c|c|c|c|}
\hline UF & $\ln Y_{t}^{i}-\ln Y_{t-1}^{i}$ & $\ln K_{t}^{i}-\ln K_{t-1}^{i}$ & $\ln L_{t}^{i}-\ln L_{t-1}^{i}$ & $H_{t}^{i}-H_{t-}^{i}$ & $\ln T_{t}^{i}-\ln T_{t-1}^{i}$ \\
\hline $\begin{array}{l}\text { RS75-70 } \\
\end{array}$ & 0,33 & 0,87 & 0,17 & 0,31 & 0,01 \\
\hline RS80-70 & 0,34 & 1,36 & 0,15 & 0,67 & 0,03 \\
\hline RS85-70 & 0,60 & 1,51 & 0,16 & 1,18 & 0,01 \\
\hline RS95/96-70 & 1,16 & 1,65 & $-0,06$ & 2,68 & $-0,08$ \\
\hline MT75-70 & 0,32 & 1,57 & 0,29 & 0,34 & 0,09 \\
\hline MT80-70 & 0,87 & 2,46 & 0,40 & 0,78 & 0,35 \\
\hline MT85-70 & 1,38 & 2,83 & 0,54 & 1,30 & 0,41 \\
\hline MT95/96-70 & 2,60 & 3,18 & 0,43 & 2,93 & 0,59 \\
\hline GO75-70 & 0,34 & 1,08 & 0,20 & 0,30 & 0,23 \\
\hline GO80-70 & 0,74 & 1,89 & 0,31 & 0,69 & 0,33 \\
\hline GO85-70 & 1,06 & 2,05 & 0,42 & 1,17 & 0,31 \\
\hline GO95/96-70 & 2,06 & 2,53 & 0,20 & 2,77 & 0,27 \\
\hline DF75-70 & 0,25 & 0,89 & 0,14 & 0,57 & $-0,03$ \\
\hline DF80-70 & 1,26 & 2,54 & 0,77 & 1,33 & 0,48 \\
\hline DF85-70 & 1,94 & 2,96 & 0,98 & 1,78 & 0,65 \\
\hline DF95/96-70 & 3,14 & 3,15 & 0,81 & 3,02 & 0,41 \\
\hline
\end{tabular}

Fonte: Dados calculados pelo autor a partir da Tabela 3.1.

Tabela 3.3. Dados utilizados no processo de estimação da equação (57)

UF $\quad \ln Y_{t}^{i}-\ln K_{t}^{i}-\ln L_{t}^{i}-\ln T_{t}^{i}-H l_{t}^{i}-H 2_{t}^{i}-H 3_{t}^{i}-H 4_{t}^{i}-H 5_{t}^{i}-H 6_{t}^{i}-$ $\ln Y_{t-1}^{i} \ln K_{t-1}^{i} \ln L_{t-1}^{i} \ln T_{t-1}^{i} H 1_{t-1}^{i} \quad H 2_{t-1}^{i} \quad H 3_{t-1}^{i} \quad H 4_{t-1}^{i} \quad H 5_{t-1}^{i} \quad H 6_{t-1}^{i}$

\begin{tabular}{lrrrrrrrrrr}
\hline RO75-70 & $\mathbf{0 , 8 7}$ & $\mathbf{0 , 5 1}$ & 1,52 & $\mathbf{0 , 8 6}$ & 0,53 & 0,12 & 0,00 & 0,00 & 0,00 & 0,00 \\
RO80-70 & 1,35 & 2,86 & 2,12 & 1,38 & 0,53 & 0,64 & 0,00 & 0,00 & 0,00 & 0,00 \\
RO85-70 & 2,28 & 3,53 & 2,72 & 1,52 & 0,53 & 1,00 & 0,12 & 0,00 & 0,00 & 0,00 \\
RO95/96-70 & 2,81 & 4,42 & 2,70 & 1,90 & 0,53 & 1,00 & 1,00 & 0,71 & 0,00 & 0,00 \\
AC75-70 & 0,33 & 1,22 & 0,16 & 0,05 & 0,07 & 0,00 & 0,00 & 0,00 & 0,00 & 0,00 \\
AC80-70 & 0,38 & 2,84 & 0,38 & 0,32 & 0,15 & 0,00 & 0,00 & 0,00 & 0,00 & 0,00 \\
AC85-70 & 0,49 & 3,03 & 0,56 & 0,23 & 0,43 & 0,00 & 0,00 & 0,00 & 0,00 & 0,00 \\
AC95/96-70 & 0,75 & 3,42 & 0,36 & $-0,27$ & 0,84 & 1,00 & 0,03 & 0,00 & 0,00 & 0,00 \\
AM75-70 & 0,05 & 0,56 & 0,31 & 0,39 & 0,13 & 0,00 & 0,00 & 0,00 & 0,00 & 0,00 \\
AM80-70 & 0,19 & 2,95 & 0,44 & 0,46 & 0,51 & 0,07 & 0,00 & 0,00 & 0,00 & 0,00 \\
AM85-70 & 0,42 & 2,87 & 0,59 & 0,28 & 0,51 & 0,32 & 0,00 & 0,00 & 0,00 & 0,00 \\
AM95/96-70 & 0,56 & 2,78 & 0,21 & $-0,29$ & 0,51 & 1,00 & 0,09 & 0,00 & 0,00 & 0,00 \\
RR75-70 & 0,62 & 2,38 & 0,73 & 0,13 & 0,00 & 0,22 & 0,00 & 0,00 & 0,00 & 0,00 \\
RR80-70 & 0,89 & 4,14 & 0,68 & 0,42 & 0,00 & 0,48 & 0,00 & 0,00 & 0,00 & 0,00 \\
RR85-70 & 1,28 & 4,35 & 0,97 & 0,27 & 0,00 & 0,95 & 0,08 & 0,00 & 0,00 & 0,00 \\
RR95/96-70 & 1,29 & 5,13 & 1,42 & 0,59 & 0,00 & 0,95 & 1,00 & 0,85 & 0,00 & 0,00 \\
PA75-70 & 0,38 & 0,71 & 0,31 & 0,51 & 0,00 & 0,19 & 0,00 & 0,00 & 0,00 & 0,00 \\
PA80-70 & 0,98 & 1,97 & 0,59 & 0,74 & 0,00 & 0,41 & 0,00 & 0,00 & 0,00 & 0,00
\end{tabular}


Tabela 3.3. Dados utilizados no processo de estimação da equação (57)

\begin{tabular}{|c|c|c|c|c|c|c|c|c|c|c|}
\hline UF & \multicolumn{10}{|c|}{$\ln Y_{t}^{i}-\ln K_{t}^{i}-\ln L_{t}^{i}-\ln T_{t}^{i}-H 1_{t}^{i}-H 2_{t^{-}}^{i} \quad H 3_{t^{-}}^{i} \quad H 4_{t}^{i}-H 5_{t^{-}}^{i} \quad H 6_{t}^{i}-$} \\
\hline PA85-70 & 1,33 & 2,00 & 0,73 & 0,95 & 0,00 & 0,65 & 0,00 & 0,00 & 0,00 & 0,00 \\
\hline PA95/96-70 & 1,37 & 2,25 & 0,49 & 0,91 & 0,00 & 0,98 & 0,35 & 0,00 & 0,00 & 0,00 \\
\hline AP75-70 & 0,32 & 0,42 & 0,55 & 0,15 & 0,00 & 0,13 & 0,00 & 0,00 & 0,00 & 0,00 \\
\hline AP80-70 & 0,79 & 1,15 & 0,38 & 0,08 & 0,00 & 0,26 & 0,00 & 0,00 & 0,00 & 0,00 \\
\hline AP85-70 & 1,12 & 1,51 & 0,69 & 0,65 & 0,00 & 0,60 & 0,00 & 0,00 & 0,00 & 0,00 \\
\hline AP95/96-70 & 1,68 & 1,93 & 0,50 & 0,17 & 0,00 & 0,79 & 0,73 & 0,00 & 0,00 & 0,00 \\
\hline MA75-70 & 0,16 & 1,24 & 0,23 & 0,20 & 0,12 & 0,00 & 0,00 & 0,00 & 0,00 & 0,00 \\
\hline MA80-70 & 0,54 & 3,11 & 0,34 & 0,40 & 0,27 & 0,00 & 0,00 & 0,00 & 0,00 & 0,00 \\
\hline MA85-70 & 0,67 & 3,31 & 0,33 & 0,43 & 0,48 & 0,00 & 0,00 & 0,00 & 0,00 & 0,00 \\
\hline MA95/96-70 & 2,01 & 3,49 & 0,18 & 0,33 & 0,85 & 0,67 & 0,00 & 0,00 & 0,00 & 0,00 \\
\hline PI75-70 & 0,34 & 0,75 & 0,12 & 0,08 & 0,11 & 0,00 & 0,00 & 0,00 & 0,00 & 0,00 \\
\hline PI80-70 & 0,47 & 2,25 & 0,41 & 0,04 & 0,26 & 0,00 & 0,00 & 0,00 & 0,00 & 0,00 \\
\hline PI85-70 & 0,84 & 2,44 & 0,43 & 0,14 & 0,50 & 0,00 & 0,00 & 0,00 & 0,00 & 0,00 \\
\hline PI95/96-70 & 1,23 & 2,58 & 0,24 & 0,00 & 0,97 & 0,79 & 0,00 & 0,00 & 0,00 & 0,00 \\
\hline CE75-70 & 0,33 & 0,97 & $-0,09$ & $-0,15$ & 0,11 & 0,00 & 0,00 & 0,00 & 0,00 & 0,00 \\
\hline CE80-70 & 0,57 & 2,08 & 0,06 & 0,02 & 0,24 & 0,00 & 0,00 & 0,00 & 0,00 & 0,00 \\
\hline CE85-7 & 1,16 & 2,04 & 0,20 & $-0,15$ & 0,49 & 0,00 & 0,00 & 0,00 & 0,00 & 0,00 \\
\hline CE95/s & 1,50 & 2,12 & 0,13 & $-0,35$ & 0,95 & 0,63 & 0,00 & 0,00 & 0,00 & 0,00 \\
\hline RN75-? & 0,34 & 1,07 & 0,12 & 0,05 & 0,12 & 0,00 & 0,00 & 0,00 & 0,00 & 0,00 \\
\hline RN80-70 & 0,46 & 2,06 & 0,31 & 0,08 & 0,27 & 0,00 & 0,00 & 0,00 & 0,00 & 0,00 \\
\hline RN85-70 & 1,06 & 1,98 & 0,30 & 0,01 & 0,79 & 0,06 & 0,00 & 0,00 & 0,00 & 0,00 \\
\hline RN95/96-7 & 1,31 & 2,11 & 0,08 & $-0,23$ & 0,79 & 1,00 & 0,05 & 0,00 & 0,00 & 0,00 \\
\hline PB75-70 & 0,38 & 0,72 & 0,22 & 0,01 & 0,11 & 0,00 & 0,00 & 0,00 & 0,00 & 0,00 \\
\hline PB80- & 29 & 1,63 & 0,12 & 0,05 & 0,54 & 0,00 & 0,00 & 0,00 & 0,00 & 0,00 \\
\hline PB85-70 & 0,98 & 1,51 & 0,25 & 0,04 & 0,44 & 0,00 & 0,00 & 0,00 & 0,00 & 0,00 \\
\hline PB95/96-70 & 1,04 & 1,52 & $-0,18$ & $-0,16$ & 0,87 & 0,54 & 0,00 & 0,00 & 0,00 & 0,00 \\
\hline PE75-70 & 0,26 & 0,77 & $-0,04$ & 0,02 & 0,11 & 0,00 & 0,00 & 0,00 & 0,00 & 0,00 \\
\hline PE80-70 & 0,37 & 1,49 & 0,10 & 0,14 & 0,24 & 0,00 & 0,00 & 0,00 & 0,00 & 0,00 \\
\hline PE85-7 & & 1,39 & 0,15 & 0,11 & 0,52 & 0,00 & 0,00 & 0,00 & 0,00 & 0,00 \\
\hline PE95/96-70 & 1,01 & 1,43 & $-0,12$ & $-0,04$ & 0,86 & 1,00 & 0,08 & 0,00 & 0,00 & 0,00 \\
\hline AL75-70 & 0,48 & 1,07 & 0,10 & 0,07 & 0,09 & 0,00 & 0,00 & 0,00 & 0,00 & 0,00 \\
\hline AL80-70 & & 1,52 & & 0,18 & & & 0,00 & 0,00 & 0,00 & 0,00 \\
\hline AL85-70 & 0,95 & 1,47 & 0,38 & 0,19 & 0,65 & 0,00 & 0,00 & 0,00 & 0,00 & 0,00 \\
\hline AL95/96-70 & 1,06 & 1,39 & 0,06 & 0,12 & 0,98 & 0,67 & 0,00 & 0,00 & 0,00 & 0,00 \\
\hline SE75-70 & & 0,95 & & 0,11 & & & 0,00 & 0,00 & 0,00 & 0,00 \\
\hline SE80-70 & 0,88 & 1,60 & 0,09 & 0,17 & 0,28 & 0,00 & 0,00 & 0,00 & 0,00 & 0,00 \\
\hline SE85-70 & 0,80 & 1,57 & 0,26 & 0,19 & 0,56 & 0,00 & 0,00 & 0,00 & 0,00 & 0,00 \\
\hline SE95/96-70 & 1,03 & 1,83 & 0,19 & 0,09 & 0,92 & 1,00 & 0,10 & 0,00 & 0,00 & 0,00 \\
\hline & & 1,12 & 0,15 & 0,13 & 0,09 & 0,00 & 0,00 & 0,00 & 0,00 & 0,00 \\
\hline BA80-70 & 0,34 & 2,24 & 0,26 & 0,33 & 0,20 & 0,00 & 0,00 & 0,00 & 0,00 & 0,00 \\
\hline BA85-70 & 0,86 & 2,37 & 0,44 & 0,43 & 0,45 & 0,00 & 0,00 & 0,00 & 0,00 & 0,00 \\
\hline BA95/96- & 8,87 & 2,79 & 0,22 & 0,37 & 0,85 & 0,84 & 0,00 & 0,00 & 0,00 & 0,00 \\
\hline
\end{tabular}


Tabela 3.3. Dados utilizados no processo de estimação da equação (57).

\begin{tabular}{|c|c|c|c|c|c|c|c|c|c|c|}
\hline UF & $\begin{array}{l}\ln Y_{t}^{i}- \\
\ln Y_{t-1}^{i}\end{array}$ & $\begin{array}{l}K_{t}^{i}- \\
K_{t-1}^{i}\end{array}$ & $\begin{array}{l}\mathrm{n} L_{t}^{i} \\
\mathrm{n} L_{t-1}^{i}\end{array}$ & $\begin{array}{l}\mathrm{n} T_{t}^{i}- \\
\mathrm{n} T_{t-1}^{i}\end{array}$ & $\begin{array}{l}H 1_{t}^{i}- \\
H l_{t-1}^{i}\end{array}$ & $\begin{array}{l}H 2_{t}^{i}- \\
H 2_{t-1}^{i}\end{array}$ & $\begin{array}{l}H 3_{t}^{i}- \\
H 3_{t-1}^{i}\end{array}$ & $\begin{array}{l}H 4_{t}^{i}- \\
H 4_{t-1}^{i}\end{array}$ & $\begin{array}{l}H 5_{t}^{i}- \\
H S_{t-1}^{i}\end{array}$ & $\begin{array}{l}H \sigma_{t}^{i}- \\
H \sigma_{t-1}^{i}\end{array}$ \\
\hline MG75-70 & 0,36 & 1,06 & 0,08 & 0,06 & 0,00 & 0,30 & 0,00 & 0,00 & 0,00 & $\overline{0,00}$ \\
\hline MG80-70 & 0,55 & 1,90 & 0,16 & 0,10 & 0,00 & 0,68 & 0,00 & 0,00 & 0,00 & 0,00 \\
\hline MG85-70 & 0,88 & 2,06 & 0,31 & 0,10 & 0,00 & 0,80 & 0,32 & 0,00 & 0,00 & 0,00 \\
\hline MG95/96-70 & 1,11 & 2,50 & 0,04 & $-0,02$ & 0,00 & 0,80 & 1,00 & 0,74 & 0,00 & 0,00 \\
\hline ES75-70 & 0,14 & 0,79 & 0,03 & 0,04 & 0,00 & 0,38 & 0,00 & 0,00 & 0,00 & 0,00 \\
\hline ES80-70 & 0,30 & 1,85 & 0,19 & 0,06 & 0,00 & 0,72 & 0,00 & 0,00 & 0,00 & 0,00 \\
\hline ES85-70 & 0,77 & 2,23 & 0,34 & 0,09 & 0,00 & 0,72 & 0,74 & 0,00 & 0,00 & 0,00 \\
\hline ES95/96-70 & 0,99 & 2,42 & 0,19 & 0,00 & 0,00 & 0,72 & 1,00 & 1,00 & 0,31 & 0,00 \\
\hline RJ75-70 & 0,21 & 0,60 & 0,05 & 0,04 & 0,00 & 0,26 & 0,00 & 0,00 & 0,00 & 0,00 \\
\hline RJ80-70 & 0,44 & 0,91 & 0,13 & $-0,01$ & 0,00 & 0,58 & 0,00 & 0,00 & 0,00 & 0,00 \\
\hline RJ85-70 & 0,66 & 0,00 & 0,21 & 0,01 & 0,00 & 0,65 & 0,48 & 0,00 & 0,00 & 0,00 \\
\hline RJ95/96-70 & 0,74 & 0,89 & $-0,39$ & $-0,27$ & 0,00 & 0,65 & 1,00 & 1,00 & 0,39 & 0,00 \\
\hline SP75-70 & 0,30 & 0,64 & $-0,04$ & 0,02 & 0,00 & 0,13 & 0,24 & 0,00 & 0,00 & 0,00 \\
\hline SP80-70 & 0,86 & 1,08 & 0,01 & 0,02 & 0,00 & 0,13 & 0,68 & 0,00 & 0,00 & 0,00 \\
\hline SP85-70 & 1,23 & 1,22 & 0,00 & 0,02 & 0,00 & 0,13 & 1,00 & 0,22 & 0,00 & 0,00 \\
\hline SP95/96-70 & 1,29 & 1,31 & $-0,38$ & $-0,13$ & 0,00 & 0,13 & 1,00 & 1,00 & 0,81 & 0,00 \\
\hline PR75-70 & 0,05 & 1,40 & 0,03 & 0,10 & 0,00 & 0,42 & 0,00 & 0,00 & 0,00 & 0,00 \\
\hline PR80-70 & 0,35 & 1,91 & $-0,06$ & 0,19 & 0,00 & 0,61 & 0,36 & 0,00 & 0,00 & 0,00 \\
\hline PR85-70 & 0,52 & 2,12 & $-0,02$ & 0,23 & 0,00 & 0,61 & 0,92 & 0,00 & 0,00 & 0,00 \\
\hline PR95/96-70 & 0,81 & 2,41 & $-0,38$ & 0,21 & 0,00 & 0,61 & 1,00 & 1,00 & 0,62 & 0,00 \\
\hline SC75-70 & 0,28 & 1,19 & 0,07 & 0,00 & 0,00 & 0,00 & 0,41 & 0,00 & 0,00 & 0,00 \\
\hline SC80-70 & 0,63 & 2,07 & 0,10 & 0,14 & 0,00 & 0,00 & 0,69 & 0,20 & 0,00 & 0,00 \\
\hline SC85-70 & 1,03 & 2,45 & 0,18 & 0,15 & 0,00 & 0,00 & 0,69 & 0,78 & 0,00 & 0,00 \\
\hline SC95/96-70 & 1,71 & 2,87 & $-0,01$ & 0,07 & 0,00 & 0,00 & 0,69 & 1,00 & 1,00 & 0,47 \\
\hline RS75-70 & 0,33 & 0,87 & 0,17 & 0,01 & 0,00 & 0,00 & 0,31 & 0,00 & 0,00 & 0,00 \\
\hline RS80-70 & 0,34 & 1,36 & 0,15 & 0,03 & 0,00 & 0,00 & 0,47 & 0,19 & 0,00 & 0,00 \\
\hline RS85-70 & 0,60 & 1,51 & 0,16 & 0,01 & 0,00 & 0,00 & 0,47 & 0,72 & 0,00 & 0,00 \\
\hline RS95/96-70 & 1,16 & 1,65 & $-0,06$ & $-0,08$ & 0,00 & 0,00 & 0,47 & 1,00 & 1,00 & 0,21 \\
\hline MT75-70 & 0,32 & 1,57 & 0,29 & 0,09 & 0,00 & 0,34 & 0,00 & 0,00 & 0,00 & 0,00 \\
\hline MT80-70 & 0,87 & 2,46 & 0,40 & 0,35 & 0,00 & 0,79 & 0,00 & 0,00 & 0,00 & 0,00 \\
\hline MT85-70 & 1,38 & 2,83 & 0,54 & 0,41 & 0,00 & 0,84 & 0,46 & 0,00 & 0,00 & 0,00 \\
\hline MT95/96-70 & 2,60 & 3,18 & 0,43 & 0,59 & 0,00 & 0,84 & 1,00 & 1,00 & 0,10 & 0,00 \\
\hline GO75-70 & 0,34 & 1,08 & 0,20 & 0,23 & 0,00 & 0,30 & 0,00 & 1,00 & 0,00 & 0,00 \\
\hline GO80-70 & 0,74 & 1,89 & 0,31 & 0,33 & 0,00 & 0,69 & 0,00 & 1,00 & 0,00 & 0,00 \\
\hline GO85-70 & 1,06 & 2,05 & 0,42 & 0,31 & 0,00 & 0,99 & 0,18 & 1,00 & 0,00 & 0,00 \\
\hline GO95/96-70 & 2,06 & 2,53 & 0,20 & 0,27 & 0,00 & 0,99 & 1,00 & 0,79 & 0,00 & 0,00 \\
\hline DF75-70 & 0,25 & 0,89 & 0,14 & $-0,03$ & 0,00 & 0,21 & 0,36 & 0,00 & 0,00 & 0,00 \\
\hline DF80-70 & 1,26 & 2,54 & 0,77 & 0,48 & 0,00 & 0,21 & 1,00 & 0,12 & 0,00 & 0,00 \\
\hline DF85-70 & 1,94 & 2,96 & 0,98 & 0,65 & 0,00 & 0,21 & 1,00 & 0,57 & 0,00 & 0,00 \\
\hline DF95/96-70 & 3,14 & 3,15 & 0,81 & 0,41 & 0,00 & 0,21 & 1,00 & 1,00 & 0,81 & 0,00 \\
\hline
\end{tabular}

Fonte: Calculados pelo autor a partir dos dados da Tabela 3.1. 
Tabela 3.4. Dados utilizados no processo de estimação da equação (61).

\begin{tabular}{|c|c|c|c|c|c|c|}
\hline UF & $\begin{array}{c}\ln Y_{t}^{i}- \\
\ln Y_{t-1}^{i}\end{array}$ & $H_{t}^{i}$ & $H_{t}^{i}\left(\frac{Y_{t}^{\max }}{Y_{t}^{i}}\right)$ & $\begin{array}{l}\ln K_{t}^{i}- \\
\ln K_{t-1}^{i}\end{array}$ & $\begin{array}{l}\ln L_{t}^{i}- \\
\ln L_{t-1}^{i}\end{array}$ & $\begin{array}{c}\ln T_{t}^{i}- \\
\ln T_{t-1}^{i}\end{array}$ \\
\hline R075-70 & 0,87 & 0,77 & 168,92 & 0,51 & 1,52 & 0,86 \\
\hline RO80-70 & 1,35 & 1,13 & 109,02 & 2,86 & 2,12 & 1,38 \\
\hline RO85-70 & 2,28 & 1,64 & 173,20 & 3,53 & 2,72 & 1,52 \\
\hline RO95/96-70 & 2,81 & 2,12 & 127,02 & 4,42 & 2,70 & 1,90 \\
\hline AC75-70 & 0,34 & 0,46 & 39,88 & 1,22 & 0,16 & 0,05 \\
\hline AC80-70 & 0,38 & 0,53 & 35,09 & 2,84 & 0,38 & 0,32 \\
\hline AC85-70 & 0,49 & 0,61 & 68,31 & 3,03 & 0,56 & 0,23 \\
\hline AC95/96-70 & 0,75 & 0,89 & 127,33 & 3,42 & 0,36 & $-0,27$ \\
\hline AM75-70 & 0,05 & 0,79 & 16,70 & 0,56 & 0,31 & 0,39 \\
\hline AM80-70 & 0,19 & 0,92 & 19,56 & 2,95 & 0,44 & 0,46 \\
\hline AM85-70 & 0,42 & 1,07 & 34,46 & 2,87 & 0,59 & 0,28 \\
\hline AM95/96-70 & 0,56 & 1,32 & 48,97 & 2,78 & 0,21 & $-0,29$ \\
\hline RR75-70 & 0,62 & 1,05 & 212,31 & 2,38 & 0,73 & 0,13 \\
\hline RR80-70 & 0,89 & 1,27 & 146,03 & 4,14 & 0,68 & 0,42 \\
\hline RR85-70 & 1,28 & 1,53 & 179,81 & 4,35 & 0,97 & 0,27 \\
\hline RR95/96-70 & 1,29 & 2,08 & 196,32 & 5,13 & 1,42 & 0,59 \\
\hline PA75-70 & 0,38 & 1,02 & 14,76 & 0,71 & 0,31 & 0,51 \\
\hline PA80-70 & 0,98 & 1,21 & 12,72 & 1,97 & 0,59 & 0,74 \\
\hline PA85-70 & 1,33 & 1,43 & 14,46 & 2,00 & 0,73 & 0,95 \\
\hline PA95/96-70 & 1,37 & 1,67 & 17,15 & 2,25 & 0,49 & 0,91 \\
\hline AP75-70 & 0,33 & 1,21 & 405,77 & 0,42 & 0,55 & 0,15 \\
\hline AP80-70 & 0,79 & 1,34 & 343,16 & 1,15 & 0,38 & 0,08 \\
\hline AP85-70 & 1,12 & 1,48 & 417,20 & 1,51 & 0,69 & 0,65 \\
\hline AP95/96-70 & 1,68 & 1,81 & 530,37 & 1,93 & 0,50 & 0,18 \\
\hline MA75-70 & 0,16 & 0,45 & 19,08 & 1,24 & 0,23 & 0,20 \\
\hline MA80-70 & 0,54 & 0,57 & 21,96 & 3,11 & 0,34 & 0,40 \\
\hline MA85-70 & 0,67 & 0,72 & 33,61 & 3,31 & 0,33 & 0,43 \\
\hline MA95/96-70 & 2,01 & 0,93 & 54,97 & 3,49 & 0,18 & 0,33 \\
\hline PI75-70 & 0,34 & 0,33 & 12,46 & 0,75 & 0,12 & 0,08 \\
\hline PI80-70 & 0,47 & 0,44 & 12,58 & 2,25 & 0,41 & 0,04 \\
\hline PI85-70 & 0,84 & 0,59 & 25,67 & 2,44 & 0,43 & 0,14 \\
\hline PI95/96-70 & 1,23 & 0,83 & 36,12 & 2,58 & 0,24 & 0,01 \\
\hline CE75-70 & 0,33 & 0,35 & 6,45 & 0,97 & $-0,09$ & $-0,15$ \\
\hline CE80-70 & 0,57 & 0,46 & 6,36 & 2,08 & 0,06 & 0,02 \\
\hline CE85-70 & 1,16 & 0,59 & 11,37 & 2,04 & 0,20 & $-0,15$ \\
\hline CE95/96-70 & 1,50 & 0,84 & 12,97 & 2,12 & 0,13 & $-0,36$ \\
\hline RN75-70 & 0,34 & 0,51 & 19,96 & 1,07 & 0,12 & 0,05 \\
\hline RN80-70 & 0,46 & 0,63 & 18,59 & 2,06 & 0,31 & 0,08 \\
\hline RN85-70 & 1,06 & 0,78 & 35,96 & 1,98 & 0,30 & 0,01 \\
\hline RN95/96-70 & 1,31 & 1,06 & 38,55 & 2,11 & 0,08 & $-0,23$ \\
\hline PB75-70 & 0,38 & 0,43 & 8,30 & 0,72 & 0,22 & 0,01 \\
\hline PB80-70 & 0,29 & 0,54 & 7,48 & 1,63 & 0,12 & 0,05 \\
\hline PB85-70 & 0,98 & 0,68 & 18,00 & 1,51 & 0,25 & 0,04 \\
\hline PB95/96-70 & 1,04 & 0,87 & 16,85 & 1,52 & $-0,18$ & $-0,16$ \\
\hline
\end{tabular}


Tabela 3.4. Dados utilizados no processo de estimação da equação (61).

\begin{tabular}{|c|c|c|c|c|c|c|}
\hline UF & $\begin{array}{c}\ln Y_{t}^{i}- \\
\ln Y_{t-1}^{i}\end{array}$ & $H_{t}^{i}$ & $\left.\frac{Y_{t}^{\max }}{Y_{t}^{i}}\right)$ & $\begin{array}{l}\ln K_{t}^{i}- \\
\ln K_{t-1}^{i}\end{array}$ & $\begin{array}{l}\ln L_{t}^{i}- \\
\ln L_{t-1}^{i}\end{array}$ & $\begin{array}{c}\ln T_{t}^{i}- \\
\ln T_{t-1}^{i}\end{array}$ \\
\hline PE75-70 & 0,26 & 0,44 & 3,37 & 0,77 & $-0,04$ & 0,02 \\
\hline PE80-70 & 0,37 & 0,55 & 3,41 & 1,49 & 0,10 & 0,14 \\
\hline PE85-70 & 0,87 & 0,68 & 6,67 & 1,39 & 0,15 & 0,11 \\
\hline PE95/96-70 & 1,01 & 0,96 & 8,29 & 1,43 & $-0,12$ & $-0,04$ \\
\hline AL75-70 & 0,48 & 0,33 & 4,94 & 1,07 & 0,10 & 0,07 \\
\hline AL80-70 & 0,81 & 0,41 & 4,07 & 1,52 & 0,23 & 0,18 \\
\hline AL85-70 & 0,95 & 0,51 & 6,40 & 1,47 & 0,38 & 0,19 \\
\hline AL95/96-70 & 1,06 & 0,97 & 15,35 & 1,39 & 0,06 & 0,12 \\
\hline SE75-70 & 0,33 & 0,38 & 12,62 & 0,95 & 0,08 & 0,11 \\
\hline SE80-70 & 0,88 & 0,50 & 12,62 & 1,60 & 0,09 & 0,17 \\
\hline SE85-70 & 0,80 & 0,66 & 16,97 & 1,57 & 0,26 & 0,19 \\
\hline SE95/96-70 & 1,03 & 0,94 & 37,79 & 1,83 & 0,19 & 0,09 \\
\hline BA75-70 & 0,25 & 0,45 & 1,49 & 1,12 & 0,15 & 0,13 \\
\hline BA80-70 & 0,34 & 0,54 & 1,48 & 2,24 & 0,26 & 0,33 \\
\hline BA85-70 & 0,86 & 0,65 & 2,85 & 2,37 & 0,44 & 0,43 \\
\hline BA95/96-70 & 0,87 & 0,91 & 3,40 & 2,79 & 0,22 & 0,37 \\
\hline MG75-70 & 0,36 & 1,20 & 1,67 & 1,06 & 0,08 & 0,07 \\
\hline MG80-70 & 0,55 & 1,50 & 1,54 & 1,90 & 0,16 & 0,11 \\
\hline MG85-70 & 0,88 & 1,88 & 2,81 & 2,06 & 0,31 & 0,10 \\
\hline MG95/96-70 & 1,12 & 2,32 & 3,59 & 2,50 & 0,04 & $-0,02$ \\
\hline ES75-70 & 0,14 & 1,28 & 7,96 & 0,79 & 0,03 & 0,04 \\
\hline ES80-70 & 0,30 & 1,66 & 9,55 & 1,85 & 0,19 & 0,06 \\
\hline ES85-70 & 0,77 & 2,16 & 18,53 & 2,23 & 0,34 & 0,09 \\
\hline ES95/96-70 & 0,99 & 2,74 & 21,19 & 2,42 & 0,19 & 0,00 \\
\hline RJ75-70 & 0,21 & 1,35 & 13,29 & 0,60 & 0,05 & 0,04 \\
\hline RJ80-70 & 0,44 & 1,61 & 13,64 & 0,91 & 0,13 & $-0,02$ \\
\hline RJ85-70 & 0,66 & 1,93 & 22,67 & 0,00 & 0,21 & 0,01 \\
\hline RJ95/96-70 & 0,74 & 2,48 & 33,88 & 0,89 & $-0,39$ & $-0,27$ \\
\hline PR75-70 & 0,05 & 1,39 & 1,72 & 1,40 & 0,03 & 0,10 \\
\hline PR80-70 & 0,35 & 1,81 & 2,25 & 1,91 & $-0,06$ & 0,19 \\
\hline PR85-70 & 0,52 & 2,36 & 3,84 & 2,12 & $-0,02$ & 0,23 \\
\hline PR95/96-70 & 0,81 & 2,92 & 5,75 & 2,41 & $-0,38$ & 0,21 \\
\hline SC75-70 & 0,28 & 2,32 & 12,59 & 1,19 & 0,07 & 0,00 \\
\hline SC80-70 & 0,63 & 2,72 & 11,83 & 2,07 & 0,10 & 0,14 \\
\hline SC85-70 & 1,03 & 3,20 & 17,33 & 2,45 & 0,18 & 0,15 \\
\hline SC95/96-70 & 1,71 & 3,78 & 19,69 & 2,87 & $-0,01$ & 0,07 \\
\hline RS75-70 & 0,33 & 2,53 & 4,15 & 0,87 & 0,17 & 0,01 \\
\hline RS80-70 & 0,34 & 2,84 & 3,54 & 1,36 & 0,15 & 0,03 \\
\hline RS85-70 & 0,60 & 3,20 & 6,92 & 1,51 & 0,16 & 0,01 \\
\hline RS95/96-70 & 1,16 & 3,71 & 8,93 & 1,65 & $-0,06$ & $-0,08$ \\
\hline
\end{tabular}


Tabela 3.4. Dados utilizados no processo de estimação da equação (61).

\begin{tabular}{lrrrrrr}
\hline \multicolumn{1}{c}{ UF } & $\begin{array}{c}\ln Y_{t}^{i}- \\
\ln Y_{t-1}^{i}\end{array}$ & $H_{t}^{i}$ & $H_{t}^{i}\left(\frac{Y_{t}^{\max }}{Y_{t}^{i}}\right)$ & $\begin{array}{l}\ln K_{t}^{i}- \\
\ln K_{t-1}^{i}\end{array}$ & $\begin{array}{l}\ln L_{t}^{i}- \\
\ln L_{t-1}^{i}\end{array}$ & $\begin{array}{c}\ln T_{t}^{i}- \\
\ln T_{t-1}^{i}\end{array}$ \\
\hline MT75-70 & 0,32 & 1,16 & 11,00 & 1,57 & 0,29 & 0,09 \\
MT80-70 & 0,87 & 1,50 & 10,94 & 2,46 & 0,40 & 0,35 \\
MT85-70 & 1,38 & 1,95 & 14,34 & 2,83 & 0,54 & 0,41 \\
MT95/96-70 & 2,60 & 2,46 & 15,70 & 3,18 & 0,43 & 0,59 \\
GO75-70 & 0,34 & 1,01 & 8,09 & 1,08 & 0,20 & 0,23 \\
GO80-70 & 0,74 & 1,31 & 7,89 & 1,89 & 0,31 & 0,33 \\
GO85-70 & 1,06 & 1,70 & 12,02 & 2,05 & 0,42 & 0,31 \\
GO95/96-70 & 2,06 & 2,18 & 16,27 & 2,53 & 0,20 & 0,27 \\
DF75-70 & 0,25 & 1,79 & 904,35 & 0,89 & 0,14 & $-0,03$ \\
DF80-70 & 1,26 & 2,36 & 991,16 & 2,54 & 0,77 & 0,48 \\
DF85-70 & 1,94 & 3,12 & 832,63 & 2,96 & 0,98 & 0,65 \\
DF95/96-70 & 3,14 & 3,56 & 697,35 & 3,15 & 0,81 & 0,41 \\
\hline
\end{tabular}

Fonte: Calculados pelo autor a partir dos dados da Tabela 3.1 
APÊNDICE 4: Regressões estimadas por períodos

Tabela 4.1. Resultados das estimativas, por períodos, da equação (53) ajustada pelo método ECVH de White.

\begin{tabular}{crrrrrrrr}
\hline $\begin{array}{l}\text { Parâ- } \\
\text { metro }\end{array}$ & \multicolumn{2}{c}{$1975-1970^{*}$} & \multicolumn{2}{c}{$1980-1970^{*}$} & \multicolumn{2}{c}{$1985-1970^{*}$} & \multicolumn{2}{c}{$1996-1970^{*}$} \\
\hline & \multicolumn{1}{c}{ Coef. } & Est. $T$ & \multicolumn{1}{c}{ Coef. } & \multicolumn{1}{c}{ Est. $T$} & \multicolumn{1}{c}{ Coef. } & Est. $T$ & Coef. & Est. $t$ \\
\hline$A_{t}^{*}$ & $0,263^{\mathrm{a}}$ & 3,791 & $0,470^{\mathrm{a}}$ & 2,673 & $0,583^{\mathrm{a}}$ & 3,444 & $0,886 \mathrm{~b}$ & 2,332 \\
$\delta_{K}$ & $0,013^{\mathrm{NS}}$ & 0,250 & $(0,072)^{\text {Ns }}$ & $(0,920)$ & $(0,049)^{\text {Ns }}$ & $(0,716)$ & $(0,0003)^{\mathrm{NS}}$ & $(0,002)$ \\
$\delta_{L}$ & $0,528^{\mathrm{a}}$ & 3,707 & $0,343^{\mathrm{d}}$ & 1,631 & $0,529^{\mathrm{a}}$ & 2,829 & $0,238^{\mathrm{N} S}$ & 0,574 \\
$\delta_{T}$ & $(0,291)^{\mathrm{f}}$ & $(1,170)$ & $0,214^{\mathrm{NS}}$ & 0,673 & $0,117^{\mathrm{NS}}$ & 0,425 & $0,528^{\mathrm{f}}$ & 1,258 \\
$\delta_{H}$ & $(0,148)^{\mathrm{NS}}$ & $(1,099)$ & $0,253^{\mathrm{d}}$ & 1,635 & $0,265^{\mathrm{C}}$ & 1,849 & $0,171^{\mathrm{f}}$ & 1,190 \\
$\mathrm{R}^{2}$ & 0,609 & & 0,507 & & 0,625 & & 0,435 & \\
\hline
\end{tabular}

Fonte: Valores calculados usando dados da Tabela 3.1 (Apêndice 3). Os sobreíndices a, b, c, d, f e NS indicam que os parâmetros são significativos a até $1 \%, 5 \%, 10 \%, 15 \%$ e $25 \%$ de probabilidade e não-significativos, respectivamente. ${ }^{*}$ Os valores entre parênteses indicam que o número é negativo

Tabela 4.2. Resultados das estimativas, por períodos, da equação (57) ajustada pelo método ECVH de White**.

\begin{tabular}{|c|c|c|c|c|c|c|c|c|}
\hline Parâ- & 1975 & $970^{*}$ & & $970^{*}$ & 1985 & $70^{*}$ & 1996-1 & \\
\hline & Coef. & Est. $t$ & Coef. & Est. $T$ & Coef. & Est. $T$ & Coef. & Est. $T$ \\
\hline$A_{t}^{*}$ & $0,205^{\mathrm{a}}$ & 3,188 & $0,665^{\mathrm{a}}$ & 4,482 & $\overline{0,730^{\mathrm{a}}}$ & 3,080 & $1,735^{\mathrm{a}}$ & 2,680 \\
\hline$\delta_{K}$ & $\begin{array}{r}0,0413 N \\
S\end{array}$ & 0,838 & $(0,078)^{e}$ & $(1,389)$ & $(0,049)^{\mathrm{NS}}$ & $(0,733)$ & $0,099 \mathrm{NS}$ & 0,701 \\
\hline$\delta_{L}$ & $0,463^{a}$ & 3,550 & $0,486^{a}$ & 2,855 & $0,666^{a}$ & 2,714 & $0,157 \mathrm{NS}$ & 0,445 \\
\hline$\delta_{T}$ & $(0,319)^{\mathrm{NS}}$ & $(0,999)$ & $0,285^{\mathrm{e}}$ & 1,342 & $0,079 \mathrm{NS}$ & 0,261 & $0,567 \mathrm{c}$ & 1,693 \\
\hline$\delta_{H 1}$ & $0,340^{\mathrm{NS}}$ & 0,911 & $(0,712)^{a}$ & $(2,717)$ & $(0,058)^{N S}$ & $(0,150)$ & $0,367 \mathrm{NS}$ & 1,073 \\
\hline$\delta_{H 2}$ & $(0,119)^{\mathrm{NS}}$ & $(0,605)$ & $(0,140)^{N S}$ & $(0,755)$ & $(0,104)^{N S}$ & $(0,441)$ & $(1,432)^{\mathrm{a}}$ & $(2,597)$ \\
\hline$\delta_{H 3}$ & $0,026^{N S}$ & 0,242 & $0,154 \mathrm{NS}$ & 1,115 & $0,283^{\mathrm{e}}$ & 1,336 & $0,904 d$ & 1,494 \\
\hline$\delta_{H 4}$ & $0,107 \mathrm{C}$ & 1,826 & $0,010 \mathrm{NS}$ & 0,092 & $0,130^{a}$ & 0,980 & $(0,425)^{\mathrm{NS}}$ & $(0,628)$ \\
\hline$\delta_{H 5}$ & - & - & - & - & - & - & $(0,488)^{\mathrm{NS}}$ & $(0,498)$ \\
\hline$\delta_{H 6}$ & - & - & - & - & $\begin{array}{l}- \\
-\end{array}$ & - & $(0,250)^{\mathrm{NS}}$ & $(0,194)$ \\
\hline $\mathrm{R}^{2}$ & 0,646 & & 0,626 & & 0,639 & & 0,566 & \\
\hline
\end{tabular}

Fonte: Valores calculados usando dados da Tabela 3.1 (Apêndice 3). Os sobreíndices a, c, d, e e NS indicam os parâmetros serem significativos a até $1 \%, 10 \%, 15 \%, 20 \%$ de probabilidade e nãosignificativos, respectivamente. ${ }^{*}$ Os valores entre parênteses indicam que o número é negativo

** Onde não aparece os dados referentes à $\delta_{H 5}$ e $\delta_{H 6}$ é porque nestes períodos não havia o número médio de ano de estudo para calcular as variáveis $H 5$ e $H 6$. 
Tabela 4.3. Resultados das estimativas, por períodos, da equação (61) ajustada pelo método ECVH de White.

\begin{tabular}{|c|c|c|c|c|c|c|c|c|}
\hline \multirow{2}{*}{$\begin{array}{l}\text { Parâ- } \\
\text { metro }\end{array}$} & \multicolumn{2}{|c|}{$1975-1970 *$} & \multicolumn{2}{|c|}{ 1980-1970* } & \multicolumn{2}{|c|}{$1985-1970 *$} & \multicolumn{2}{|c|}{ 1996-1970* } \\
\hline & Coef. & Est. $T$ & Coef. & Est. $t$ & Coef. & Est. $T$ & Coef. & Est. $t$ \\
\hline$C_{H}$ & $0,278^{a}$ & 5,281 & $0,552^{a}$ & 3,138 & $0,701^{a}$ & 5,135 & $0,535 \mathrm{c}$ & 1,749 \\
\hline$\delta_{H}$ & $(0,041)^{d}$ & $(1,620)$ & $(0,002)^{N S}$ & $(0,037$ & $0,038^{N S}$ & 0,678 & $0,195^{c}$ & 1,745 \\
\hline$\delta_{H C}$ & $(0,0002)^{c}$ & $(1,766)$ & $0,00061^{a}$ & ) & $0,0006^{a}$ & 2,573 & $\begin{array}{r}(0,00003) \\
a\end{array}$ & $(2,843)$ \\
\hline$\delta_{K}$ & $0,007^{N S}$ & 0,147 & $(0,077)^{N S}$ & $\begin{array}{r}(1,053 \\
)\end{array}$ & $(0,046)^{\mathrm{NS}}$ & $(0,732)$ & $0,157 \mathrm{NS}$ & 0,995 \\
\hline$\delta_{L}$ & $0,608^{a}$ & 4,121 & $0,177^{\mathrm{NS}}$ & 1,090 & $0,536^{a}$ & 3,827 & $0,376^{N S}$ & 0,935 \\
\hline$\delta_{T}$ & $(0,404)^{d}$ & $(1,472)$ & $0,446 \mathrm{c}$ & 1,760 & $0,062^{\mathrm{NS}}$ & 0,240 & $0,298^{\mathrm{NS}}$ & 0,688 \\
\hline $\mathrm{R}^{2}$ & 0,654 & & 0,629 & & 0,692 & & 0,545 & \\
\hline
\end{tabular}

Fonte: Valores calculados usando dados da Tabela 3.1 (Apêndice 3). Os sobreíndices a, c, d e e NS indicam que os parâmetros são significativos a até $1 \%, 10 \%, 15 \%$ e $20 \%$ de probabilidade e nãosignificativos, respectivamente. ${ }^{*}$ Os valores entre parênteses indicam que o número é negativo 